University of Louisville ThinkIR: The University of Louisville's Institutional Repository

Electronic Theses and Dissertations

$12-2015$

\title{
Trapped in the Tiebout model : the impact of federal affordable housing programs on migration of wealthier residents.
}

Yu-Chih Lin

University of Louisville

Follow this and additional works at: https://ir.library.louisville.edu/etd

Part of the Public Policy Commons, and the Urban Studies Commons

\section{Recommended Citation}

Lin, Yu-Chih, "Trapped in the Tiebout model : the impact of federal affordable housing programs on migration of wealthier residents." (2015). Electronic Theses and Dissertations. Paper 2339.

https://doi.org/10.18297/etd/2339

This Doctoral Dissertation is brought to you for free and open access by ThinkIR: The University of Louisville's Institutional Repository. It has been accepted for inclusion in Electronic Theses and Dissertations by an authorized administrator of ThinkIR: The University of Louisville's Institutional Repository. This title appears here courtesy of the author, who has retained all other copyrights. For more information, please contact thinkir@louisville.edu. 
TRAPPED IN THE TIEBOUT MODEL-

THE IMPACT OF FEDERAL AFFORDABLE HOUSING PROGRAMS ON MIGRATION OF WEALTHIER RESIDENTS

\author{
By \\ Yu-Chih Lin \\ B.A., National Chengchi University, Taiwan, 2007 \\ M.A., National Taiwan University, Taiwan, 2010
}

\begin{abstract}
A Dissertation
Submitted to the Faculty of the

College of Arts and Sciences of the University of Louisville in Partial Fulfillment of the Requirements for the Degree of

Doctor of Philosophy in Urban and Public Affairs

Department of Urban and Public Affairs University of Louisville Louisville, Kentucky
\end{abstract}

December 2015 
Copyright 2015 by Yu-Chih Lin

All rights reserved 

TRAPPED IN THE TIEBOUT MODEL-

THE IMPACT OF FEDERAL AFFORDABLE HOUSING PROGRAMS ON MIGRATION OF WEALTHIER RESIDENTS

\author{
By \\ Yu-Chih Lin \\ B.A., National Chengchi University, Taiwan, 2007 \\ M.A., National Taiwan University, Taiwan, 2010 \\ A Dissertation Approved on
}

September 18, 2015

by the following Dissertation Committee:

$\overline{\text { Dr. Janet M. Kelly (Dissertation Director) }}$

Dr. David L. Imbroscio

Dr. Sumei Zhang

Dr. Haifeng (Charlie) Zhang (External Examiner) 


\section{DEDICATION}

I would like to dedicate this book to my beloved familymy parents and my younger sister, who have given me invaluable educational opportunities and always been very supportive. 謹將此書獻給我最親愛的家人 


\section{ACKNOWLEDGMENTS}

I would like to thank my major professor, Dr. Janet M. Kelly, for her guidance, patience, and supports. Besides suggesting sources to find the economic literature and the data I needed for my dissertation, she spent time checking the logic of my idea, reading my manuscripts, and even giving me editorial suggestions. I would also like to express my thanks to the other committee members, Dr. David L. Imbroscio, Dr. Sumei Zhang,

and Dr. Haifeng (Charlie) Zhang, for their comments and suggestions. The insightful suggestions from each professor helped me significantly improve this dissertation. 


\section{ABSTRACT \\ TRAPPED IN THE TIEBOUT MODEL- \\ THE IMPACT OF FEDERAL AFFORDABLE HOUSING PROGRAMS \\ ON MIGRATION OF WEALTHIER RESIDENTS \\ Yu-Chih Lin}

September 18, 2015

Housing mobility programs have been implemented in America since the 1990s to solve poverty concentration and to improve the economic self-sufficiency of low-income families through housing subsidies. This policy was based on the assumption that mixed-income neighborhoods provide better resources and opportunities to low-income families so that program participants who relocate to low-poverty neighborhoods improve their economic status. Currently, few studies examine the effectiveness of housing mobility programs under a decentralized fiscal system. Specifically, the migration of program participants may stimulate Tiebout's vote-with-feet mechanisms and may limit the duration of the newly-created mixed-income environment, leaving poverty concentration and poverty unsolved. This research uses a dynamic economic model to analyze the impacts of housing mobility programs on local taxes and public goods in both the sending and receiving municipalities and the impacts of this change on further migration of different economic classes. An ANOVA model and a MANCOVA model were used to support the findings from the economic model. The ANOVA results indicate that residents of higher-poverty municipalities did not pay more taxes for welfare and 
health than residents of lower-poverty municipalities did because the expenses mostly came from intergovernmental funds. However, the MANCOVA results show that the percentage of population growth between 2000 and 2012 in the low-poverty municipalities with more low-income affordable housing program participants was still significantly smaller than that in the low-poverty municipalities with no/fewer low-income affordable housing program participants. These findings accord with the dynamic economic model, which suggests that even if the non-poor living with the poor do not pay more taxes for the public goods used exclusively by the poor, like welfare and health, further migration may still occur under a decentralized fiscal system. Property taxation requires wealthier residents to pay more for each unit of other nonexclusive public goods than the poor do. The research implies that funding anti-poverty programs at the local level rather than the national level may stimulate the out-migration of wealthier residents. As wealthier residents exit the newly mixed-income municipalities, poverty may re-concentrate, limiting the effectiveness of housing mobility programs. 
TABLE OF CONTENTS

PAGE

ACKNOWLEDGMENTS ............................................................................... iv

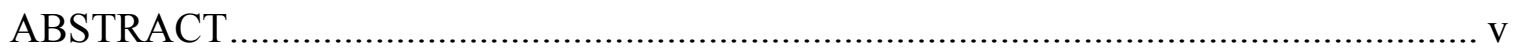

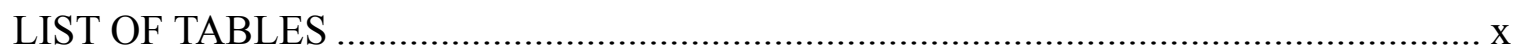

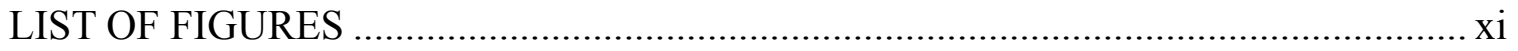

CHAPTER I INTRODUCTION ........................................................................ 1

CHAPTER II LITERATURE REVIEW ........................................................... 9

1. The Tiebout Model—Voting with One's Feet................................................... 9

2. Ineffectiveness of the Tiebout Model …......................................................... 12

3. Impacts of Federal Policies on the Tiebout Model ............................................ 19

3.1 Federal policies that worsened the negative consequences .................... 20

3.2 Federal policies that attempted to mitigate the negative consequences...... 23

3.2.1 Definition of housing mobility programs ................................. 24

3.2.2 Program theories of housing mobility programs ........................ 25

3.2.3 Outcomes of housing mobility programs................................. 28

4. Aim of the Research................................................................................. 38

CHAPTER III DYNAMIC ECONOMIC MODEL OF URBAN MIGRATION ............ 42

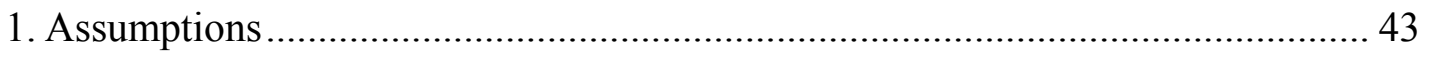

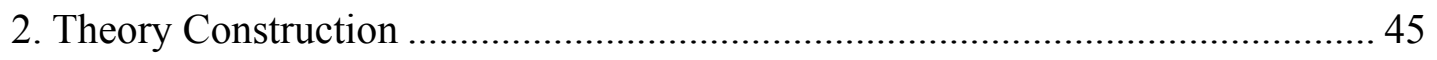

2.1 Two homogeneous municipalities................................................. 46

2.2 Impact of the poor's out-migration on the poor sending municipality ...... 47

2.3 Impact of the poor's in-migration on the rich receiving municipality ........ 49 
2.4 Dynamic economic model based on both impacts............................... 53

CHAPTER IV HYPOTHESES, METHOD, AND DATA ......................................... 58

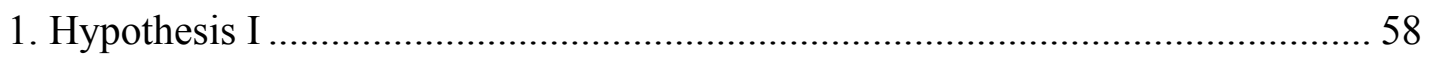

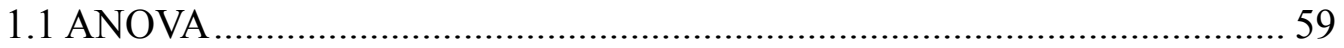

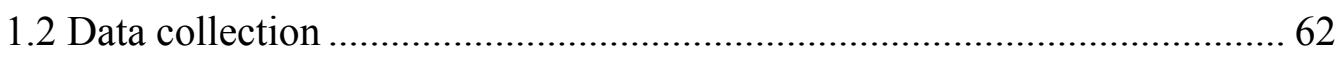

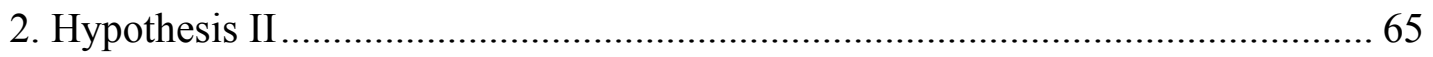

2.1 Why select affordable housing programs in low-poverty municipalities ... 65

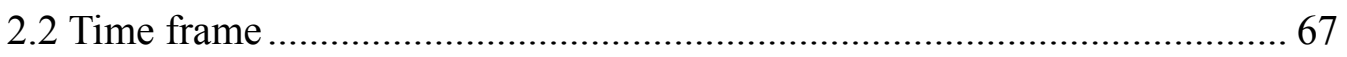

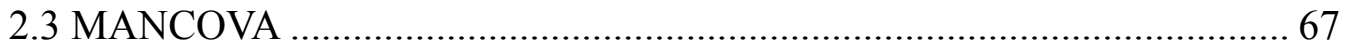

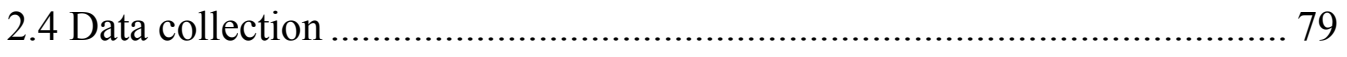

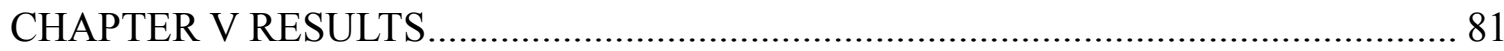

1. Results of the ANOVA Model for Hypothesis I........................................... 81

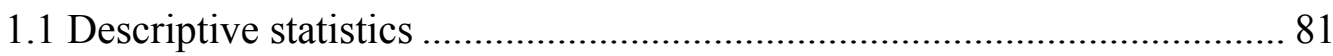

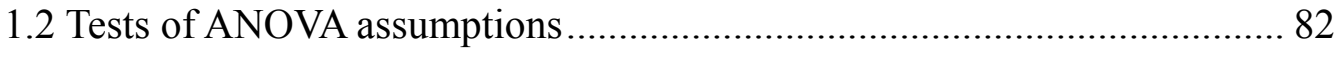

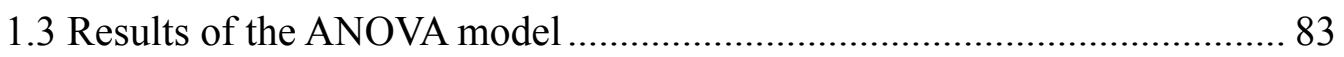

2. Results of the MANCOVA Model for Hypothesis II ....................................... 83

2.1 Descriptive statistics for the four models.......................................... 84

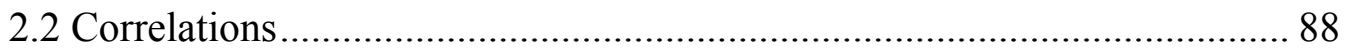

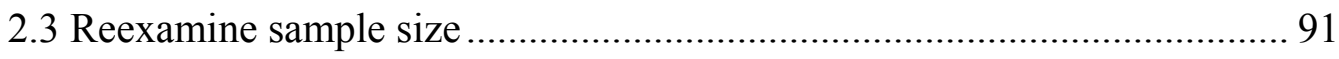

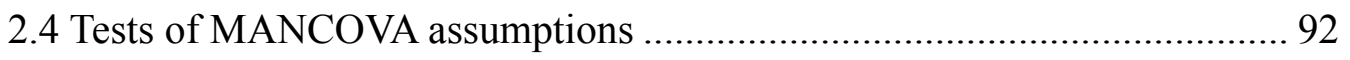

2.5 Results of the MANCOVA model......................................................... 96

2.5.1 Multivariate test: Group differences in joint dependent variables... 96

2.5.2 Univariate test: Group differences in each dependent variable ....... 97 
CHAPTER VI DISCUSSION AND CONCLUSION …….......................................... 100

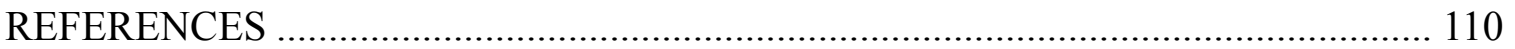

APPENDIX 1: ALGEBRAS USED IN THE DYNAMIC ECONOMIC MODEL ........ 119

APPENDIX 2: POVERTY THRESHOLDS FOR 1990, 2000, 2012 ........................... 121

APPENDIX 3: GEOGRAPHIC DISTRIBUTION OF MUNICIPALITIES ................... 125

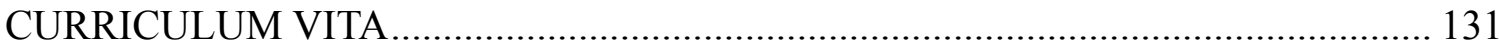




\section{LIST OF TABLES}

TABLE

PAGE

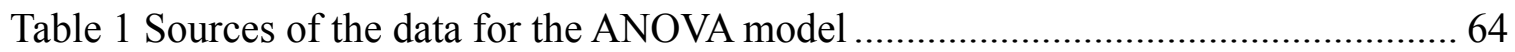

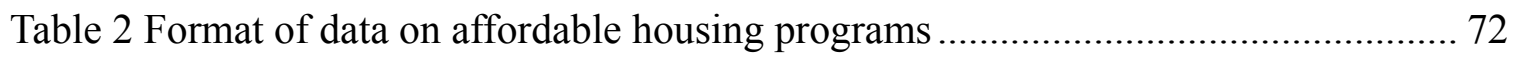

Table 3 Data of travel time to work from the Census Bureau........................................ 76

Table 4 Sources of the data for the MANCOVA model............................................... 80

Table 5 Descriptive statistics on health and welfare paid by the local non-poor............. 82

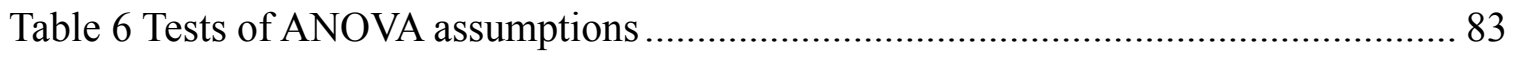

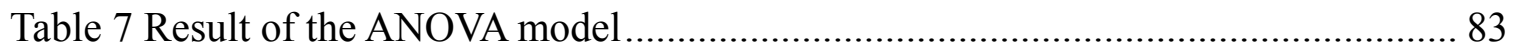

Table 8 Descriptive statistics of the four MANCOVA models ....................................... 86

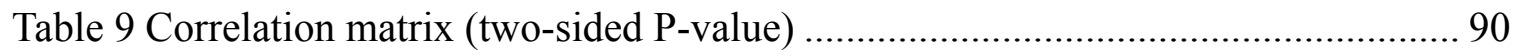

Table 10 Group sample size before and after including covariates ............................... 91

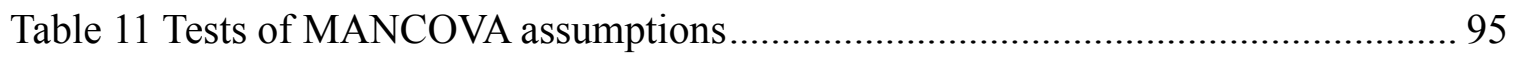

Table 12 Multivariate results on the percentage of population change (2000-2012)...... 97

Table 13 Unadjusted and adjusted group means of the percentage of population change 97

Table 14 Univariate results on each dependent variable........................................... 98

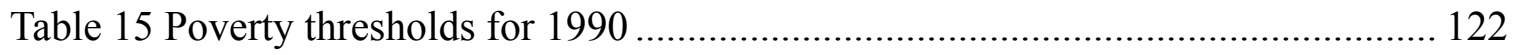

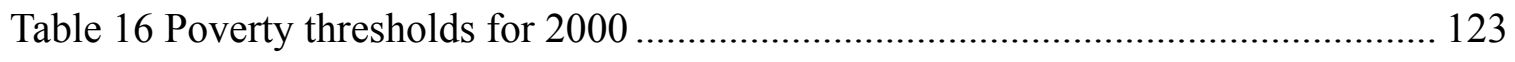

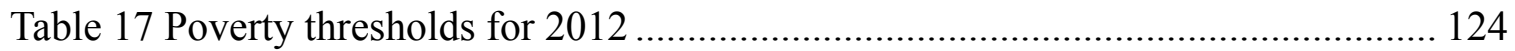




\section{LIST OF FIGURES}

FIGURE

PAGE

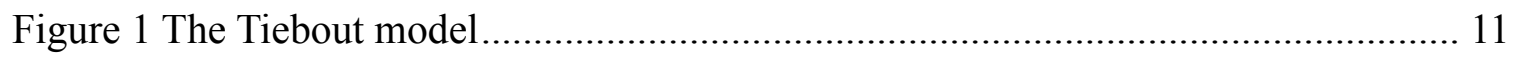

Figure 2 Model of two homogeneous municipalities ............................................... 47

Figure 3 The economic surplus of the poor in the sending municipality...................... 48

Figure 4 The economic surplus of the non-poor in the receiving municipality ............... 51

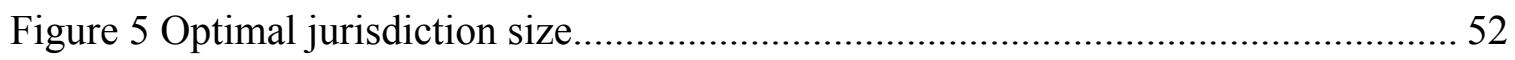

Figure 6 The economic surplus of the poor after the out-migration of the non-poor ....... 56

Figure 7 The number of municipalities within different ranges of poverty rates ............ 62

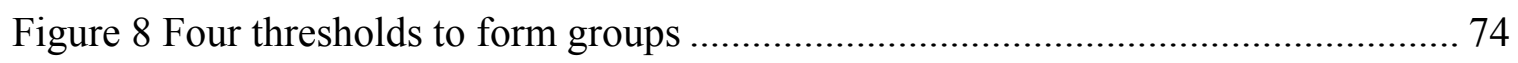

Figure 9 Geographic distribution of the two groups of municipalities used for the

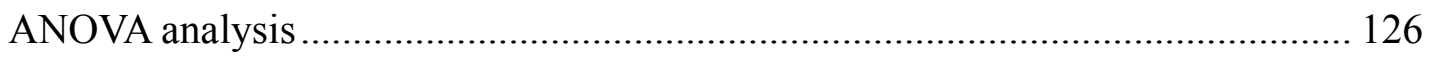

Figure 10 Geographic distribution of the two groups of municipalities formed by threshold 1

Figure 11 Geographic distribution of the two groups of municipalities formed by threshold 2 128

Figure 12 Geographic distribution of the two groups of municipalities formed by threshold 3 .

Figure 13 Geographic distribution of the two groups of municipalities formed by threshold 4 130 


\section{CHAPTER I}

\section{INTRODUCTION}

This research adopts an economic perspective to review how political fragmentation may result in urban problems, how these problems were exacerbated by federal housing and transportation policies, and how the federal government adopted housing mobility programs to solve these problems. The goal of this research is to analyze whether housing mobility programs could successfully solve the problems. This chapter briefly introduces the background, research question, purpose, dynamic economic model of urban migration, and statistical models in this research.

\section{Background}

Tiebout (1956) argued that political fragmentation can promote the efficiency of public good provision because each local government has to be effective and efficient to attract people to live in its jurisdiction. However, this theory has three problematic assumptions: the implicit assumption of head taxation ${ }^{1}$, full mobility, and no positive or negative externalities. In reality, property taxation is more widely adopted than head taxation. Property taxation has redistributive nature, which makes individuals tend to move to wealthier communities (Aronson \& Schwartz, 1973). To eliminate the externality of the poor's in-migration, local governments may adopt density zoning to prevent the

\footnotetext{
${ }^{1}$ Although this assumption is not directly written in Tiebout's article, Zodrow and Mieszkowski (1986) found that head taxation is necessary to achieve the efficiency mentioned in the Tiebout model.
} 
poor who lack economic mobility from voting with their feet (Hamilton, 1975). On the other hand, externalities also make local governments compete with each other in order to keep or attract capital (Bayindir-Upmann, 1998). Therefore, political fragmentation may cause economic segregation, overprovision of public goods for wealthier people, and underprovision of public goods for people in poverty. Besides fewer and inferior public goods, municipalities with poverty concentration may suffer from several other disadvantages, such as disease, high crime rates, unemployment, and violence (W. J. Wilson, 1997).

The problem of poverty concentration and its related social problems were exacerbated by federal policies. Federal housing and transportation policies, which subsidized those who can afford a house or a car rather than subsidized renters or those who rely on public transportation, widened the gap between wealthier people and the poor, making the poor less mobile and wealthier people more mobile. Moreover, these policies, which provided more housing mortgages to suburbs than to cities and constructed beltway, encouraged people who can afford a house and car to live in suburbs, thus shaping the spatial pattern of the urban poor and the suburban rich (Dreier, Mollenkopf, \& Swanstrom, 2004: 115-116, 121-122). This spatial pattern reduced urban poor's accesses to manufacturing, retail, and other low-skilled jobs in suburbs. In sum, these policies made the reality deviate from the assumptions of full mobility and no externalities even further, thus exacerbating the problems.

\section{$\underline{\text { Research question }}$}

Supported by considerable scholarship, the federal government attempted to break 
the economic segregation by subsidizing housing to disperse low-income families into wealthier neighborhoods with greater opportunities and resources (Imbroscio, 2008: 111). This residential mobility was expected to help low-income families achieve economic mobility because these families would have access to the jobs in suburbs, a higher level of public goods, and more opportunities to associate with the middle class, who may help expand their occupational and social networks. However, considerable scholars indicated that most program participants did not moved to low-poverty neighborhoods (Crump, 2003; DeLuca, Garboden, \& Rosenblatt, 2013; Edin, DeLuca, \& Owens, 2012; Finkel \& Buron, 2001; Goering, Feins, \& Richardson, 2003: 14; Goetz, 2004; Goetz \& Chapple, 2010; Imbroscio, 2012). These programs, which failed to relocate participants to low-poverty neighborhoods, cannot accurately test the effectiveness of the approach of relocating the poor to better neighborhoods.

This research defines housing mobility programs as the programs which successfully relocated low-income families to low-poverty localities by subsidizing housing. Unfortunately, even though low-income families were relocated to low-poverty neighborhoods, little empirical evidence showed significant difference in economic self-sufficiency between the group who moved to low-poverty neighborhoods and the group who stayed at high-poverty neighborhoods (Hanratty, McLanahan, \& Pettit, 2003; Katz, Kling, \& Liebman, 2000, 2003; Leventhal \& Brooks-Gunn, 2003; Sanbonmatsu et al., 2012; Shroder, 2002). Clampet-Lundquist and Massey (2008) argued that the mechanisms to improve employment outcomes take time to operate, so they use duration, namely months each movers stay in non-poverty neighborhoods (below 20 percent), as an independent variable and found that duration was positively associated with the odds of 
being employed.

Although this positive individual outcome implied that housing mobility programs might be effective, it is still unclear whether this positive impact will last in the long term. Duration of the poor staying in low-poverty neighborhoods depends on not only the residential mobility of the low-income families but also the residential decisions of the middle class. Since housing mobility programs highly relied on the positive impacts of mixed-income neighborhoods, or, to be more specific, the middle class, on the outcomes of low-income families, this research intends to analyze migration of different economic classes after housing mobility programs were adopted in order to reveal whether or not housing mobility programs' expected positive impacts will exist in the long term.

\section{Purpose}

Considering that housing mobility programs did not change the nature of political fragmentation by adopting supporting measures in receiving localities, this research argues that the effectiveness of housing mobility programs needs to be reexamined in the framework of political fragmentation because Tiebout's voting mechanism (1956) may still work. Since people have to pay tax to local governments and use local public goods provided by local governments, the in-migration of low-income families undoubtedly will affect the local tax revenue and the level of local public goods in receiving localities. The out-migration of low-income families will also affect the local taxes and public goods in sending localities. Based on the Tiebout model, the changes of local taxes and public goods may cause further migration.

Therefore, the main goal of this research is to create a dynamic economic model of 
urban migration to analyze the long-term impacts of housing mobility programs on sending municipalities, receiving municipalities, and the people who live in one of those municipalities. The Tiebout model is not appropriate for the analysis because of its three unrealistic assumptions. To remove these assumptions, the dynamic economic model adopts property taxation for analysis, allows people to make residential decisions whenever people move in or out in order to reflect externalities, and assumes that housing mobility programs improve the residential mobility of low-income persons. Also, most economic models related to Tiebout's theory are static models while this research attempts to create a dynamic model because any migration may become a driver of further migration. Last, instead of analyzing the impact of housing mobility programs on either individual outcomes or receiving localities, the economic model in this research includes both impacts by analyzing how housing mobility programs affect the bundle of taxes and public goods in receiving municipalities and thus cause further migration, which may further affect the long-term individual outcomes of program participants. Since municipalities are the smallest geographical unit with the power to decide its own tax rate and public goods, the analysis unit in this research is municipalities.

\section{Dynamic economic model of urban migration}

Unlike most previous economic migration models which are based on utility maximization, the dynamic model in this research borrows the concept of "dissatisfaction" from literature of sociology to explain migration. This concept implies that people will not move to other location as long as they are satisfied with their current location, even if they know they would be better off in other jurisdictions (Ellen, 2000: 105). Therefore, 
instead of comparing the utility of different municipalities, this dynamic model compares people's economic surplus in the same municipality before and after some people move in or out to analyze whether people have motivation to move.

The model helps to reveal a possible outcome if the federal government promotes greater mobility. The federal government has been historically and currently funding assisted housing to improve the residential mobility of low-income families. The approach of promoting greater mobility is still supported by many urban scholars. This approach indeed make reality more accord with Tiebout's full mobility assumption, but externalities and property taxation still have effects under a decentralized fiscal system. Residents can still be attracted by other municipalities if they do not satisfy the living environment of their current residences. And property taxation still has redistributive nature. This economic model analyzed the effects of externalities and property taxation and revealed a possible cycle of providing greater mobility without supporting measures: The federal government dispersed the poor, the poor moved, the non-poor in receiving municipalities out-migrated in the long term, receiving municipalities suffered from poverty concentration and poverty, and the federal government had to disperse the poor again to solve the same old problem in different municipalities.

\section{Statistical models to test the hypotheses}

The first statistical model, analysis of variance (ANOVA), is used to compare the non-poor's expenditure on health and welfare between the two groups-low-poverty municipalities (below 15 percent) and high-poverty municipalities (above 25 percent). The dynamic economic model does not distinguish different types of public goods; 
however, there are public goods that are used exclusively by the poor, like health and welfare. Therefore, ANOVA is used to test the null hypothesis that the non-poor in high-poverty municipalities pay the same for public welfare and health as the non-poor in low-poverty municipalities do. The result can show whether people living with the poor have to pay extra welfare expenditure besides subsidizing the poor on other nonexclusive public goods through property taxation. If data reject the null hypothesis, it means that the dynamic process predicted by the economic model may happen more or less quickly.

The second statistical model, multivariate analysis of covariance (MANCOVA), is used to analyze the out-migration of non-poor population between two groupslow-poverty municipalities with no/few low-income affordable housing program participants and low-poverty municipalities with many low-income affordable housing program participants. Housing mobility programs help the poor move by housing subsidies so affordable housing programs were selected for analysis. Also, only the affordable housing programs which were located in wealthier municipalities can help low-income families move to low-poverty municipalities and thus can be seen as housing mobility programs. Considering that people's economic status may change during the time span of this research, the research tested the group differences in both the percentage of the non-poor population change between 2000 and 2012 and the percentage of the total population change between 2000 and 2012. MANCOVA can control other variables, called covariates, which may affect moving decisions. By removing covariates' extraneous variation in the dependent variables, MANCOVA can show the effect of group differences on the two dependent variables. Tentative covariates included the percentage of population with long travel time (longer than 30 minutes), the construction of new 
housing units, the change of racial/ethnic composition, the change of crime rate, and region. The bivariate correlation coefficients of each tentative covariate with the dependent variables were tested to decide which covariates were included in the model.

This research is organized in the following way. Chapter II reviews the literature regarding the Tiebout model, the consequences of applying the Tiebout model, federal policies that exacerbated or intended to solve these consequences, and empirical studies on housing mobility programs which were created to solve the consequences. This chapter was concluded by framing the goals of this research based on the literature. Chapter III creates a dynamic economic model as a new theoretical framework to understand urban migration after housing mobility programs were adopted. Chapter IV states the hypotheses of this research and presents the methods to test them. Chapter V reports the results of statistical models. Chapter VI discusses the implications of the findings and provides policy suggestions on supporting measures and recommendations for future research. 


\section{CHAPTER II}

\section{LITERATURE REVIEW}

This chapter explains how political fragmentation can theoretically achieve spatial equilibrium in the Tiebout model. Second, further economic models and empirical evidence were reviewed to discuss the consequences of applying the Tiebout theory to the real world. The third section describes main federal policies that strengthened or attempted to weaken the effects of the Tiebout model — federal housing and transportation policies and federal housing mobility programs. The final section explains why housing mobility programs were trapped in Tiebout's voting mechanism and thus may not solve the problem of poverty concentration and its related problems. This chapter ends with the aim of the research - to create a dynamic economic model of urban migration to analyze the long-term impact of housing mobility programs on sending municipalities, receiving municipalities, and the people who live in one of those municipalities.

\section{The Tiebout Model-Voting with One's Feet}

Since 1920 s, states started to delegate the authority to regulate land use to local governments (Dreier, et al., 2004:113). By 1968, zoning laws were enacted by 65 percent of the 7,609 local governments in America (Dreier, et al., 2004: 113). Based on Tiebout's theory (1956), this political fragmentation can promote the efficiency of public good provision because each local government has to be effective and efficient to attract people 
to live in its jurisdiction. The theory greatly influenced today's service delivery system - fragmentation. Since the dynamic economic model in this research is based on the Tiebout model, Tiebout's theory of the spatial equilibrium is briefly described.

There are seven assumptions in the Tiebout model. First, people are fully mobile and will move to a community where the pattern of public goods provision accords with their preference (Tiebout, 1956). Second, people have full knowledge about the revenue and expenditure pattern in different communities (Tiebout, 1956). Third, there are a large number of communities from which people can choose (Tiebout, 1956). Fourth, the model does not consider the restrictions due to job opportunities (Tiebout, 1956). Fifth, public services provision in one community has no positive or negative externalities on other communities (Tiebout, 1956). Sixth, a city manager will follow the preference of their current residents so there will be an optimal size of the community, which is defined "in terms of the number of residents for which this bundle of services can be produced at the lowest average cost" (Tiebout, 1956: 419). Seventh, communities below the optimal population size will try to attract more residents to lower the average cost while those at the optimal size will try to maintain the same population (Tiebout, 1956). On the other hand, if communities are above the optimal size and thus generate congestion cost, residents there will vote for other communities with their feet, which means relocating to other communities (Tiebout, 1956).

Figure 1 shows how Tiebout's theory works. Assume there are two jurisdictions and each jurisdiction has 100 citizens (Brueckner, 2011: 167). Under head taxation, the cost of per unit of public goods $(C)$ is shared by everyone $(C / 100)$ (Brueckner, 2011: 167). Assume people have different preferences. High-demand consumers, called the rich, have 
a demand curve denoted as $D_{r}$. Low-demand consumers, called the poor, have a demand curve denoted as $D_{p}$. Despite heterogeneous composition of population in each community, the socially optimal quantity of public goods can be achieved by people voting with their feet. The quantity of public goods provided in jurisdiction I is $Z_{p 0}$ because of the poor majority while that in jurisdiction II is $Z_{r 0}$ because of the rich majority. The rich in jurisdiction I will move to jurisdiction II to obtain extra public goods they need while the poor in jurisdiction II will move to jurisdiction I to avoid paying for public goods that exceeds their needs. Eventually, people with the same preference for a bundle of tax and public goods will live in the same jurisdiction, achieving the spatial equilibrium of public goods provision.

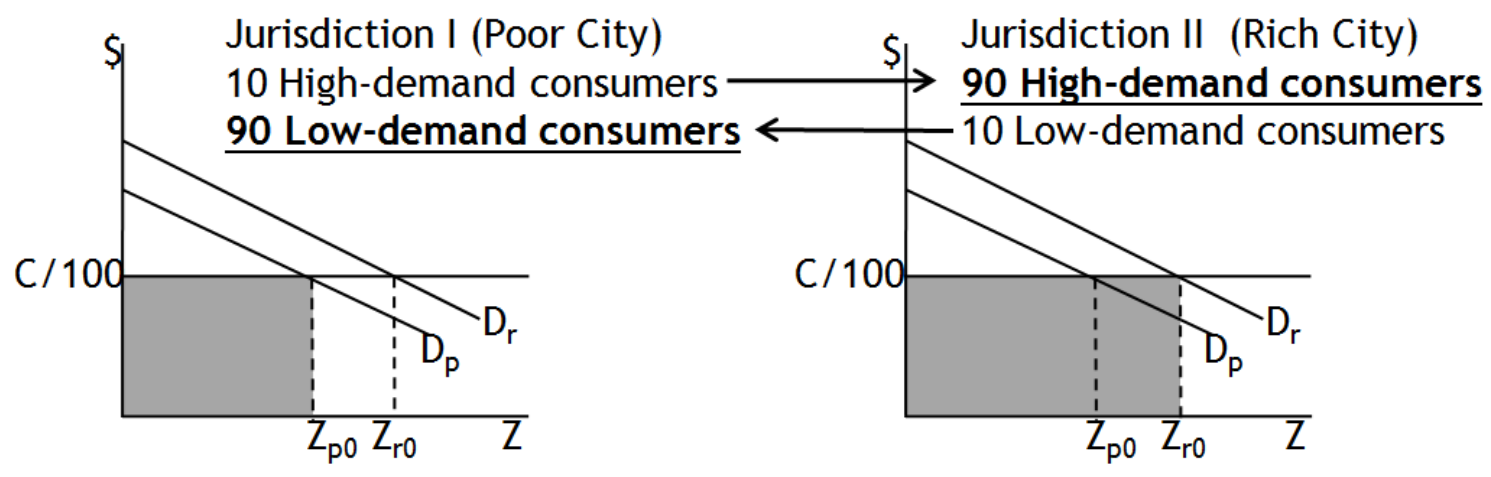

Figure 1 The Tiebout model

Source: Brueckner (2011: 167)

The difference between several terms in the Tiebout model needs to be clarified. Shared cost is defined as the cost shared by each person in the same political jurisdiction for each unit of public goods (see $C / 100$ in figure 1). Although shared cost is paid in a form of tax, the two terms - shared cost and tax-are different. Equation 1 shows the relationship of the two terms. Tiebout (1956: 417) indicates that "a government's 
objective is to figure out what public goods its consumers want and tax them accordingly." In figure 1, even though the shared cost is the same in the two jurisdictions, people in different jurisdictions pay different amounts of tax, which is decided by the quantity of public goods consumers in each jurisdiction want (see the shaded part in figure 1). (People in the rich city demand more public goods $\left(Z_{r 0}>Z_{p 0}\right)$ so they pay more tax than the people in the poor city do.) Different people may have different preferences for the bundle of tax and public goods. Eventually, each resident will live in a community where the pattern of public goods and tax accords with their preference (Tiebout, 1956). Considering that most researchers did not distinguish between the two terms and used "tax" for their analysis, this research uses the same term, tax, when citing their work. However, this research uses both terms for their specific meanings when creating the economic model.

Tax $=$ Shared cost * Quantity

\section{Ineffectiveness of the Tiebout Model}

Based on Tiebout's theory (1956), public services can be better provided in a decentralized system, like local governments, because this model requires multiple public service providers for people to choose from. This section reviews theoretical models and empirical evidence to examine whether the Tiebout model is effective or ineffective. This section shows three unrealistic assumptions of the Tiebout model-the implicit assumption of head taxation, the assumption of no externalities, and the assumption of full mobility - and explains the consequences resulting from the violation of the three assumptions. 
Neutral head taxation is the implicit assumptions in the Tiebout model to achieve the efficiency of public good provision (Zodrow \& Mieszkowski, 1986). However, property taxation is more widely adopted by local governments in America (Konishi, 2008: 462). Property taxation is redistributive taxation, meaning wealthier people have a higher tax burden than poorer people do even though everyone in the same political jurisdiction receives the same level of public services (Aronson \& Schwartz, 1973). Since people prefer to be subsidized by wealthier people rather than subsidize poorer people, individuals tend to move to wealthier communities (Aronson \& Schwartz, 1973). Moreover, people usually do not consider the negative ripple effects of their migration on other people's tax burden when making residential decisions. Therefore, this externality problem due to property taxation implies that Tiebout's prediction about homogeneous communities where people with the same preference live together may not happen. With the heterogeneous preference of people, the optimal quantity of public goods may not exist (Wildasin \& Wilson, 1991: 321). Even if the optimal quantity does exist, the public goods may not be efficiently distributed to different types of individuals (Wildasin \& Wilson, 1991: 321).

However, Hamilton (1975) indicated that the problems of public good provision due to property taxation may not actually happen because local governments' zoning policy can segregate consumers by their preferences to prevent free-riding, thus eliminating the distortions resulting from property taxation. By zoning out apartments and regulating minimum lot sizes for single-family homes, local governments can prevent people who cannot afford high-priced housing from moving in (Dreier, et al., 2004: 68). Empirical evidence also showed a strong relationship between density zoning and income 
segregation (Rothwell \& Massey, 2010). When density zoning excludes free riders and makes communities homogeneous, property taxation is actually a form of head taxation (Hamilton, 1975), thus achieving the equilibrium.

Since this equilibrium is not based on free-choice migration but on the migration free from choice, this so-called equilibrium sometimes is called economic segregation or poverty concentration. Although public choice theorists justifies that economic segregation is simply a result of people with similar tastes for the bundle of tax and public goods gathering together (Dreier, et al., 2004: 108), this research argues that the homogeneous communities are actually the consequences resulting from two problematic assumptions in the Tiebout model: full mobility and no externality. Since the in-migration of the poor may have negative impacts on local public finance, each community tends to take advantage of poor people's weak economic mobility and adopt density zoning to create a barrier to keep the poor out. Therefore, economic segregation, which accords with Tiebout's prediction, cannot verify the accuracy of the Tiebout model because segregation is a distorted outcome resulting from the fact that the negative externality is diminished by weakening poor people's mobility.

Even though zoning policies made communities more homogeneous, the problem of public good provision remained unsolved and more problems occurred in the communities with poverty concentration. As Tiebout himself admitted, the higher the costs of moving, the less likely to achieve optimal allocation of resources (Tiebout, 1956: 422). Therefore, as zoning increased poor people's cost of moving, the public good provision for the poor would be more away from equilibrium. Scholars noted that these poverty-concentrated communities usually have fiscal problems and have to either 
increase tax rates or reduce the level of public services (Dreier, et al., 2004: 157). Either decision motivates people to leave, further decreasing local governments' financial ability to provide public goods to their low-income citizens (Dreier, et al., 2004). Besides inferior public goods, there are other negative effects of living in high-poverty neighborhoods, such as disease, high crime rates, unemployment, and violence (W. J. Wilson, 1997). In short, zoning keeps problems confined within some localities rather than actually solves them.

Although zoning policies curb the in-migration of the poor, it cannot prevent the out-migration of the middle class so the equilibrium of public good provision cannot be achieved either in poverty-concentrated communities or in other communities. Tiebout's assumption that "[t]he public services supplied exhibit no external economies or diseconomies between communities" (Tiebout, 1956: 419) seriously distorts reality. From a political economy perspective, local governments tend to engage in tax competition or public good competition to keep their current wealthy population and attract additional ones from other jurisdictions (Bayindir-Upmann, 1998). However, scholars warned that tax competition may lead to underprovision of local public goods² (J. D. Wilson, 1986; Zodrow \& Mieszkowski, 1986) while public good competition may lead to overprovision of local public goods ${ }^{3}$ (Bayindir-Upmann, 1998). In sum, since zoning still cannot eliminate the effect of externality, municipalities cannot achieve the equilibrium through Tiebout's market-analog mechanism.

\footnotetext{
2 The problem of underprovided local public goods occurs because local governments tend to choose inefficiently low tax rates to attract capital investment and the low tax revenue further causes a low level of public goods provision (J. D. Wilson, 1986; Zodrow \& Mieszkowski, 1986).

${ }^{3}$ Since a high level of public services can benefit industry, local governments which engage in public good competition tend to overly provide public goods to mitigate capital flight or attract additional capital (Bayindir-Upmann, 1998).
} 
Scholars provide different models to explain the motivation of local governments to compete for business. For Peterson (1981), the competition is an economic problem: Governments operate in an economic system which is dominated by private business so local governments need to attract capital. For Kantor (1995: 2-3), cities depend on the tax revenue from the jobs and dollars of business for public services, but they do not need poor people to prosper. For Frug (1990), the competition is a legal problem: Since federal and state laws control much of what cities can do, cities have limited legal tools ${ }^{4}$ to control their economic destiny and thus tend to engage in the competition for capital to maintain the urban economy. For Logan and Molotch (1987 [2002]: 469), the competition is a cultural problem. Everyone in cities pursues economic growth so politicians take actions to attract new investments and sustain old investments (Logan and Molotch, 1987 [2002]: 469). For C. N. Stone (1989 [2013]: 20-34), the competition is a political problem. Cities are governed by those who control important concentrations of resources ${ }^{5}$ (C. N. Stone (1989 [2013]: 20-34). Whatever local governments' motivations are, these models all showed local governments' tendency to please wealthy individuals or institutions.

Therefore, the main problem of the Tiebout model is that Tiebout overlooked the fact that not everyone is a target that local governments want to attract. In the context of heterogeneous population, the difficulty of providing public goods to the poor is not merely the shortage of tax revenue. Another obstacle is that even if local governments have sufficient revenue, they may still not adopt the policies that benefit the poor because

\footnotetext{
${ }^{4}$ For example, city governments have no rights to impose tax on non-residents who live in suburbs but work in cities even though they use public services in cities every work days (Dreier, et al., 2004: 160).

${ }^{5}$ Although some scholars think voting power means cities are governed by the public, Stone uses an example in Atlanta to explain how high-resource groups, like business, employed the resources to protect their privilege: Business used its resource to mobilize the unemployed workers, making city council agreed to continue financial relief on business during the economic recession in 1930s (C. N. Stone, 1989 [2013]).
} 
they want to avoid becoming a welfare magnet (Kantor, 1995). Even worse, cities with financial problems may adopt strategies that worsen poor people's situation. Empirical evidence found that even with limited resources, poorer cities provided businesses indirect incentives, like tax abatements or reduced utility fees, which made the high-income people pay less for some public goods than the low-income people do, creating a more uneven situation (Rubin \& Rubin, 1987). The local governments' strategic behavior may cause underprovided merit goods ${ }^{6}$ like public health and welfare (Ferreira, Varsano, \& Afonso, 2005). Therefore, in the context of heterogeneous population, the problem is not just underprovision or overprovision of local public goods. The problem may also include wasteful duplication of public goods for high-income people and scarcity of public goods for low-income people.

The above competition model is just one side of the story. Besides maximizing tax revenue, politicians may also want to maximize the share of the voters who support them. Glaeser and Shleifer (2005) built an economic model to demonstrate that political leaders may adopt policies that encourage the out-migration of voters opposing them, thus increasing the likelihood of their reelection. Therefore, instead of attracting wealthy residents, it is possible that politicians repel the middle class for their personal interests-reelection. Unfortunately, as the competition model predicted, helping minorities, regardless of politicians' intentions, may cause the stagnation of cities. For example, Coleman Young, the first black mayor of Detroit in 1973, taxed his richer constituents to fund redistribution and supported public housing (Glaeser \& Shleifer, 2005: 12-13). Although he adopted these policies to gain his political advantage - reelection and served as the mayor of Detroit for 20 years (1974- 1994),

\footnotetext{
${ }^{6}$ Merit goods are commodities provided on the basis of needs rather than the ability to pay.
} 
Detroit stagnated. Population declined by $32 \%$, the percentage of households living below the poverty line rose from $18.6 \%$ to $29.8 \%$, and the unemployment rate was twice as high when Young left office than when he first entered it (Glaeser \& Shleifer, 2005). David Dinkins, New York City's first black mayor, also made a commitment to the poor and homeless, causing a significant growth in homeless people (Kantor, 1995: 3-4). The increase in the poor population limited the city's financial capacity to support these programs (Kantor, 1995: 4).

The above analysis indicates that the problem of public good provision for the poor mainly resulted from two reasons. First, every policy involves redistribution (D. Stone, 2002 [2007]: 93). Each policy is funded by all citizens but may only benefit certain groups of people. Second, political fragmentation implies that helping the poor is the responsibility of the people who live in the same jurisdiction with the poor. The two reasons explained why applying the Tiebout model may produce unfavorable attitudes of local governments and wealthy people toward the poor. These attitudes give rise to uneven provision of public goods for different economic classes. If local governments help the poor, they cannot control the out-migration of the middle class and the in-migration of the poor $^{7}$, thus causing poverty concentration. Eventually, these local governments may lack the financial capacity to provide public goods for their citizens. In sum, the problem occurs because localities are either unwilling or unable to adopt policies that benefit the poor.

\footnotetext{
${ }^{7}$ People have to be the highest bidder to live in a certain location (Brueckner, 2011: 52). Density zoning can only regulate the size of houses; it cannot regulate the price of the houses, which is decided by housing markets. Therefore, even though the local governments still adopt zoning policies while helping the poor in their jurisdictions, the zoning policy may not prevent the in-migration of the poor from other jurisdictions if the middle class refuse to bid for living in that communities and decide to move to other jurisdictions, making the poor the highest bidder in that communities. Under this circumstance, the in-migration of the poor cannot be stopped by zoning.
} 
Like advocates of free markets believe that the welfare of the society can be maximized if everyone adopts strategies that maximize his/her own benefit, Tiebout's market-analog mechanism suggests that the effectiveness of public good provision can be achieved if every local government competes for potential consumers by effectively and efficiently providing public goods. However, the prisoners' dilemma describes a situation that individuals' best actions may lead to a disaster for the group (Dixit \& Nalebuff, 2008 [2009]: 18). Similarly, the analysis in this section shows that the interlocal competition may make local governments adopt policies that tend to privilege the high-income individuals, disadvantage the low-income individuals, and therefore fail to achieve the optimal bundle of tax and public goods.

\section{Impacts of Federal Policies on the Tiebout Model}

Markets are never free from government influences (Dreier, et al., 2004: 109) and Tiebout's market-analog mechanism is no exception. The analysis of a smaller unit should include the impacts of its surrounding political systems (Ostrom, 1990 [2012]: 222). However, the Tiebout model failed to address the role of multiple levels of governments (Baicker, Clemens, \& Singhal, 2012: 1086). Most empirical research to test Tiebout's theory (Cebula \& Nair-Reichert, 2012; Ellson, 1980; Grassmueck, 2011; Rhode \& Strumpf, 2003) only examined the variables at the local level, like tax and public goods, on the sorting process and did not take federal policies during the time-span of their data into consideration. Although some theoretical research described how federal policies shaped people's residential decisions and created the spatial pattern of the urban poor and the suburban rich (Dreier, et al., 2004: 103-151), few economic models include 
the impact of federal policies on the Tiebout model. Most federal policies can affect local governments more or less. This section only reviews the main federal policies that influenced people's residential decisions because these policies may exacerbate or mitigate the negative consequences - the disadvantages of the poor- resulting from Tiebout's competition model.

The problems resulting from the Tiebout model made many scholars believe that municipalities should be folded into bigger entities in order to efficiently and equally provide public goods (Kirby, 2004: 754). However, it is the adequate policies, not the size of the government, that solve urban problems (Siegel, 1999). In fact, misusing the power of the "big box" government may even exacerbate rather than solve the problem ${ }^{8}$. This research begins by reviewing how early federal policies worsened the unfavorable situation of the poor and then describes what policies the federal government adopted to correct its mistakes.

\subsection{Federal policies that worsened the negative consequences}

Federal transportation and housing policies strengthened the mobility of the middle class, reinforcing the inequality between different economic classes. Federal transportation policies benefited those who own a car instead of those who cannot afford a car: the federal government spent 1.15 trillion on roads and highways but only 187 billion on mass transit between 1975 and 1995 (Dreier, et al., 2004: 117). The federal government also set low fuel prices, imposed low taxes on cars, and subsidized parking

\footnotetext{
${ }^{8}$ Savitch, Vogel, and Ye (2010) examined the outcomes of city-county consolidation of Louisville and Jefferson County in Kentucky by comparing data from premerged and postmerged Louisville over a full 8 -year period, they found that the economic development in the larger metropolis did not dramatically change, even declined.
} 
costs (Williamson, Imbroscio, \& Alperovitz, 2002: 77). As for federal housing subsidies, Federal Housing Administration (FHA) provided mortgages to white middle-class families in suburbs but little aid to black, urban residents, and renters (Dreier, et al., 2004: 121-122), increasing the wealth gap between the white and the black, between house-owners and house-renters, and between central cities and suburbs.

Besides widening the gap of economic mobility between different economic classes, federal transportation and housing policies, along with globalization (1980s forward), caused the problem of spatial mismatch and thus blocked poor people's upward economic mobility. FHA provided more mortgages to those who purchased a house in suburbs than those who purchased a house in cities, which encouraged the middle class to live in suburbs (Dreier, et al., 2004: 121-122). Federal transportation subsidies strengthened this trend by reducing commuting costs of living in suburbs. The spatial pattern of the urban poor and the suburban rich had been gradually formed since these federal policies were adopted in the $1930 \mathrm{~s}^{9}$. Later, the development of information technologies in the age of globalization allowed those industries that benefit less from agglomeration economies, like manufacturing, retail, and other low-skilled jobs, to relocate to the suburbs (Wyly, Glickman, \& Lahr, 1998: 9) while those highly-skilled professional jobs which rely on urban density to spread knowledge or to stimulate innovation remained in cities (Dreier, et al., 2004: 67). This spatial distribution of high/low-skilled jobs, along with the spatial pattern of the urban poor and the suburban

\footnotetext{
9 As to housing subsidies, Home Owners Loan Corporation (HOLC) was created in 1933 by Congress to provide low-interest loan to owners (Dreier, et al., 2004: 120). Later, FHA and Veterans Administration (VA) were established to promote home ownership (Dreier, et al., 2004: 120). As to transportation subsidies, in 1934, states were required to receive federal highway funds to build roads (Dreier, et al., 2004: 115). Later, the fund expenditure increased dramatically: $\$ 79$ million in 1946, $\$ 429$ million in 1950, $\$ 2.9$ billion in 1960, and \$20.5 billion in 1997 (Dreier, et al., 2004: 116).
} 
rich (high/low-skilled workers), created spatial mismatch. Although this problem was partly attributed to the global economic restructuring, the comparison between the spatial polarization in America and that in other developed countries revealed that political institutions and policies were the main cause of this pattern rather than economic forces (Dreier, et al., 2004: 61).

Spatial mismatch was especially harmful to the urban poor, although it harmed both economic classes. The middle class suffered less because of their economic ability to afford commuting costs and because of federal subsidies on highway construction, gasoline, parking and other car-related costs. On the contrary, those who could not afford an automobile to access the labor market in suburbs received few federal subsidies on public transit service (W. J. Wilson, 1997: 42; 2009: 10). This spatial inaccessibility of jobs further made the urban poor suffer from joblessness (W. J. Wilson, 1997). Even if the poor managed to work in suburbs, evidence showed that people who left welfare for work tended to be poorer in the next year because the low wage could not cover the cost of transportation, health insurance, baby-sitting, and other costs (W. J. Wilson, 1997: 79-80). In short, poor people's upward economic mobility was limited, and so was their ability to vote with their feet. Their situation implies that federal policies indirectly weakened the economic mobility of the poor.

In sum, these federal housing and transportation policies exacerbated the negative outcomes of Tiebout's competition model. Instead of providing sufficient resources and channels to help the poor to improve their economic mobility, the federal government weakened their economic mobility, thus prohibiting them from leaving their residences (usually in inner cities). On the other hand, the federal policies strengthened the 
economic mobility of the middle class by subsidizing them to move to other jurisdictions more easily, therefore intensifying the competition between local governments. The intense competition implied that local governments may need to provide more tax incentives or a higher level of public goods to keep the middle class or to attract new ones. In sum, the federal government exacerbated the problem of inequality between different economic classes and the disadvantages of the poor by increasing the economic gap and intensifying interlocal competition.

\subsection{Federal policies that attempted to mitigate the negative consequences}

Concerns over urban poverty and its related social problems ${ }^{10}$ grew throughout the 1980s, leading to anti-poverty policies in early 1990s (Imbroscio, 2004b: 447). Among all policy alternatives, many American urban scholars believed that the dispersal of low-income families to wealthier neighborhoods is the best solution to fight poverty (Imbroscio, 2008). This mobility approach was based on the belief that residential mobility can improve economic mobility. That is, once the poor are relocated to the neighborhoods with greater resources and opportunities, they can escape from constant poverty. This section reviewed current findings to show whether housing mobility programs were effective or not.

Section 3.2.1 explains the definition of housing mobility programs in this research. Not all programs which provide housing subsidies are defined as housing mobility programs in this research. Section 3.2.2, program theories of housing mobility programs, outlines the theoretical mechanisms how residential mobility can improve economic

\footnotetext{
${ }^{10}$ When people cannot obtain their daily necessities through conventional channels, namely jobs, people turned to crime (Dreier, et al., 2004: 93). In fact, central-city crime rates were three times suburban crime rates in 1990s (Dreier, et al., 2004: 92).
} 
mobility. Section 3.2.3 examined if housing mobility programs could activate each mechanism and if program participants' economic mobility improved.

\subsubsection{Definition of housing mobility programs}

Housing mobility programs were created to help low-income families move to low-poverty neighborhoods by subsidizing housing rent. The affordable rents allowed program participants to move to where they otherwise cannot afford. However, considerable research indicated that many programs failed to help program participants relocate, or even if they did, participants moved to vulnerable neighborhoods (Crump, 2003; DeLuca, Garboden, \& Rosenblatt, 2013; Edin, DeLuca, \& Owens, 2012; Finkel \& Buron, 2001; Goering, Feins, \& Richardson, 2003: 14; Goetz \& Chapple, 2010; Imbroscio, 2012). Although many researchers have analyzed the effectiveness of housing mobility programs by examining participants' individual outcomes, this research argues that the programs that failed to relocate participants to low-poverty neighborhoods would be a weak test of mobility-based solution: The outcomes can only show whether or not that specific program was effective and cannot answer whether or not the approach of relocating the poor to better neighborhoods were effective.

Since the key assumption of housing mobility programs is the benefits associated with wealthier neighbors (Briggs, 1997: 195; Pattillo, 2008: 36), only those cases which actually received rental assistance and successfully relocated to low-poverty localities were identified as housing mobility programs. Thus, this research defined housing mobility programs in cases rather than in programs. Project-based housing assistance needs to be located in a low-poverty locality to be considered as housing mobility 
programs. Those located in high-poverty localities are not housing mobility programs because the assistance only helps low-income families move to other high-poverty localities. As to tenant-based housing assistance, only when program participants use rental assistance to move to a low-poverty locality, the assistance is considered as a housing mobility program. For example, among the participants of Moving to Opportunity $\left(\mathrm{MTO}^{11}\right)$ program, only those who successfully moved to low-poverty neighborhoods are considered as the participants of housing mobility programs.

This research focuses only on the policies that move the poor from high-poverty neighborhoods to low-poverty neighborhoods, so the disturbance from gentrification programs, like Housing Opportunities for People Everywhere (HOPE VI) programs, was removed. Housing mobility programs emphasized on helping the poor move in to low-poverty receiving neighborhoods while gentrification programs forced the poor to move out of sending neighborhoods and emphasized the reconstruction of sending neighborhoods. This research concerns the impacts of housing mobility programs on receiving localities and on individual outcomes of the low-income families who moved in these receiving localities. These impacts cannot be observed if gentrification programs forced low-income families to leave these receiving places. Therefore, this research excludes the localities which experienced gentrification programs after housing mobility programs were adopted.

\subsubsection{Program theories of housing mobility programs}

Housing mobility programs, which improved residential mobility, were expected to

\footnotetext{
${ }^{11}$ MTO, operated from 1994 to 1998, aimed to "assist very low income families with children......to move out of areas with high concentrations of persons living in poverty to areas with low concentrations of such persons" (Section 152 of the Housing and Community Development Act of 1992).
} 
improve economic mobility through the following mechanisms. First, the theory of spatial mismatch and empirical finding indicated that poverty was positively related to the lack of physical accessibility to economic opportunities (Holzer, 1991). Since housing mobility programs could bridge the gap between low-skilled workers and low-skilled jobs in suburbs, housing mobility programs were considered the best solution to fight poverty by many urban scholars (Imbroscio, 2004b, 2006).

Second, housing mobility programs could create mixed-income neighborhoods, which help expand low-income persons' job network. Wilson's theory $(1987,1996)$ of social isolation indicated that people in extreme poverty neighborhoods usually had limited resources, opportunities, and channels to find a job, causing joblessness after the selective out-migration of the middle class. Based on Wilson's theory, Kasintiz and Rosenberg (1996) analyzed the connection between social isolation and employment in the Red Hook section of Brooklyn, New York, and found that the poor, although they lived close to blue-collar jobs, remained unemployed because most jobs there were filled through social networks and the poor did not have the connection and references. By creating mixed-income neighborhoods, housing mobility programs may help program participants establish social networks with employed middle-class neighbors, who can provide information about jobs and more useful referrals, thus increasing the poor's chance of finding a job (Kleit, 2002; W. J. Wilson, 1996).

Creating mixed-income neighborhoods by housing mobility programs was also based on peer influence on shaping individual's behavior (Ellen \& Turner, 2003: 327). Wilson's social isolation theory $(1987,1996)$ indicated that high-poverty neighborhoods lacked positive role models, so the environment may shape people's social behavior 
which was unfavorable in job markets. Advocates believed that housing mobility programs can improve the poor's economic mobility by breaking the isolation and depending on the presence of middle-class role models to influence the social choices of low-income individuals (Chaskin \& Joseph, 2013; DeFilippis \& Fraser, 2010: 137).

Third, housing mobility programs could improve low-income persons' access to better and more public goods and services because these goods are collective consumptions and are better provided in wealthy neighborhoods than in poor ones (DeFilippis \& Fraser, 2010: 137). With residential segregation, unequal access to public goods like schools, healthy environment, safety, and medical services can shape or constrain people's upward opportunity (Dreier, et al., 2004: 28). For example, besides spatial mismatch, skills mismatch is another explanation for unemployment (Bauder \& Perle, 1999). People in high-poverty localities tended to have poor education resources, like unqualified teachers, improper equipment and books (W. J. Wilson, 1997: 9-10). The inferior education resources limited people's skills and thus limited their opportunities for high-paid jobs. Since schools in low-poverty neighborhoods had more resources, more stable academic environments, and lower pupil-teacher ratio, housing mobility programs were expected to increase children's skills and thus enhance their life opportunities (Orr et al., 2003: 109; Sanbonmatsu et al., 2011: 220). Also, since mental and physical health affects job performances, resources to improve individuals' mental and physical health, like healthcare access, park, neighborhood walkability, lower pollution, and better sanitation, may also be a positive factor to improve employment outcomes.

The above theories revealed that housing mobility programs emphasize exposing low-income individuals to higher socioeconomic status peers (Sanbonmatsu et al., 2012: 
$112,114)$ and heavily rely on the middle class to bring positive changes to low-income individuals (Pattillo, 2008: 36). In fact, some scholars even criticized that housing mobility programs overemphasize the importance of the middle class, indicating the inappropriate assumption that the middle class can be role models while the poor tend to have problematic behavior, which needs to be modified or controlled (Pattillo, 2008: 38). This dissertation sets the topic in an economic context and does not intend to argue for or against theories related to social network or middle-class role models. From an economic view, however, wealthy people do have positive influence on the poor because of property taxation. Many poverty-concentrated cities struggle to provide adequate public goods for citizens due to the limited tax revenue from their low-income residents and the lack of power to tax the rich free-riders in suburbs, who work in cities and use the urban public services paid by the urban poor (Dreier, et al., 2004: 156-157). Without providing financial aid or public goods to receiving localities, housing mobility programs actually relied on wealthier residents to share public goods and services with their new low-income neighbors. Property taxation allows the poor to pay relatively less than the others do while enjoying the same level of public goods.

\subsubsection{Outcomes of housing mobility programs}

The discussion of outcomes focuses on the impacts of housing mobility programs on economic mobility because enhancing economic mobility was not only the main goal of providing the poor residential mobility but also related to whether or not housing mobility programs could weaken the effects of property taxation and externalities. This section reviews the impact of housing mobility programs on each mechanism- the 
accessibility to work, social network, behavior, and the availability of public goods - and then discusses if the economic mobility of participants was enhanced.

One of the main difficulties to evaluate the effect of housing mobility programs on economic mobility comes from the self-selection problem, which means individual or household attributes may affect participants' decisions on not moving, moving to low-poverty neighborhoods, or moving to other high-poverty neighborhoods (Shroder \& Orr, 2012). Most housing mobility programs allowed program participants to decide where to live, and their decisions may influence outcomes. Thus, scholars were unable to distinguish whether the change of economic mobility was related to participants' attributes or other neighborhood contextual variables (Ludwig, Duncan, \& Pinkston, 2000: 4).

Since MTO was expected to overcome the self-selection bias due to its nature of social experimental design, this research mainly reviewed the outcomes of MTO. MTO participants were randomly assigned to one of three groups: the experimental group was given housing vouchers that could only be used in low-poverty (below 10 percent) neighborhoods; the comparison group was given housing vouchers with no geographical restriction; and the control group was not given housing vouchers. Since residential decisions in MTO were made by random assignments rather than individual choices, MTO was expected to overcome the self-selection bias.

Ideally, if all participants complied with the MTO program requirements, scholars can isolate the neighborhoods effects from individual or family attributes by the comparison between the experimental group and the control group. However, less than 
half of MTO experimental group participants (47\%) moved with their vouchers ${ }^{12}$. Therefore, there are two types of group-based analysis. The intent-to-treat (ITT) effect is measured by the comparison between the average outcome of the full experimental group and that of the control group while the treatment-on-the-treated (TOT) effect is between the experimental movers, who actually relocated with MTO vouchers, and the control group (Sanbonmatsu et al., 2011: XIII). The following used both the ITT and TOT effects to discuss the findings of MTO.

\section{A. Impact on accessibility to work}

MTO alone could not improve the accessibility to work unless public transportation was near receiving neighborhoods. Although the experimental group was given vouchers to move to low-poverty neighborhoods, both the ITT and TOT effects showed no significant difference across groups when people were asked if they have a working car or live less than 15 minutes to public transportation (Sanbonmatsu et al., 2011: 62). Since MTO did not improve participants' access to jobs, MTO's disappointing employment outcomes cannot be seen as evidence that spatial mismatch was not the cause of poverty (Quigley \& Raphael, 2008). In fact, Blumenberg and Pierce (2014) found that MTO movers who gained access to a car or public transit were positively related to employment outcomes after controlling the effect of demographic and socioeconomic characteristics, housing attributes, and neighborhood quality.

\section{B. Impact on social network}

Research showed mixed evidence of the effect of social networks on employment.

12 The data comes from exhibit 2.5 in Orr and others (2003). 
Ellen and Turner (2003) examined existing empirical evidence and concluded that qualitative research tended to show the importance of social networks on employment, like people learning job opportunities by "word-of-mouth," while quantitative research tended to show weak relationships between social networks and employment.

Whether social networks had effect on employment or not, MTO alone had few effects on expanding participants' social networks with the middle class. Both the ITT and TOT effects showed that neighborhoods of the experimental group significantly had more share of college graduates, more share of employed civilians, and more share of workers in managerial or professional occupation (Sanbonmatsu et al., 2011: 60-61). However, participants encountered difficulties to build meaningful relationships with wealthier neighbors (Varady \& Walker, 2003: 20). Instead of socioeconomic mix, Curley (2010) indicated that the key predictor of social network is the neighborhood resources, like libraries, recreation facilities, parks, grocery stores, and social services, which provide opportunities for direct interaction between neighbors. In sum, creating mixed-income neighborhoods without these public facilities may not improve participants' social networks with their middle-income neighbors.

\section{Impact on behavior}

Interim impacts evaluation (4-7 years after random assignment) showed that both children and adolescents were less likely to commit crimes or be exposed to crimes after moving with MTO vouchers (Hanratty, McLanahan, \& Pettit, 2003; Katz, Kling, \& Liebman, 2000, 2003; Ludwig, Duncan, \& Hirschfield, 2001; Ludwig, Duncan, \& Ladd, 2003; Orr et al., 2003). People without criminal records are more employable than those 
with criminal records. Thus, scholars expected MTO to have positive long-term effects on economic self-sufficiency (Wasserman, 2001: 31).

However, the final impacts evaluation (10-15 years after random assignment) indicated that both ITT and TOT effects for grown children ages 21-30 and adults showed no significant group difference in criminal behavior (Sanbonmatsu et al., 2011: 202-205). What is worse, both ITT and TOT effects showed that the youth ages 15-20 (those who had been living in low-poverty neighborhoods early in their childhoods) in experimental group had higher property crime arrest rates than those in the control group (Sanbonmatsu et al., 2011: 200).

\section{Impact on public goods}

Although the experimental group children attended schools with greater resources, fewer limited English proficient students, and higher ranks on state exams than did the control group children, no significant ITT or TOT effects on educational outcomes was found (Ladd \& Ludwig, 2003; Newman \& Harkness, 2003; Orr et al., 2003: 109-110, 116-121; Sanbonmatsu, Kling, Duncan, \& Brooks-Gunn, 2006). Indicators of educational outcomes included reading, math, word identification, passage comprehension, applied problems, calculation, concept formation, grades received, advanced coursework, ever repeated a grade, and SAT/ACT (Orr et al., 2003: 109-110). The final evaluation (10-15 years after assignment) also drew a similar conclusion that MTO had few detectable impacts on educational outcomes for youth (Sanbonmatsu et al., 2011: 230-238).

Due to the improvement in public sanitation and public safety, the experimental group adults experienced fewer physical and mental health problems than did the control 
group adults, but the positive effects were weaker in the long term. Compared with the control group, the experimental group reported fewer problems with vermin, felt safer in their current neighborhoods, and had higher likelihood of police response to 911 emergency calls in both the interim impacts and final impacts evaluation (Orr et al., 2003: 74-75; Rosenbaum \& Harris, 2001; Sanbonmatsu et al., 2011: 102-103). The interim evaluation (both ITT and TOT effects) showed that the experimental group adults had significantly better health than did the control group adults, including reducing extreme obesity (BMI $\geq 35 \mathrm{~kg} / \mathrm{m}^{2}$ ), less psychological distress or depression, and higher likelihood of being calm and peaceful (Orr et al., 2003: 77). In the final evaluation, although the ITT and TOT effects showed that the experimental group adults is less likely to have serious illness like diabetes, high blood sugar, and serious stomach problem than the control group adults, there was no longer a statistically significant impact on adults' mental health (Sanbonmatsu et al., 2011: 102-103, 133-135).

\section{E. Impact on economic mobility}

The above analysis suggested that MTO may not effectively activate the mechanisms that were expected to improve employment outcomes. MTO could improve accessibility to work only when receiving neighborhoods were close to public transit. MTO could expand participants' social network with the middle class only when receiving neighborhoods had public goods that provided a space for neighbors to interact with each other. Although interim impacts evaluation showed that MTO may have reduced participants' tendency to commit crimes, this tendency was no longer statistically significant in a longer term. Better schools had limited effect on the educational outcomes 
of the MTO youths. The public sanitation and public safety in receiving neighborhoods may improve MTO adults' physical and mental health at first, but no significant difference across groups in mental health was found in a longer term.

Therefore, it is not surprising that few studies found significant impacts of MTO on participants' economic self-sufficiency. Researchers used different variables to measure the ITT and TOT effects on economic self-sufficiency. Early-impact analysis suggested no significant group difference in the changes of employment, earnings, and welfare participation from baseline to follow-up (Hanratty, McLanahan, \& Pettit, 2003; Katz, Kling, \& Liebman, 2000, 2003; Leventhal \& Brooks-Gunn, 2003). Considering that MTO had obvious positive impacts on neighborhood resources, decreased criminal behavior, increased health, and possible children's educational achievement, scholars believed that the improvement of economic self-sufficiency had just not yet happened. However, the results from recent follow-up evaluation (10-15 years after assignment) still did not show significant improvement in MTO adults' employment, earnings, or welfare participation (Sanbonmatsu et al., 2012: XXVII). This final impact evaluation also showed that MTO did not improve children's life opportunities: There were no group difference (both ITT and TOT estimates) on school enrollment, idleness, and weekly earning for MTO youth ages 15-20 (Sanbonmatsu et al., 2012: 157). Even worse, the experimental group youth were significantly less likely to be employed than the control group youth (Sanbonmatsu et al., 2012: 157).

However, Clampet-Lundquist and Massey (2008) argued that the mechanisms to improve economic self-sufficiency required time to take effect but the previous findings from group-based analysis overlooked the possibility of subsequent residential changes. 
In other words, the TOT effects still could not show the effectiveness of housing mobility programs because even if the experimental group families moved with their housing vouchers, they were not required to stay in low-poverty neighborhoods after one year when the lease expired (Clampet-Lundquist and Massey, 2008: 121). To overcome this deficiency of group-based analysis, Clampet-Lundquist and Massey (2008) used individual movers as an analysis unit and measured duration, namely months MTO movers stay in non-poor neighborhoods (below 20 percent), as an independent variable, and found a strong positive relationship between the duration and the odds of being employed. Moreover, if the low-poverty neighborhoods were racially integrated, the duration was positively related to weekly earnings (Clampet-Lundquist and Massey, 2008).

Generally speaking, scholars have two opposite interpretations regarding the outcomes of no significant difference across groups and positive outcomes from mover-based analysis. One group of scholars believes that the potential of housing mobility programs was limited because the federal government failed to "provide voucher holders access to high opportunity areas" (Sard, 2008: 1). Based on this logic, if all MTO participants complied with the program requirements and kept staying in the receiving neighborhoods, economic outcomes should be significantly different across groups. Therefore, instead of questioning housing mobility programs for the disappointing outcomes, this group of scholars analyzed factors that restricted or fostered mobility or factors that prevented low-income families from staying in receiving neighborhoods in order to provide policy suggestions for greater mobility (e.g., DeLuca, Garboden, \& Rosenblatt, 2013; Edin, DeLuca, \& Owens, 2012; Shroder, 2003). 
Based on the disappointing outcomes from group-based analysis, another group of scholars questioned the effectiveness of housing mobility programs and revealed the limitations of housing mobility programs. Since the number of neighborhoods with good public services and job opportunities has been decreasing, housing mobility programs lack enough good areas to accommodate all low-income families (Booza, Cutsinger, \& Galster, 2006). It is inevitable that many poor people would be left behind in the high-poverty neighborhoods. Moreover, although concentrated poverty had been dramatically declined in the 1990s (Jargowsky, 2003), Galster's model (2005a) showed that this new distribution of poor population may reduce the overall well-being of a metropolitan area because the poor comers may push the threshold of the poverty rate in receiving localities which started to cause negative external effects on their neighboring localities. Based on this finding, Galster (2005b) reminded urban scholars to consider the impact of housing mobility programs on the well-being of other members of society besides the poor.

This research argues that policy supporters may commit reductionist fallacy ${ }^{13}$ while policy opponents may commit ecological fallacy ${ }^{14}$. Although the assignment to the three groups was random, participants still could decide whether or not to use their housing vouchers and whether or not to stay in receiving neighborhoods once their leases expired. Therefore, the positive impacts on the movers with long duration of living in low-poverty neighborhoods may not solely result from neighborhood effects but also from their

\footnotetext{
${ }^{13}$ Reductionist fallacy is defined as "an error in reasoning that occurs when incorrect conclusions about group-level processes are based on individual-level data" (Schutt, 2012: 174).

${ }^{14}$ Ecological fallacy is defined as "an error in reasoning in which incorrect conclusions about individual-level processes are drawn from group-level data" (Schutt, 2012: 174).
} 
similar individual attributes ${ }^{15}$. Thus, it is not appropriate for housing mobility programs supporters to use the individual-level (mover-based) finding to assume that housing mobility programs would work on any kinds of low-income families as long as the federal government sends them to low-poverty neighborhoods and helps them stay there for a longer period of time. On the other hand, it is also inappropriate for housing mobility programs opponents to use the disappointing group-based findings to claim that housing mobility programs had little effect on improving economic outcomes of all types of movers. What can be concluded so far is that housing mobility programs improved the employment outcomes of the low-income families who were willing to move, successfully moved to, and stayed in low-poverty neighborhoods for longer time. However, it is still unclear if this positive impact will remain in the long run.

The impacts of housing mobility programs on receiving neighborhoods may also affect employment outcomes. Research on the impacts of subsidized housing on receiving localities (for a summary, see Galster, Tatian, Santiago, Pettit, \& Smith, 2003: 74-86) implied that neighborhoods that initially met the criteria of resources, opportunities, and wealthy neighbors may change after the poor moved in. Once receiving neighborhoods fail to meet those criteria, they may not bring positive influence on low-income movers.

Unfortunately, the impacts of housing mobility programs on receiving localities are still indecisive for two reasons. First, most research did not have convincing argument about the direction of the causation between assisted housing and the conditions of receiving localities (Galster et al., 2003: 83). For example, it is unclear whether the low

\footnotetext{
${ }^{15}$ Shroder (2003) found that some household characteristics of MTO movers are significantly related to successful lease-up.
} 
property values or high crime rates in receiving localities was because assisted housing caused the decline or because assisted housing tended to be located in the declining neighborhoods with low property value and quality of life (Galster et al., 2003: 83-84). This spatial pattern of assisted housing is possible because affluent jurisdictions may adopt zoning regulations to limit rental housing, developers may build affordable housing on cheaper land which is more likely to be in weak housing markets, and landowners may be more willing to agree on the construction of assisted housing if their land cannot be used for higher-value activities (Galster et al., 2003: 84; Turner, Popkin, \& Cunningham, 2000). This research could avoid this selection of bias because only assisted housing located in low-poverty localities is considered as housing mobility programs (see section 3.2.1 in this chapter). Assisted housing in weak markets like high-poverty neighborhoods is not considered as housing mobility programs in this research.

Second, the selection of impact range may affect research findings. Different research used different range to measure the impact of housing mobility programs on receiving localities, such as census tracts or circular areas with a different radius. Most research did not provide a theoretical basis to justify their selection or explain why the impact will happen in the selected range. Since different findings may be related to their selection of impact range, this research can only conclude that housing mobility programs may change the conditions of receiving localities but whether the change is positive or negative remained uncertain.

\section{Aim of the Research}

This research aims to analyze the impact of housing mobility programs on the 
migration of different economic classes in both high-poverty sending municipalities and low-poverty receiving municipalities. Since housing mobility programs highly depend on mixed-income environment, the analysis on housing mobility programs' impacts on further migration can reveal whether or not the created mixed-income environment will last in a longer term, thus helping explain the effectiveness of housing mobility programs. A dynamic economic model of urban migration was created to analyze the migration of different economic classes after housing mobility programs were adopted. Statistical models focused on the migration of wealthier residents in low-poverty receiving municipalities to test if data support the economic model.

This research is based on the Tiebout model because housing mobility programs did not change the nature of political fragmentation by adopting supporting measures in receiving localities and because most housing mobility programs' mechanisms require input of adequate public goods to operate. Housing mobility programs need public goods such as public transit, public spaces for social interaction, and educational and health facilities to activate the mechanisms that were expected to improve individual economic outcomes. However, without support from the federal government, the cost of extra public goods due to the increased poor population was mostly shared by non-poor population in receiving municipalities because the tax from these new poor comers may be minimal. This changed bundle of taxes and public good levels may influence the residential decisions of the non-poor persons in receiving municipalities, especially the middle class with economic mobility to move. This argument of voting mechanism provides a clear direction of causation to explain the decline of receiving localities after housing mobility programs were adopted. By analyzing how housing mobility programs 
affect the bundle of taxes and public goods in both sending and receiving municipalities and how these impacts influence people voting with their feet, this research includes the impact of housing mobility programs on receiving municipalities to predict the long-term impact of housing mobility programs on individual outcomes.

Based on the Tiebout model, "municipality", the smallest geographical unit with the power to decide its own tax rate and public goods, would be a reasonable impact range of housing mobility programs on receiving localities. Therefore, municipality, defined as a type of governmental unit incorporated under state law and having legally prescribed powers and functions ${ }^{16}$, is the analysis unit in this research.

The Tiebout model cannot be directly used for analysis due to its three unrealistic assumptions - the implicit assumption of head taxation, full mobility, and no externalities, so this research needs to remove these assumptions and creates a new model to analyze the migration of different economic classes. The economic model in this research uses widely-adopted property taxation for analysis. To reflect externalities, people are allowed to make residential decisions every time other people move in or out. As to the assumption of full mobility, this research assumes that housing mobility programs improve the residential mobility of the poor. This assumption helps predict possible outcomes if the federal government promotes greater degree of mobility.

Also, this new economic model needs to be dynamic because each migration may become a driver of further migration. This research analyzes moving decisions of the residents in both receiving and sending municipalities in order to show the dynamic process of urban migration and the spatial distribution of different economic classes at

\footnotetext{
${ }^{16}$ According to this definition, municipalities in this research simply mean a type of governmental unit. It is possible that they are located in either central cities or suburbs.
} 
the end of the dynamic. This dynamic can reveal the long-term impacts of housing mobility programs on urban migration, which may affect the individual outcomes of program participants.

This research does not intend to isolate neighborhood effects from selection bias. Previous research indicated that individual outcomes may be related to individual variables. This research does not intend to generalize the impact of housing mobility programs on all types of low-income families. Instead, the research only focuses on the movers who experienced positive employment outcomes found by Clampet-Lundquist and Massey (2008). Although this research does not directly measure individual outcomes, the findings of the research can indirectly predict possible long-term effects of housing mobility programs on participants by showing whether receiving municipalities will remain mixed-income or suffer from poverty concentration in the long term. 


\section{CHAPTER III}

\section{DYNAMIC ECONOMIC MODEL OF URBAN MIGRATION}

This chapter creates a dynamic economic model to explain the urban migration after housing mobility programs were adopted. The model provides a theoretical perspective different from the Tiebout model and other economic models described in Chapter II. Most economic models of mobility, like the Tiebout model, were based on utility maximization, which means people make residential choices to maximize their well-being (Ellen, 2000: 105). Tiebout's framework involves both moving out of the jurisdictions with lower utility and moving to the jurisdictions with higher utility. Since this research focuses on people's move-out decisions, the dynamic economic model borrowed the concept of "dissatisfaction" from literature of sociology because this sociological concept is often used to explain out-migration. Unlike an economic theoretical framework, the sociological concept of "dissatisfaction" indicates that people consider moving only when they are unsatisfied with their current location (Ellen, 2000: 105). In other words, satisfied households have no motivation to move to another location even if they know they would be better off in other jurisdictions (Ellen, 2000: 105). Satisfied households do not spend time, energy, and cost on gathering information of other municipalities, let alone plan on moving based on the information they don't bother obtaining. Therefore, instead of comparing the utility of different municipalities, this dynamic economic model compares people's economic surplus in the same municipality 
before and after some people move in or out to analyze whether or not people have motivation to move. This dynamic model is less affected by the incomplete information problem because it only requires households to assess their situation based on the information they already have. This chapter includes the assumptions and theory construction of the dynamic model.

\section{Assumptions}

The economic model of urban migration includes the following assumptions. First, housing mobility programs increase the likelihood that the poor can move to wealthier municipalities. The strategy of solving poverty via geographic opportunity has been popular since the 1990s (Imbroscio, 2004b: 447). Many urban scholars still support this strategy and promote greater mobility (see Edin et al., 2012; Turner, Popkin, \& Rawlings, 2009). Moreover, the federal government historically and currently funds assisted housing to improve the residential mobility of low-income families. Therefore, this research assumes housing mobility programs increase the possibility that poor families with the intention to move to low-poverty municipalities may do so.

Second, this research assumes that the role of local governments is neutral, which means local governments follow preferences of their current residents. Although the competition model indicated that local governments may only adopt policies to attract capital or high-income persons, Glaeser and Shleifer's model (2005) showed that it is possible for political leaders of a municipality with a high percentage of poor population to adopt policies that benefit the poor in order to win reelection.

Third, this research assumes there are two economic classes - the poor and the 
non-poor. The gap between different economic classes only decides the degree of the effect of property taxation. As long as the economic gap exists, property taxation has an effect after housing mobility programs break economic segregation. Therefore, including only two economic classes is sufficient to analyze the effect of housing mobility programs on local taxes and public goods under property taxation (Including more economic classes in the dynamic model only makes the model more complicated but does not change the results deduced from the model).

Fourth, this research assumes that persons with higher income (the non-poor) demand more public goods than persons with lower income (the poor) do. Based on the positive relationship between housing prices and the level of public goods ${ }^{17}$, this research assumes that persons who can afford to purchase houses tend to require more public goods to maximize their property values than the poor do.

Fifth, this research assumes the quantity of public goods is fixed in a short term because local governments do not demolish the built public goods for a decreasing population and are unable to increase the quantity of public goods for an increasing population in the short term because the construction of public goods takes time. Public goods can be built for the increased population only in a long term.

Sixth, this research assumes that the tax paid by the people who do not move is fixed in a short term. Tax is the product of tax base and tax rate. This assumption is based on that fact that the change of population in a municipality does not change people's tax base in the short run and local governments are also unlikely to quickly adjust tax rate for the changed population in the short term. For example, it would be impractical for a local

\footnotetext{
${ }^{17}$ The positive impact of public goods on housing price is called capitalization effect of public goods (Brueckner, 2011: 179).
} 
government to increase a tax rate from $6 \%$ to $6.0001 \%$ for a shrinking population or to decrease a tax rate from $6 \%$ to $5.9999 \%$ for a growing population. Therefore, this research assumes that the poor who stay in sending municipalities and the non-poor who stay in receiving municipalities pay the same amount of tax before and after housing mobility programs were adopted.

Seventh, this research assumes receiving municipalities may have excess capacity of public goods. Public good competition between localities tend to make local governments over-provide local public goods (Bayindir-Upmann, 1998). Thus, the research assumes municipalities, especially wealthier municipalities, tend to have excess capacity of public goods.

Eighth, this research assumes that there is no transaction cost for information about the budget of a local government. People are assumed to have full knowledge of the change of their economic surplus before and after any migration. Since households are required to know only the information about the municipality where they live, the research assumes that people can obtain that information without transaction costs.

\section{Theory Construction}

Since housing mobility programs were designed to solve poverty by breaking the segregation of different economic classes, the dynamic model of urban migration starts with two homogeneous municipalities — one poor municipality and one rich municipality. The model then analyzes the impact of the poor's out-migration on the poor sending municipality and the impact of the poor's in-migration on the rich receiving municipality. The last section explains the dynamic migration based on the above two impacts and 
reveals three possible long-term consequences after the whole dynamic. A list of algebras used in the dynamic economic model can be found in appendix 1 .

\subsection{Two homogeneous municipalities}

Figure 2 represents two homogeneous municipalities (economic segregation) before housing mobility programs were adopted. The horizontal and vertical axes have the same meaning as that in the Tiebout model: shared cost (SC) and quantity of public goods (Z). $D_{p}$ is the demand curve of the poor while $D_{r}$ is the demand curve of the non-poor. In a homogeneous municipality, property taxation is similar to head taxation because every resident in the municipality is equally wealth or equally poor. Thus, the shared cost in the poor sending municipality, denoted by $C_{p 0}$, is calculated by dividing the price of a unit of public good $P$ by the population of the sending municipality $N_{p 0}$ (see equation 2) while the shared cost in the rich receiving municipality, denoted by $C_{r 0}$, is calculated by dividing the price of a unit of public good $P$ by the population of the receiving municipality $N_{r 0}$ (see equation 3 ). The optimal quantity of public goods in the poor sending municipality is denoted by $Z_{p 0}$ while that in the rich receiving municipality is denoted by $Z_{r 0}$ (see figure 2).

$$
\begin{aligned}
& C_{p 0}=P / N_{p 0} \\
& C_{r 0}=P / N_{r 0}
\end{aligned}
$$




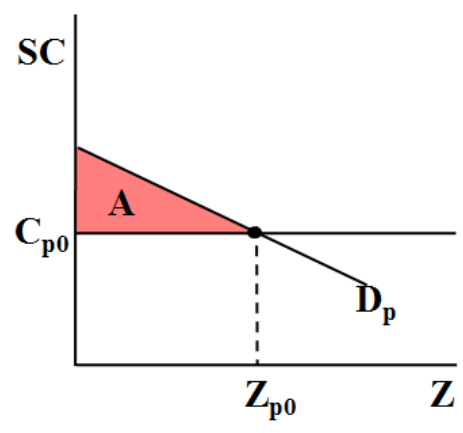

Sending municipality (Poor municipality)

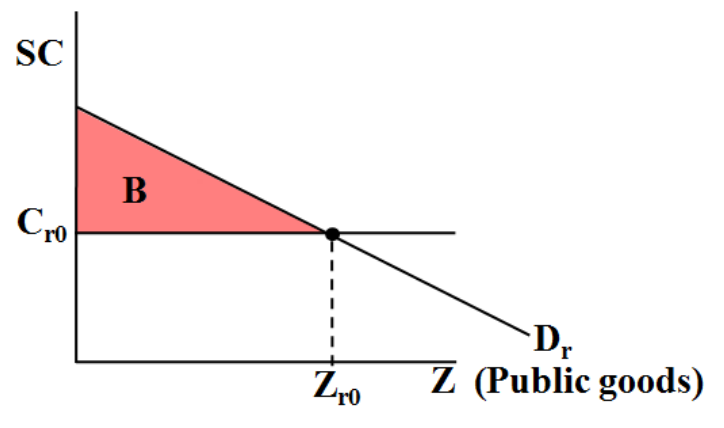

Receiving municipality (Rich municipality)

Figure 2 Model of two homogeneous municipalities

Economic surplus is defined as the gain when a consumer purchases a product with a price lower than his/her highest willingness-to-pay. In economics, a demand curve is people's highest willingness-to-pay. Since people in the poor sending municipality only pay $C_{p 0}$ for each unit of public good, the triangle $A$ in figure 2 is the poor's economic surplus before housing mobility programs were adopted. Similarly, people in the rich receiving municipality only pay $C_{r 0}$ rather than $D_{r}$ so the triangle $B$ in figure 2 is the non-poor's economic surplus before housing mobility programs were adopted.

\subsection{Impact of the poor's out-migration on the poor sending municipality}

Figure 3 is used to analyze the change of people's economic surplus in the sending municipality after housing mobility programs help some low-income persons move out of the poor sending municipality. The number of these movers is denoted by $N_{p 1}$. Decreased population (from $N_{p 0}$ to $N_{p 0}-N_{p 1}$ ) means fewer people share the unit price of public goods $P$. Therefore, the poor's shared cost after housing mobility programs, $C_{p 1}$ (see 
equation 4), is larger ${ }^{18}$ than the poor's shared cost before housing mobility programs, $C_{p 0}$ (see equation 2), so the line $C_{p 1}$ in figure 3 is higher than $C_{p 0}$.

$$
C_{p 1}=P /\left(N_{p 0^{-}} N_{p 1}\right)
$$
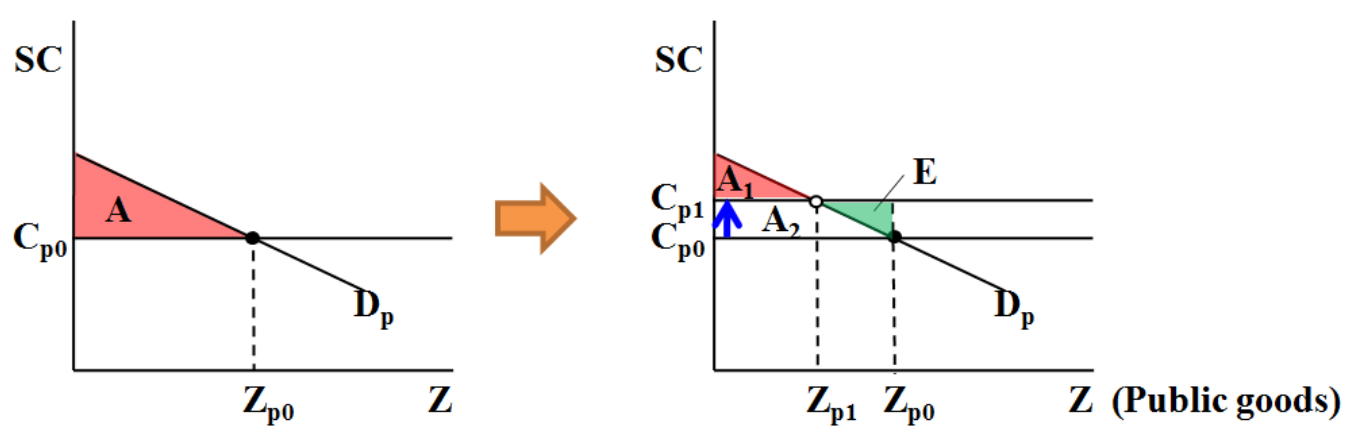

Figure 3 The economic surplus of the poor in the sending municipality

With the new shared cost $\left(C_{p 1}\right)$, the new optimal quantity of public goods should be $Z_{p 1}$ and the poor's economic surplus should decrease to $A_{1}$ (see figure 3). However, considering that local governments do not demolish built public goods for decreasing population, the quantity of public goods is still fixed at $Z_{p 0}$. Therefore, besides the economic surplus $A_{1}$, people have economic loss $E$ (see figure 3), which is defined as the amount people pay that is higher than their highest willingness-to-pay (the demand curve). Thus, the poor's economic surplus is $A_{1^{-}} E$ after housing mobility programs were adopted.

The assumption of fixed taxes raises a question on how the poor pay the extra loss $E$ (see figure 3) if they still pay the same amount of tax and have the same quantity of public goods $Z_{p 0}$. Since the poor still pay the same amount of tax while their shared cost increases (from $C_{p 0}$ to $C_{p 1}$ ), it means the tax can cover fewer public goods $\left(Z_{p 1}\right)$. When

\footnotetext{
${ }^{18}$ Equation 2 and 4 show that $C_{p 0}$ and $C_{p 1}$ have the same numerator, $P$, but $C_{p 1}$ has a smaller denominator than $C_{p 0}$ does and thus $C_{p 1}$ is larger than $C_{p 0}$.
} 
the tax is distributed to more than this new optimal quantity of public goods, there may not be enough for maintenance fees, management fee and other fees to assure the same quality of public goods. Thus, $E$ is paid in a form of decreasing quality of public goods.

Decreasing economic surplus (from $A$ to $A_{1}-E$ in figure 3) increases people's motivation to move out to the rich receiving municipality. The more the number of people who move out, the higher shared cost will be. As the shared cost gradually increases, $A_{1}$ (see figure 3) gradually shrinks and $E$ (see figure 3) gradually swells, meaning that the quality of public goods gradually decreases. This decreased quality of public goods further strengthens people's motivation to exit. In other words, the more people move out, the motivation to move out increases.

\subsection{Impact of the poor's in-migration on the rich receiving municipality}

After the poor's in-migration breaks the status of homogeneous population in the rich receiving municipality, property taxation starts to take effect. Some variables are needed to calculate the new shared costs of different economic classes. As mentioned in section 2.2, $N_{p 1}$ is the number of low-income persons moving from the poor sending municipality to the rich receiving municipality. These low-income persons' new shared cost is denoted by $C_{p 2}$ while the non-poor's shared cost is denoted by $C_{r 1}$. The ratio of $C_{p 2}$ and $C_{r 1}$ is $X: 1$, and $X$ is larger than 0 but smaller than 1 because the poor pay less shared cost than the non-poor do due to property taxation (see equation 5). Equation 5 shows, based on this ratio, the shared cost paid by a poor person $\left(C_{p 2}\right)$ equals $X$ times the shared cost paid by a non-poor person $\left(C_{r 1}\right)$, meaning the shared cost from one poor person is 
equivalent to the shared cost from $X$ non-poor person ${ }^{19}$. Thus, the shared cost from $N_{p 1}$ new low-income comers is equivalent to the shared cost from $N_{p 1^{*}} X$ non-poor persons. This relationship can convert the number of poor persons into the non-poor-population unit so that the researcher can calculate the shared cost of a non-poor person $\left(C_{r 1}\right)$ (see equation 6). Based on equation 5 , the poor's shared $\operatorname{cost}\left(C_{p 2}\right)$ is calculated by equation 7 . (The example ${ }^{20}$ in footnote may make these equations easier to understand.)

$$
\begin{aligned}
& C_{p 2}: C_{r 1}=X: 1, \text { while } 0<X<1 ; \text { thus, } C_{p 2}=X^{*} C_{r 1} \\
& C_{r 1}=P /\left(N_{r 0}+N_{p 1} * X\right) \\
& C_{p 2}=X^{*} C_{r 1}=X^{*}\left[P /\left(N_{r 0}+N_{p 1} * X\right)\right]
\end{aligned}
$$

Figure 4 shows the change of the non-poor's economic surplus in the receiving municipality after some housing mobility program participants move in. Equation 3 and 6 show that $C_{r 0}$ and $C_{r 1}$ have the same numerator, $P$, but $C_{r 1}$ has a larger denominator than $C_{r 0}$ does, which means $C_{r 0}>C_{r 1}$. This relationship implies that although property taxation allows the poor to pay relatively less for each unit of public goods than the non-poor do, the non-poor's shared cost after some poor persons move in still decreases from $C_{r 0}$ to $C_{r 1}$ because more people (the denominator) share the same price of a unit of public good (the numerator). Therefore, as shown in figure 4 , the line $C_{r 1}$ is lower than $C_{r 0}$. And since the poor pay less shared cost than the non-poor do, the line $C_{p 2}$ is lower than $C_{r 1}$ in figure 4 .

\footnotetext{
${ }^{19}$ For example, if the poor only have to pay half of the non-poor's shared cost, meaning $X=0.5$, then the shared cost from a poor person is equivalent to the shared cost from 0.5 non-poor person.

20 This example uses numbers to show how to calculate $C_{r 1}$ and $C_{p 2}$. Assuming $P$ is 10,000 dollars and 10 non-poor persons live in the rich municipality, each person has to pay $10,000 / 10=1,000$ for each unit of public goods before housing mobility programs were adopted. Assuming 5 poor people move in and the ratio of the poor's shared cost and the non-poor's shared cost is $X: 1=0.8: 1$, the shared cost of a non-poor person will be $10,000 /\left(10+5^{*} 0.8\right)=10000 / 14 \fallingdotseq 714.28$ while the shared cost of a poor person will be $0.8^{*}\left[10,000 /\left(10+5^{*} 0.8\right)\right] \fallingdotseq \mathbf{5 7 1 . 4 2}$. Thus, each unit of public goods is shared by the ten non-poor persons paying $714.28 * 10 \fallingdotseq 7143$ dollars and the five poor person paying $571.42 * 5 \fallingdotseq 2857$. (Note: $10000=7143+2857)$
} 

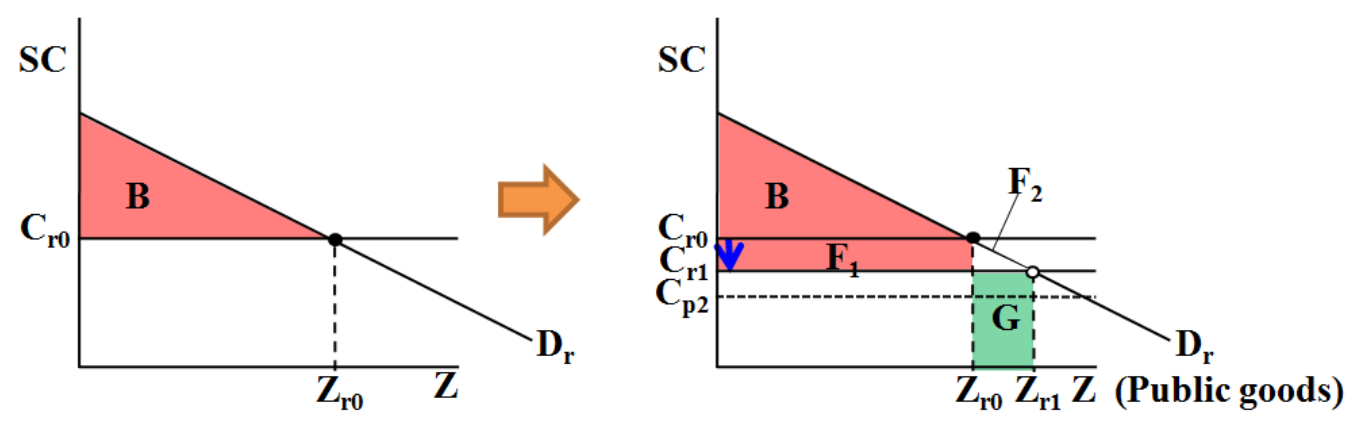

Figure 4 The economic surplus of the non-poor in the receiving municipality

With the non-poor's new shared cost $\left(C_{r 1}\right)$, the new optimal quantity of public goods for the non-poor should be $Z_{r 1}$ and their economic surplus should increase to $B+F_{1}+F_{2}$ (see figure 4) if the quantity of public goods can easily be adjusted to the change of people's demand. However, construction of public goods takes time, so the quantity of public goods may still be fixed at $Z_{r 0}$ and thus the non-poor do not have the economic surplus $F_{2}$ (see figure 4). Moreover, local government may not be able to quickly adjust tax rate for the changed population in the short term, so the non-poor still pay the same amount of tax even though their shared cost decreases. With the decreased shared cost, the same amount of tax paid by the non-poor should be able to purchase more public goods. However, since the quantity of public goods is fixed at $Z_{r 0}, G$ (see figure 4) is identified as economic loss; this represents the public goods the non-poor pay for but cannot obtain in the short term. After considering the assumptions of fixed quantity of public goods and fixed tax, the non-poor's economic surplus is $\left(B+F_{1}+F_{2}\right)-F_{2}-G$, which equals $B+F_{1-} G$ (see figure 4 ), after housing mobility programs were adopted.

The impact of the poor's in-migration on the congestion cost of public goods also needs to be considered. Theoretically, pure public goods tend to have unlimited excess capacity because of their features of non-rivalry and non-excludability. However, not all 
goods provided by governments are pure public goods. Figure 5 shows that the average cost of public goods gradually decreases as an increasing population shares the cost, and then gradually increases as the population starts to cause congestion cost. In other words, the excess capacity will disappear when the number of users increases to a certain level (see $N^{*}$ in figure 5). Since the effects of property taxation and externalities may make local governments engage in public good competition and thus over-provide public goods (see Chapter II), congestion cost may not occur right after the poor move to the rich receiving municipality. However, if congestion cost occurs, the economic surplus of the non-poor after housing mobility programs would be $B+F_{1}$ - $G$ - congestion cost (see figure 4). The time when congestion cost occurs depends on the amount of excess capacity of public goods in the receiving municipality and the number of poor persons moving in to the receiving municipality during a given time.

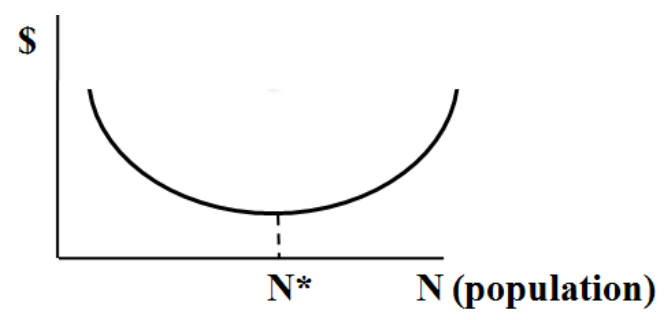

Figure 5 Optimal jurisdiction size $\mathrm{e}^{21}$

Source: Brueckner (2011: 175)

The non-poor's motivation of moving out is analyzed by comparing their economic surplus before and after housing mobility programs were adopted. If their economic surplus is the same or increases, the non-poor tend to stay even though the poor move in.

${ }^{21}$ Tiebout thinks each local government will eventually reach this optimal jurisdiction population size where shared cost is the lowest and no congestion cost occurs. 
If their economic surplus decreases, the non-poor have motivation to move out. After subtracting the non-poor's economic surplus before housing mobility programs from the economic surplus after housing mobility programs, the change of the non-poor's economic surplus equals $F_{1^{-}}$G- congestion cost (see figure 4). Although this equation cannot reveal whether the non-poor will move out or not, it implies that a dramatic increase of poor population in a short time may cause high congestion cost, thus increasing the likelihood of out-migration of the non-poor.

\subsection{Dynamic economic model based on both impacts}

If the federal government adopts no other supporting measures except dispersal of the poor, the dynamic model predicts out-migration of the non-poor based on the impact of the poor's out-migration on the sending municipality and the impact of the poor's in-migration on the receiving municipality. Both impacts showed how housing mobility programs affect the bundle of public goods and shared cost and therefore may cause further migration. After housing mobility programs help some low-income persons move out of the poor sending municipality, the remaining poor people's motivation to move out increases because the tax revenue collected from the decreased population may not be able to cover the expenses to maintain the same quality of public goods in the sending municipality (see section 2.2). With active housing mobility programs, these low-income persons are able to move to the rich municipality. Unfortunately, the more poor people move in to the receiving municipality in a short term, the more likely that the non-poor's economic surplus decreases because of the increase of congestion cost, thus enhancing the possibility of the non-poor's out-migration (see section 2.3). The exodus of the 
non-poor implies that housing mobility programs' expected positive impact of wealthier residents on low-income persons is questionable.

Based on this dynamic economic model of urban migration, the impact of housing mobility programs on the residential decisions of different economic classes may cause three long-term negative consequences. First, the problem of urban sprawl may be aggravated. When the non-poor decide to move out of the receiving municipality, they prefer municipalities with fewer poor people to municipalities where the poor predominate because of the redistributive nature of property taxation. Most poor people live in central cities because the accessibility to public transportation in central cities is better than that in suburbs (Glaeser, Kahn, \& Rappaport, 2008). Therefore, the non-poor tend to move to the suburbs, thus worsening the problem of urban sprawl.

Second, instead of solving poverty or poverty concentration, the number of poor municipalities increases after the receiving municipality turns into a new poor municipality due to the out-migration of the non-poor. In other words, without supporting measures, housing mobility programs can only temporarily break the segregation between different economic classes because housing mobility programs do not alter the nature of fiscal decentralization, which makes the non-poor want to move out of the receiving municipality to avoid subsidizing the poor. Thus, once the poor's in-migration starts to decrease the non-poor's economic surplus and causes the exodus of the non-poor, the problem of poverty concentration will be produced in the receiving municipality. The whole process is expensive $e^{22}$ and does not solve the problem. Policies that disperse the poor to solve poverty concentration may actually create more municipalities suffering

\footnotetext{
${ }^{22}$ The cost included not only monetary cost like administration cost to implement the policies, the cost for
} the poor to move, and the cost for the non-poor to move but also nonmonetary costs like replacement cost. 
from poverty concentration after the non-poor out-migrate.

Third, the poor's economic surplus in both the original poor municipality and the new poor municipality (the receiving municipality after the out-migration of the non-poor) becomes smaller after the whole dynamic of migration. Since the total population of the poor $\left(N_{p 0}\right)$ are scattered to both the original poor municipality and the new poor municipality, both municipalities have fewer persons to share the cost for each unit of public goods; thus, the poor's shared cost in both municipalities increases. Assume that when the number of low-income in-migrants increases from $N_{p 1}$ to $N_{p 2}$, the non-poor in the receiving municipality start to out-migrate. In the original poor municipality (the sending municipality), the further decreased population from $N_{p 0}-N_{p 1}$ to $N_{p 0}-N_{p 2}$ makes the remaining poor pay higher shared cost from $C_{p 1}$ to $C_{p 3}$ (see equation 8) and have smaller economic surplus from $A_{1^{-}} E$ (see figure 3 ) to $A_{11^{-}} E-J$ (see figure 6). In the new poor municipality, the poor no longer have the non-poor's subsidies on public goods after the out-migration of the non-poor. Therefore, the shared cost of the poor in the new poor municipality increases from $C_{p 2}$ to $C_{p 4}$ (see equation 9), and the economic surplus decrease to H-I (see figure 6). Comparing with the poor's condition before housing mobility programs, the poor in both the original poor municipality and the new poor municipality pay higher shared cost for lower quality of public goods after the whole dynamic of migration.

$$
\begin{aligned}
& C_{p 3}=P /\left(N_{p 0^{-}} N_{p 2}\right) \\
& C_{p 4}=P /\left(N_{p 2}\right)
\end{aligned}
$$




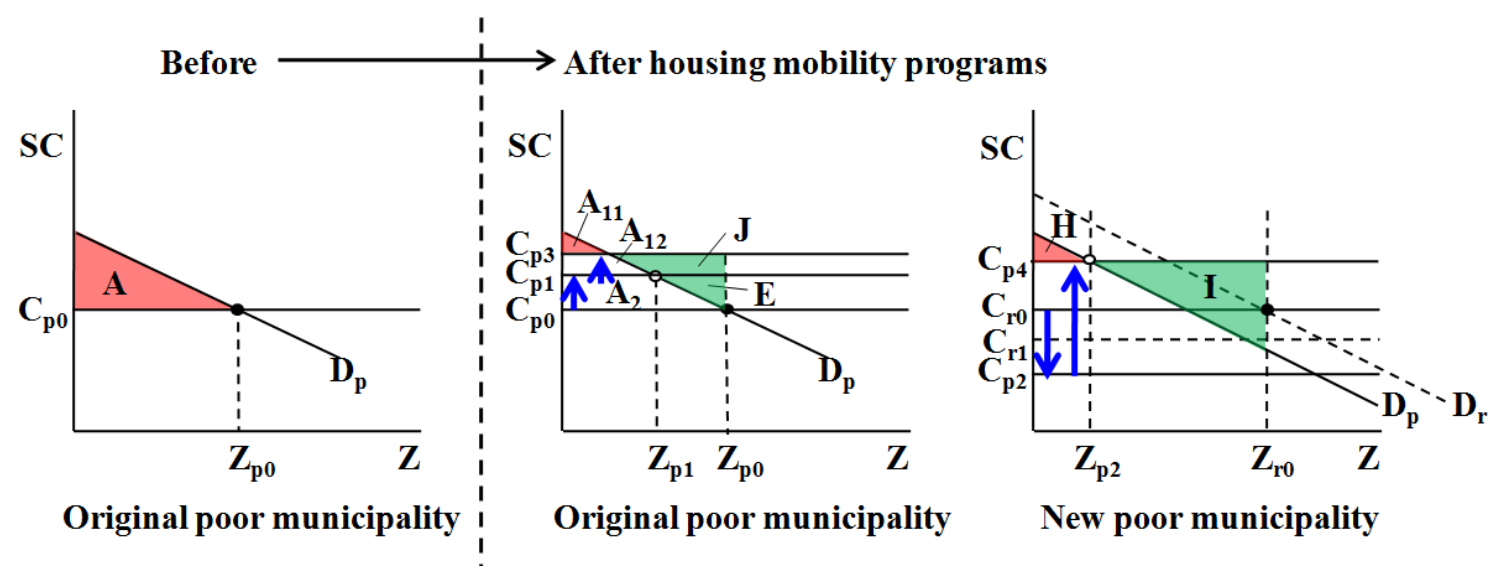

Figure 6 The economic surplus of the poor after the out-migration of the non-poor

The implication of this dynamic model is that housing mobility programs only relieved the symptom of the problem (economic segregation/ poverty concentration) but failed to tackle the root cause of the problem (political fragmentation/ fiscal decentralization) so the problem may become more serious rather than be solved. Housing mobility programs broke the economic segregation by improving the poor's residential mobility. However, the programs did not change the nature of fiscal decentralization so the individual behavior (the out-migration of the non-poor) under a decentralized fiscal system may reproduce the problem of poverty concentration and create other urban problems like urban sprawl. Under a decentralized fiscal system, the cost of local public goods is shared by everyone in the same municipality. And property taxation means a non-poor person pays relatively more shared cost for each unit of public goods than a poor person does, which implies that housing mobility programs rely on the non-poor in the receiving localities to subsidize the poor on public goods through property taxation and hope the accessibility to adequate public goods and resources can help improve the poor's economic self-sufficiency. This dynamic economic model 
suggested that, under a decentralized fiscal system, the in-migration of the poor may eventually cause the exodus of wealthier residents ${ }^{23}$. After the out-migration of wealthier residents, the poor who successfully moved into the receiving municipality may still live in a municipality with poverty concentration (the new poverty-concentrated municipality).

${ }^{23}$ There are other programs that may also affect the spatial distribution of different economic classes, like HOPE VI programs, which dispersed the poor and aimed to revitalize sending localities to attract wealthy people. However, this research focused only on analyzing the impact of the housing mobility programs which relocated low-income families to low-poverty receiving localities. 


\section{CHAPTER IV}

\section{HYPOTHESES, METHOD, AND DATA}

Statistical models are designed to analyze the impact of housing mobility programs on migration of the wealthier residents in receiving municipalities because the migration of the non-poor is closely related to both the effectiveness of housing mobility programs and the three possible long-term consequences deduced from the dynamic economic model. Two hypotheses are tested to analyze this impact. This chapter describes the method and data for each hypothesis respectively.

\section{Hypothesis I}

The first hypothesis is tested to judge whether residents of municipalities with a higher concentration of the poor also have higher welfare expenditure in addition to subsidizing the poor through property taxation. The dynamic model does not distinguish between different types of public goods - all people in the same municipality share the cost for the same public goods provided in the municipality. However, there are some public goods that are used exclusively by the poor, like health and welfare. Therefore, this research needs to test whether the non-poor in high-poverty municipalities pay more for public welfare and health than the non-poor in low-poverty municipalities do. If the statement is supported by data, the extra expenses on health and welfare may increase the

likelihood that the non-poor's economic surplus after housing mobility programs is 
smaller than that before housing mobility programs, which means the dynamic process predicted by the economic model may happen faster.

\section{Null hypothesis I: The non-poor in high-poverty municipalities pay the same for public welfare and health as the non-poor in low-poverty municipalities do.}

Although it may appear to be common sense that local governments with more poor people in their jurisdictions spend more on public welfare and health and thus the non-poor in the same jurisdiction are taxed more, this common sense may not be true for two reasons. First, local governments may impose restrictions on welfare recipients to avoid attracting the in-migrants who increase the welfare expenditure yet provide few taxes (Brueckner, 2000; Ferreira, et al., 2005: 298; Imbroscio, 2004a: 584-585; Kantor,

1995: 4). Second, local governments receive financial aid from state governments and grants from the federal government. After subtracting these intergovernmental funds, the expenditure on public welfare and health paid by each non-poor person may not be so different between high-poverty municipalities and low-poverty municipalities. Since it is unclear whether or not the non-poor have to pay extra expenses on health and welfare besides subsidizing the poor through property taxation, hypothesis I must be tested.

\subsection{ANOVA}

ANOVA is used to test the null hypothesis I. This statistical model is used to determine whether samples from two or more groups come from populations with equal means (Hair, Black, Babin, \& Anderson, 2010: 440). Therefore, ANOVA is an appropriate statistical model to test if there is any significant difference in the non-poor's 
payment for welfare and health expenditure between high-poverty municipalities and low-poverty municipalities. The assumptions of ANOVA, the dependent variable, and the independent variable (the groups) are described as follows.

\section{Assumptions of ANOVA}

ANOVA has three assumptions. First, the observations should be independent of one another. The data meet this assumption because the budget of each municipality is independent. Therefore, no test for this assumption is needed. Second, the population variances of each group should be the same. Levene's test is used to examine if the data meet the assumption of equal variance. Third, distribution within each group is normally distributed. The Shapiro-Wilk test is used to examine if the data meet the assumption of normality. Since the model includes two groups, the normality of each group will be tested respectively.

\section{Dependent variable}

The dependent variable (DV) is the local expenditure on health and welfare paid by every 1000 non-poor citizens (see equation 10). The dependent variable is calculated by subtracting the federal government's and state government's grants in aid on health and welfare from local governments' expenditure on health and welfare and then dividing it by the population of the non-poor. According to the Census Bureau, the poor were defined as "the families and persons whose total family income or unrelated individual income was less than the poverty threshold specified for the applicable family size, age of householder, and number of related children under 18 present" (Slater \& Hall, 1993: 
D-17). The non-poor were defined as the families and persons whose total family income or unrelated individual income was more than the poverty threshold. The poverty thresholds can be found in appendix 2 (see table 15).

$\mathrm{DV}=\frac{\mathrm{LG} \text { 's exp on } \mathrm{H} \& \mathrm{~W}-\text { Aid on } \mathrm{H} \& \mathrm{~W} \text { from SG or FG (in thousands) }}{\text { the non-poor population (in thousands) }}$

Note: LG's exp on H \& W: Local governments' expenditure on health and welfare

Aid on H \& W from SG or FG: Aid on health and welfare from state governments and the federal government

Due to the limitation of data availability, this research uses financial data from 1991 and only includes municipalities with a 1986 population larger than 300,000 to test hypothesis I. The calculate the dependent variable requires local government level data on the federal government's grant on different categories, state governments' financial aid on different categories, and local governments' expenditure on different categories. However, the Census Bureau stopped producing data about state governments' financial aid on different categories to each local government in 1992. Thus, the data in 1991 are the latest data available. Also, this data are only available for municipalities with a 1986 population of 300,000 or more (City government finances: 1990-91, 1993: x). The 1986 population was only used by the Census Bureau to decide which municipalities' data would be collected. Data on expenditure remains the data in the fiscal year 1991.

\section{Independent variable}

Figure 7 is used to explain the criteria to define high-poverty municipalities and low-poverty municipalities. These two types of municipalities are relative concepts. Therefore, as long as the two groups of municipalities have distinctively different poverty 
rates, the data of the two groups can be used to test hypothesis I. Considering that the poverty rate of America in 1991 was $14.2 \%{ }^{24}$ and only three municipalities had a poverty rate smaller than $10 \%$, low-poverty municipalities are defined as municipalities with a poverty rate no higher than $15 \%$. Although municipalities with a poverty rate higher than $20 \%$ in 1990 s were considered as high-poverty municipalities ${ }^{25}$, the research intends to widen the difference of poverty rates between the two groups and therefore defines high-poverty municipalities as municipalities with a poverty rate higher than $25 \%$. Thus, group 1 includes 15 low-poverty municipalities while group 2 includes 9 high-poverty municipalities. The geographic distribution of these 24 municipalities can be found in appendix 3 (see figure 9). Low-poverty municipalities were coded as 0 while high-poverty municipalities were coded as 1 .

\section{Total: $\mathbf{5 2}$ municipalities}
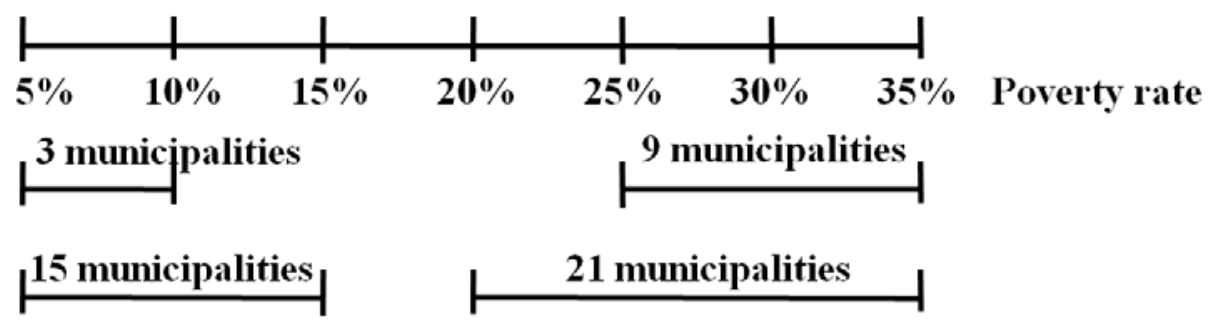

Figure 7 The number of municipalities within different ranges of poverty rates

\subsection{Data collection}

Table 1 shows the sources of data needed for the ANOVA model. The fiscal year for financial data is across 1990 and 1991. Since the Census Bureau did not conduct a

${ }^{24}$ The data are from the Census Bureau website: http://www.census.gov/hhes/www/poverty/data/historical/people.html

${ }^{25}$ Five poor cities were selected in the MTO program, which moved the poor to other wealthier places. The average poverty rate of these five cities in 1990 was about $20 \%$. (Baltimore $(21.9 \%)$, Boston $(18.7 \%)$, Chicago (21.6\%), Los Angeles (18.9\%), New York (19.3\%), and the average (20.08\%)) 
population survey at the municipality level in 1991, this research will use the data on total population and poverty rate in 1990 instead. (These two variables are needed to calculate the non-poor population for equation 10.) 
Table 1 Sources of the data for the ANOVA model

\begin{tabular}{|c|c|c|}
\hline Data & Sources & Note \\
\hline $\begin{array}{l}\text { Federal funds on health and family welfare to } \\
\text { each local government }(\$ 1,000)\end{array}$ & $\begin{array}{l}1993 \text { County and City Extra: Annual } \\
\text { Metro, City and County Data Book }\end{array}$ & $\begin{array}{l}\text { Fiscal year: from October } 1^{\text {st }} \text {, } \\
1990 \text { to September } 30^{\text {th }}, 1991\end{array}$ \\
\hline $\begin{array}{l}\text { State governments' funds on public welfare } \\
\text { to each local government }(\$ 1,000)\end{array}$ & City Government Finances: 1990-1991 & $\begin{array}{l}\text { Fiscal year: from July } 1^{\text {st }}, 1990 \\
\text { to June } 30^{\text {th }}, 1991\end{array}$ \\
\hline $\begin{array}{l}\text { State governments' funds on health and } \\
\text { hospital to each local government }(\$ 1,000)\end{array}$ & City Government Finances: 1990-1991 & $\begin{array}{l}\text { Fiscal year: from July } 1^{\text {st }}, 1990 \\
\text { to June } 30^{\text {th }}, 1991\end{array}$ \\
\hline $\begin{array}{l}\text { Each local government's expenditure on } \\
\text { public welfare }(\$ 1,000)\end{array}$ & City Government Finances: 1990-1991 & $\begin{array}{l}\text { Fiscal year: from July } 1^{\text {st }}, 1990 \\
\text { to June } 30^{\text {th }}, 1991\end{array}$ \\
\hline $\begin{array}{l}\text { Each local government's expenditure on } \\
\text { hospital }(\$ 1,000)\end{array}$ & City Government Finances: 1990-1991 & $\begin{array}{l}\text { Fiscal year: from July } 1^{\text {st }}, 1990 \\
\text { to June } 30^{\text {th }}, 1991\end{array}$ \\
\hline $\begin{array}{l}\text { Each local government's expenditure on } \\
\text { health }(\$ 1,000)\end{array}$ & City Government Finances: 1990-1991 & $\begin{array}{l}\text { Fiscal year: from July } 1^{\text {st }}, 1990 \\
\text { to June } 30^{\text {th }}, 1991\end{array}$ \\
\hline Total population & Census Bureau & 1990 \\
\hline Poverty rate & Census Bureau & 1990 \\
\hline
\end{tabular}




\section{Hypothesis II}

This hypothesis is to test the main finding from the economic model, which shows that housing mobility programs may lead to the out-migration of the non-poor because the federal government did not change fiscal decentralization by compensating receiving municipalities and therefore the in-migration of the poor may affect local taxes and public goods, which stimulate vote-with-feet behavior. This section explains why affordable housing programs in low-poverty municipalities were selected for analysis and describes the time frame of the data, the statistical model, and the sources of data on each variable.

\section{Null hypothesis II: Federal affordable housing programs have no impact on the out-migration of wealthier residents in low-poverty receiving municipalities.}

\subsection{Why select affordable housing programs in low-poverty municipalities}

Since most housing mobility programs increase participants' residential mobility by subsidizing housing expenses, affordable housing programs were selected for analysis, and only the affordable housing programs in low-poverty municipalities (below 15

percent) were considered as housing mobility programs in this research. This choice is based on two criteria. First, programs must constantly exist in order to test the dynamic economic model which is based on the assumption that housing mobility programs improve the residential mobility of low-income families so that they can move to other municipalities. If housing mobility programs were only active for a few years, the poor with move-out motivation later on would not be able to move to receiving municipalities. Since affordable housing programs continuously help the poor move to areas with greater 
opportunity by providing rental assistance (Retsinas \& Belsky, 2008: 44), the programs are appropriate for the analysis. Selecting long-duration programs also helps reveal possible outcomes of promoting greater mobility.

Second, affordable housing programs must be located in low-poverty municipalities. Moving low-income families to other high-poverty municipalities is not considered a successful housing mobility program. Therefore, not all affordable housing programs were considered as housing mobility programs. Unlike hypothesis I, the data for hypothesis II only includes municipalities with a poverty rate lower than 15 percent for analysis. Only the affordable housing programs located in these low-poverty municipalities can help the poor move into low-poverty municipalities and thus were considered as housing mobility programs.

In this research, affordable housing programs include the following programs: public housing programs, Section 8 new construction or substantial rehabilitation programs, Section 236 programs, rental assistance program, rent supplement, and low income housing tax credit (LIHTC) programs. These programs adopted different approaches to provide affordable housing. Some were constructed by governments while the others were constructed by private owners who received benefits like subsidies, lower mortgage interest rates, or lower housing tax from the federal government. The similarity of these programs is that they allow low-income households to pay affordable rent (usually $30 \%$ of the household's adjusted gross income) for apartments, thus helping the poor move to where they otherwise could not afford. 


\subsection{Time frame}

The time frame in this research is from 2000 to 2012. Although the dynamic economic model predicts the out-migration of the non-poor, it cannot predict when the in-migration of low-income persons will reach the tipping point and start causing the out-migration of the non-poor. Therefore, the research uses the earliest and the latest municipality-level data (2000-2012) to test hypothesis II.

\subsection{MANCOVA}

MANCOVA is used because this research includes multiple dependent variables and because other factors affecting moving decisions need to be controlled. Given that people's economic status may change over time, the research needs to consider both the migration of the non-poor and the migration of the total population. MANCOVA can not only compare group differences on multiple dependent variables but also permits controlling other variables that may affect these dependent variables. (These control variables are called covariates.) The following describes statistical tests used to examine the assumptions of MANCOVA, sample selection, dependent variables, thresholds to form groups (independent variable), and tentative covariates.

\section{Assumptions of MANCOVA}

The following three assumptions were tested. The first assumption is homogeneity of variance, including univariate tests on each dependent variable and a multivariate test on joint dependent variables. Levene's test is used to test homogeneous population variances on each dependent variable between groups. Box's M test is used to test equal 
population covariance matrices for joint dependent variables between groups. If Box's M test rejects the null hypothesis of equal covariance matrices, generalized variance for each group would be used to judge whether the MANCOVA results tend to be liberal or conservative.

The second assumption is normality. Although scientists cannot completely assess multivariate normality, researchers can at least use Shapiro-Wilk's W test to test the assumption of univariate normality for each dependent variable within each group. As long as the data meet the requirement of univariate normality, departures from multivariate normality is inconsequential (Hair et al., 2010: 461). Although nonnormality has little effect with larger sample size (Hair et al., 2010: 460), kurtosis still needs to be examined because platykurtosis ${ }^{26}$ on a dependent variable within a group decreases statistical power. Thus, if Shapiro-Wilk's W tests reject the null hypothesis of univariate normality, the $95 \%$ confidence interval of kurtosis for each dependent variable within each group would be examined. If the intervals include 0 (normal distribution) or include only positive numbers (leptokurtic distribution ${ }^{27}$ ), nonnormality does not decrease statistical power.

The third assumption is homogeneity of regression slopes for one covariate; parallelism of regression planes for two covariates; and homogeneity of regression hyperplanes for more than two covariates (Pituch, Whittaker, \& Stevens, 2007: 300). This assumption is tested by examining if the interaction term of covariates and an independent variable is significantly correlated with the dependent variables. If the correlation is insignificant, the research can retain the null hypothesis of homogeneous

\footnotetext{
26 Platykurtosis is a distribution with a lower peak height than that in a normal distribution.

27 Leptokurtosis is a distribution with a higher peak height than that in a normal distribution.
} 
regression hyperplanes.

\section{Sample selection}

Subjects are low-poverty municipalities (below 15 percent) with a population of 65,000 or more and without a boundary change or HOPE VI programs during the time from 2000 to 2012. After collecting data, this research adopted the following steps to find appropriate samples for the analysis. First, municipality-level data from governments, like the Census Bureau or the U.S. Department of Housing and Urban Development (HUD), usually include both incorporated places and census designated places (CDPs). This research excludes CDPs because only municipalities with the power to decide its tax and public goods are appropriate for the analysis. Thus, incorporated places, defined as "a type of governmental unit incorporated under state law having legally prescribed powers and functions ${ }^{28,}$, are appropriate, but CDPs, which are statistical areas delineated based on concentrations of population by name but not legally incorporated under the laws of the $\operatorname{state}^{29}$, are inappropriate for the analysis of this research. Second, municipalities with a poverty rate higher than 15 percent were excluded because only low-poverty municipalities are considered receiving localities of housing mobility programs. Third, municipalities with HOPE VI programs during 2000 and 2012 were excluded because HOPE VI, which required the poor to leave and attracted the non-poor to move in, greatly influenced the distribution of different economic classes and thus may bias the results. Fourth, municipalities with boundary changes during 2000 and 2012 were excluded

\footnotetext{
28 The definition of incorporated place can be found in the website of the Census Glossary (https://www.census.gov/glossary/\#term_Incorporatedplace).

29 The definition of CDP can be found in the website of the Census Glossary (https://www.census.gov/glossary/\#term_CensusDesignatedPlaceCDP).
} 
because boundary changes could bias the data on the dependent variables and other covariates. After the above process, the appropriate sample includes 284 municipalities.

\section{Dependent variables}

The percentage of population change was used as the measurements of out-migration because the Census Bureau does not produce data on out-migration (It only produces in-migration data). Considering that people's economic status may change over time, the research includes two dependent variables: The first dependent variable (DV1) is the percentage of the non-poor population change between 2000 and 2012 (see equation 11). The second dependent variable (DV2) is the percentage of the total population change between 2000 and 2012 (see equation 12). This research used the poverty thresholds from the Census Bureau to determine the poor and the non-poor. The non-poor were defined as the persons who were not classified as below the poverty level. The poverty thresholds were adjusted by the Census Bureau each year. The poverty thresholds for 2000 and 2012 can be found in appendix 2 (see table 16 and table 17).

$$
\begin{aligned}
& \text { DV1 }=\frac{(\text { Non-poor in 2012) }-(\text { Non-poor in 2000) }}{\text { Non-poor in 2000 }} * 100 \% \\
& \text { DV2 }=\frac{(\text { Total population in 2012) }-(\text { Total population in } 2000)}{\text { Total population in } 2000} * 100 \%
\end{aligned}
$$

\section{Independent variable}

The independent variable is the two groups. Group 1 (G1) is low-poverty municipalities with no/few low-income affordable housing program participants while group 2 (G2) is low-poverty municipalities with many low-income affordable housing 
program participants. Considering that some poor people had already moved in low-poverty municipalities before 2000, this research cannot simply sum up the total units provided by each affordable housing program and decide which municipalities belong to which group because if most affordable housing units in a municipality had been occupied in 2000, few poor people could actually move in the municipality after 2000. Thus, equation 13 and 14 were used to calculate the number of poor persons who can move in to low-poverty municipality $j$ through affordable housing program $i$ after 2000, denoted by Pi_after2000. (The research first calculated the percentage of vacant affordable housing units, then multiplied it by total housing units to obtain the number of vacant affordable housing units, and then multiplied the product by the average number of people per unit to estimate the number of poor persons who can move in to municipality $j$ through affordable housing program i.) Considering that some programs do not have data on average size of household, namely people_per_unit_i, for some municipalities, the research assumes that each unit can at least have one person living there. Thus, equation 13 is used when data on people_per_unit_i is available while equation 14 is used when the data is not available (see table 2). Pi_after2000 of each affordable housing program was summed up to calculate the total number of program participants after 2000, denoted by total p movers (see equation 15).

$P i \_a f t e r 2000=t o t a l \_u n i t s \_i *\left(1-p c t \_o c c u p i e d \_i\right) * p e o p l e \_p e r \_u n i t \_i$

Pi_after2000=total_units_i* $\left(1-p c t \_o c c u p i e d \_i\right) * 1$

total $p$ movers $=\sum_{\mathrm{i}}$ Pi_after2000

Note:

total_units_i: total housing units provided by program $i$ pct_occupied_i: the percentage of occupied units in program $i$ people_per_unit_i: the average number of people per unit in program $i$ 
Table 2 Format of data on affordable housing programs

\begin{tabular}{|c|c|c|c|c|c|}
\hline & \multicolumn{2}{|r|}{ Program 1} & \multicolumn{2}{|r|}{ Program i } & $\ldots$ \\
\hline & Uni & $\begin{array}{lll}\% & \mathrm{P} / \text { unit } & \mathrm{P}_{1}\end{array}$ & Unit & $\begin{array}{lll}\% & \mathrm{P} / \text { unit } & \mathrm{P}_{\mathrm{i}}\end{array}$ & $\begin{array}{l}\text { total } \mathrm{p} \text { movers } \\
=\sum \mathrm{P}_{\mathrm{ij}}\end{array}$ \\
\hline Municipality 1 & $\mathrm{~A}$ & $\mathrm{~A} \quad \mathrm{~A}$ & & A $\quad$ N/A & $\mathrm{P}_{11}+\mathrm{P}_{21}+\ldots$ \\
\hline Municipality 2 & & & & & $\mathrm{P}_{12}+\mathrm{P}_{22}+\ldots$ \\
\hline Municipality j & & & & & $\ldots$ \\
\hline
\end{tabular}

Note: A: available. N/A: not available.

The population scale of municipalities also needs to be considered. If the number of total $p$ movers is very small in terms of the non-poor population in a municipality, affordable housing programs may not have an impact on migration. Therefore, the number of total $p$ movers was divided by the non-poor population in 2000 to adjust different population scales of municipalities ${ }^{30}$ (see equation 16). This variable is denoted by $P / 1000 R$, meaning the number of poor persons every 1000 non-poor persons have to take care of.

$P / 1000 R=$ total $p$ movers/ the non-poor population in 2000 (in thousands)

Although the dynamic economic model predicts the out-migration of the non-poor, it does not predict the threshold of poor program participants which will start to cause the out-migration. Therefore, this research uses four different thresholds (see figure 8) to

\footnotetext{
30 The same number of additional poor population may not have the same effects on different municipalities. Assume that municipality $A$ has 1,000 non-poor persons while municipality $B$ has 200,000 non-poor persons, and each municipality has 200 additional poor persons who may move in to the municipality in the future. For municipality $A$, additional expenses on a poor person are shared by 5 non-poor persons $(200 / 1,000=1 / 5)$, while for municipality $B$, the same expenses are shared by 1,000 non-poor persons $(200 / 200,000=1 / 1,000)$. Although both municipalities have 200 additional poor persons moving in, different population scales of municipalities mean that the extra expenses on these 200 poor persons are shared by different numbers of the non-poor.
} 
form the two groups and runs four MANCOVA models. After P/1000R was calculated, municipalities were sorted by $P / 1000 R$ in ascending order. Among 284 municipalities, only 23 municipalities had no potential poor program participants $(P / 1000 R=0)$. The first threshold (T1) included these 23 municipalities as group 1 and included municipalities with $P / 1000 R$ larger than the mean ${ }^{31}$ as group 2 . The second threshold (T2) also included the 23 municipalities as group 1 but included municipalities with $P / 1000 R$ larger than the median ${ }^{32}$ as group 2. Although the group size of 23 meets the practical guide, which suggests 20 observations as the minimum sample size for each group, analysis with a group size of fewer than 30 observations is difficult to obtain desired statistical power (Hair et al., 2010: 453, 465). Therefore, this research also uses the third and fourth threshold (T3 and T4) to form the two groups (see figure 8). The third threshold divided the 284 municipalities into three groups and included 95 municipalities (284/ $3 \fallingdotseq 95)$ with the smallest $P / 1000 R$ as the first group ${ }^{33}$ and 95 municipalities with the largest $P / 1000 R$ as the second group ${ }^{34}$. The fourth threshold divided the total sample into four groups and included 71 municipalities $(284 / 4=71)$ with the smallest $P / 1000 R$ as the first group ${ }^{35}$ and 71 municipalities with the largest $P / 1000 R$ as the second group ${ }^{36}$. The geographic distribution of the two groups of municipalities formed by different thresholds can be found in appendix 3 (see figure 10, figure 11, figure 12, and figure 13). Low-poverty municipalities with no/few affordable housing program participants (G1) were coded as 0 while low-poverty municipalities with more affordable housing program

\footnotetext{
31 The mean of $P / 1000 R$ of the 284 municipalities is 1.76 .

32 The median of $P / 1000 R$ of the 284 municipalities is 0.785 .

33 Group 1 includes 95 low-poverty municipalities with $P / 1000 R$ ranging from 0 to 0.272 .

${ }^{34}$ Group 2 includes 95 low-poverty municipalities with $P / 1000 R$ ranging from 1.672 to 15.313 .

35 Group 1 includes 71 low-poverty municipalities with $P / 1000 R$ ranging from 0 to 0.160 .

${ }^{36}$ Group 2 includes 71 low-poverty municipalities with $P / 1000 R$ ranging from 2.265 to 15.313 .
} 
participants (G2) were coded as 1 .

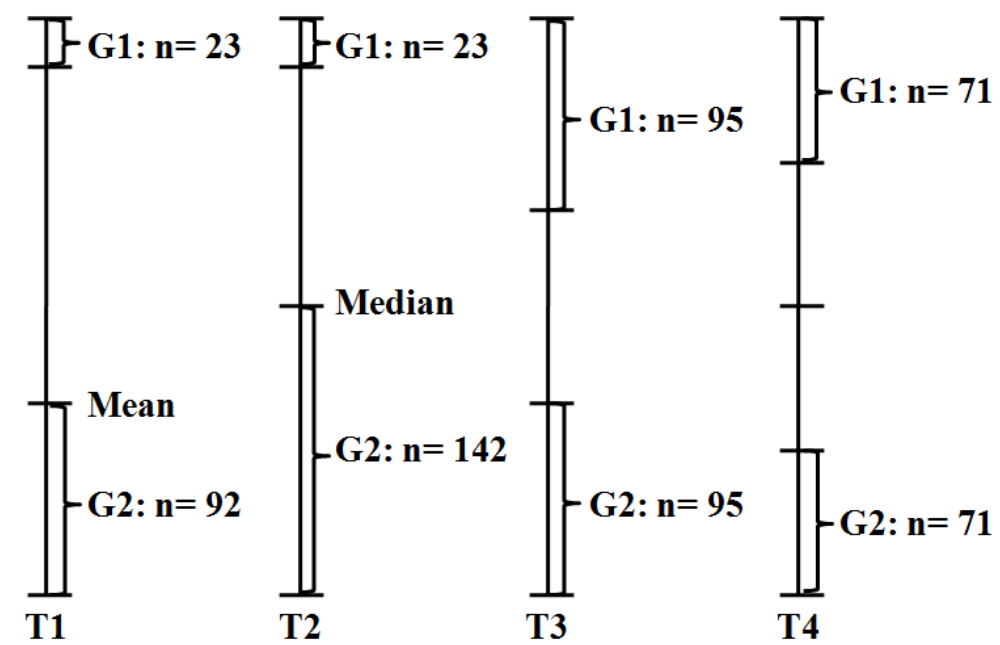

Figure 8 Four thresholds to form groups

\section{Tentative covariates}

Based on the American Housing Survey (2001, 2003, 2005, 2007, 2009, 2011) ${ }^{37}$ and relevant literature, six tentative covariates were selected to be considered for inclusion in the MANCOVA models to remove extraneous variation in the dependent variables. The bivariate correlation coefficients of each tentative covariate with the dependent variables and independent variable (groups) were tested in order to decide appropriate covariates to be included in the MANCOVA models. Covariates must have significant correlations with the dependent variables; otherwise, including them cannot remove extraneous variation and thus cannot improve the models. However, covariates should not be significantly correlated with the independent variable (groups); otherwise, MANCOVA may remove parts of the impact of groups on the dependent variables while removing the impact of covariates on the dependent variables. By removing covariates'

\footnotetext{
37 The American Housing Survey investigates people's main reason for leaving previous residences every two years.
} 
impacts on the dependent variables, it is possible to focus on the group differences on the dependent variables. The following describes the six tentative covariates, including the percentage of population with long travel time, the construction of new housing units, the change of racial/ethnic composition, the change of crime rate, and region.

\section{Tentative covariate 1 (C1): the percentage of population with long travel time}

This covariate was selected because the American Housing Survey (2001, 2003, $2005,2007,2009,2011)$ indicated that job related reasons, like "new job or job transfer" and "to be closer to work/ school/ other," had always been one of the main reasons people relocate. Therefore, this research assumes that the higher percentage of population with long travel time, the higher percentage of population with motivation to move out, which means the smaller the dependent variables are. Ideally, data on this covariate should be collected in 2000 because any survey after people moving to a place closer to work cannot reveal people's original long travel time. However, 2005 was the first year the Census Bureau started producing this data so data from 2005 was used in this research. "Long travel time" is defined as travel time longer than 30 minutes, which is based on the national-level data in each available year (2005-2012). The data showed that the mean travel time to work for workers in America was slightly more than 25 minutes $^{38}$. Table 3 shows the data pattern. Equation 17 is used to calculate this covariate. The numerator is the population whose travel time to work in 2005 was longer than 30 minutes while the denominator is the total population in 2005 .

\footnotetext{
38 The mean travel time to work for workers in America from 2005 to 2012 is 25.1, 25.0, 25.3, 25.5, 25.1, 25.3, 25.5, and 25.7 minutes respectively.
} 
Table 3 Data of travel time to work from the Census Bureau

\begin{tabular}{|c|c|c|}
\hline Subject & Municipality 1 & Municipality ... \\
\hline $\begin{array}{l}\text { Workers } 16 \text { years and over who did not work at } \\
\text { home }\end{array}$ & $a$ & \\
\hline \multicolumn{3}{|l|}{ Travel time to work } \\
\hline Less than 10 minutes & $b_{1} \%$ & \\
\hline 10 to 14 minutes & $b_{2} \%$ & \\
\hline 15 to 19 minutes & $b_{3} \%$ & \\
\hline 20 to 24 minutes & $b_{4} \%$ & \\
\hline 25 to 29 minutes & $b_{5} \%$ & \\
\hline 30 to 34 minutes & $b_{6} \%$ & \\
\hline 35 to 44 minutes & $b_{7} \%$ & \\
\hline 45 to 59 minutes & $b_{8} \%$ & \\
\hline 60 or more minutes & $b_{9} \%$ & \\
\hline Mean travel time to work (minutes) & $C$ & \\
\hline
\end{tabular}

(Workers in 2005) * ( \% of workers with travel time 30 min or more) Total population in 2005

$(17)^{39}$

\section{Tentative covariate 2 (C2): the construction of new housing units from 2000 to 2012}

This tentative covariate was selected because, according to the American Housing Survey (2001, 2003, 2005, 2007, 2009, 2011), the housing related reasons, like "to establish own household", "needed larger house or apartment", and "wanted better home," were among the reasons people move. Although home buyers' preferences may be diverse, this research assumes that developers would try to meet the market needs in order to make profits. Therefore, the construction of new housing units was selected as the second tentative covariate. The same housing supply may be very large or very small

\footnotetext{
${ }^{39}$ Take the data in table 3 for example. The calculation of this covariate is $\left[a^{*}\left(b_{6}+b_{7}+b_{8}+b_{9}\right)\right] /$ total population in 2005.
} 
in terms of the population in a municipality so the total supply of new housing units from 2000 to 2012 was divided by the total population in 2000 to adjust different population scales of municipalities (see equation 18). The smaller this covariate is, the higher likelihood that people cannot find their ideal houses in the same municipality, causing them to move out for ideal housing. This out-migration means the dependent variables would be smaller.

The construction of new housing units from 2000 to 2012

Total population in 2000

\section{Tentative covariates 3: the change of racial/ethnic composition}

Race is another factor which may affect residential decisions. Research indicated that white flight was significantly related to the size of the minority population in the neighborhood (Crowder, 2000; Crowder \& South, 2008). Also, most research focused on how the composition in black and white residents affects people's decision to stay or exit a neighborhood (Ellen, 2000: 7, 104-130). For example, Schelling's tipping model (1971) suggests that an increase of blacks in an integrated neighborhood attracts black buyers to purchase a house there but also decreases the interest of white home buyers and motivates white residents to move out (Dixit \& Nalebuff, 2008 [2009]: 219-221).

This research includes two tentative covariates about the change of racial/ethnic composition: One is about non-white and white residents (C3-A) and the other is about black and white residents (C3-B). Equation 19 is used to measure the change of non-white/white composition between 2000 and 2012 while equation 20 is used to measure the change of black/white composition between 2000 and 2012 . 
$\Delta$ Race $=\left(\frac{\text { Non-White in 2012 }}{\text { White in } 2012}\right)-\left(\frac{\text { Non-White in 2000 }}{\text { White in } 2000}\right)$

$\Delta$ Race $=\left(\frac{\text { Black in 2012 }}{\text { White in 2012 }}\right)-\left(\frac{\text { Black in 2000 }}{\text { White in 2000 }}\right)$

Although a survey of the literature on racial preferences suggested that people were concerned about racial mix of their neighborhoods, some research indicated that the magnitude of actual white departure was small (Ellen, 2000: 7-8). Ellen's research (2000) indicated that racial/ethnic composition was less influential in move-out decisions than in move-in decisions. Since the association between the racial/ethnic composition and people's out-migration is unresolved by the literature, the research cannot predict the direction of this association. However, the correlation between each covariate and the dependent variables were tested to decide if covariates would be included in the model.

\section{Tentative covariate 4 (C4): the change of crime rate between 2000 and 2012}

Since crimes were associated with urban flight (Cullen \& Levitt, 1999), the change of crime rate between 2000 and 2012 was also selected as a tentative covariate. According to Federal Bureau of Investigation (FBI), crime rates are shown as rates per 100,000 population and are calculated by equation 21 . Only violent crimes and property crimes were counted as crime cases in this research. Equation 22 is used to calculate this covariate. This research assumes that as this covariate increases, the percentage of move-out population increases, meaning the dependent variables would be smaller.

Crime rate $=\frac{\text { the number of crime cases }}{\text { total population }} * 100,000$

$\triangle$ Crime rate $=$ Crime rate in $2012-$ Crime rate in 2000 


\section{Tentative covariate 5 (C5): reqion}

Region was selected as a tentative covariate because some regions in America have been losing more population than others (Johnson, Voss, Hammer, Fuguitt, \& Mcniven, 2005). Five-decade data from 1950 s to 1990 s revealed regions with continuous in-migration (especially Florida and the Southwest) and regions with continuous out-migration (especially the Great Plains) (Johnson, et al., 2005). The Census Bureau divided states and the District of Columbia into four regions in $1942^{40}$ : Northeast ${ }^{41}$, South $^{42}$, Midwest ${ }^{43}$, and West ${ }^{44}$. This research used the same division. The covariate region is a categorical variable indicating which of the four regions a municipality is in.

\subsection{Data collection}

As shown in table 4, the data needed for the MANCOVA model were collected from the Census Bureau, HUD, or FBI. The data were gathered for different purposes which were described in table 4 . Instead of being used as a variable or being used to calculate a variable, some data were collected simply for screening out municipalities which are not appropriate for a test of hypothesis II, including the funding history of HOPE VI demolition grants and revitalization grants and the list of municipalities with boundary changes during 2000 and 2012.

\footnotetext{
40 See the definition of region in the website of the Census Glossary: http://www.census.gov/glossary/\#term_Region

${ }^{41}$ The Northeast region includes Maine, New Hampshire, Vermont, Massachusetts, Connecticut, Rhode Island, New Jersey, New York, and Pennsylvania.

${ }^{42}$ The South region includes Maryland, Delaware, West Virginia, Virginia, Kentucky, Tennessee, North Carolina, South Carolina, Georgia, Florida, Alabama, Mississippi, Arkansas, Louisiana, Oklahoma, Texas, and District of Columbia.

43 The Midwest region includes North Dakota, South Dakota, Nebraska, Kansas, Missouri, Iowa, Minnesota, Wisconsin, Illinois, Michigan, Indiana, and Ohio.

44 The West region includes Washington, Idaho, Montana, Wyoming, Oregon, California, Nevada, Utah, Colorado, Arizona, New Mexico, Alaska, and Hawaii.
} 
Table 4 Sources of the data for the MANCOVA model

\begin{tabular}{|c|c|c|c|}
\hline Data & Sources & & Note \\
\hline Poverty rates in 2000 and 2012 & Census Bureau & & $\begin{array}{l}\text { To delete municipalities with a poverty rate larger than } 15 \text { percent } \\
\text { To calculate the non-poor population for DV1, DV2, and groups }\end{array}$ \\
\hline Total population in 2000,2005 and 2012 & Census Bureau & - & $\begin{array}{l}\text { Data from } 2000 \text { and } 2012 \text { was used to calculate the non-poor } \\
\text { population for DV1, DV2, groups, C2, and C3-A. } \\
\text { Data from } 2005 \text { was used to calculate } C 1 \text {. }\end{array}$ \\
\hline Funding history of HOPE VI programs & HUD & - & $\begin{array}{l}\text { To delete municipalities with HOPE VI programs during } 2000 \\
\text { and } 2012\end{array}$ \\
\hline Boundary changes during 2000and 2012 & Census Bureau & - & $\begin{array}{l}\text { To delete municipalities with boundary changes during } 2000 \text { and } \\
2012\end{array}$ \\
\hline $\begin{array}{l}\text { Total housing units of each affordable } \\
\text { housing program in } 2000\end{array}$ & HUD & • & To calculate the variable that was used to decide the two groups \\
\hline $\begin{array}{l}\text { Percentage of occupied units in each } \\
\text { affordable housing program in } 2000\end{array}$ & HUD & • & To calculate the variable that was used to decide the two groups \\
\hline $\begin{array}{l}\text { Average size of household in each } \\
\text { affordable housing programs in } 2000\end{array}$ & HUD & $\bullet$ & To calculate the variable that was used to decide the two groups \\
\hline Travel time to work in 2005 & Census Bureau & ? & To calculate $\mathrm{C} 1$ \\
\hline $\begin{array}{l}\text { Construction of new housing units } \\
\text { during } 2000 \text { and } 2012\end{array}$ & Census Bureau & • & To calculate $\mathrm{C} 2$ \\
\hline $\begin{array}{l}\text { Population for white American alone in } \\
2000 \text { and } 2012\end{array}$ & Census Bureau & • & To calculate $\mathrm{C} 3-\mathrm{A}$ and $\mathrm{C} 3-\mathrm{B}$ \\
\hline $\begin{array}{l}\text { Population for black or African } \\
\text { American alone in } 2000 \text { and } 2012\end{array}$ & Census Bureau & • & To calculate $\mathrm{C} 3-\mathrm{B}$ \\
\hline Crime rates in 2000 and 2012 & $\begin{array}{l}\text { Census Bureau; } \\
\text { FBI }\end{array}$ & & $\begin{array}{l}\text { To calculate } \mathrm{C} 4 \\
\text { Crime rate in } 2000 \text { is from the Census Bureau } \\
\text { Crime rate in } 2012 \text { is from FBI }\end{array}$ \\
\hline
\end{tabular}




\section{CHAPTER V}

\section{RESULTS}

This chapter includes two sections. The first section presents the results of the ANOVA model, which tests the null hypothesis that the non-poor in high-poverty municipalities pay the same for public welfare and health as the non-poor in low-poverty municipalities do. The second section presents the results of the MANCOVA model, which tests the null hypothesis that federal affordable housing programs have no impact on the migration of non-poor residents in low-poverty receiving municipalities.

\section{Results of the ANOVA Model for Hypothesis I}

The research first reviewed the descriptive statistics, then examined the assumptions of ANOVA, and then reported the results of the ANOVA model.

\subsection{Descriptive statistics}

Table 5 shows the descriptive statistics for each group. The sign of the dependent variable, local expenditure on health and welfare paid by every 1000 non-poor citizens, is negative, which means most of local expenditure on health and welfare came from intergovernmental funds from state governments and the federal government. The mean of the dependent variable in low-poverty municipalities was about $-66,628$ dollars with a standard deviation of 182,660 dollars while the mean of the dependent variable in 
high-poverty municipalities was about $-261,206$ dollars with a standard deviation of 269,326 dollars. This preliminary descriptive statistics shows that high-poverty municipalities received more intergovernmental funds on public welfare and health than low-poverty municipalities did.

Table 5 Descriptive statistics on health and welfare paid by the local non-poor

\begin{tabular}{lccc}
\hline & $\mathrm{N}$ & \multicolumn{2}{c}{$\begin{array}{c}\text { Health and welfare expenditure } \\
\text { (in thousands) }\end{array}$} \\
\cline { 3 - 4 } & & Mean & S.D. \\
\hline Group 1: Low-poverty municipalities & 15 & -66.62878 & 182.66072 \\
\hline Group 2: High-poverty municipalities & 9 & -261.20644 & 269.32651 \\
\hline
\end{tabular}

\subsection{Tests of ANOVA assumptions}

Table 6 shows the test results of the assumptions of equal variances and normality. Levene's test retains the null hypothesis that the variance of the dependent variable in low-poverty municipalities and that in high-poverty municipalities are equal $(\mathrm{p}>.05)$. As to the test of normality, considering that the $\mathrm{F}$ test is still robust even if the dependent variable moderately departs from normality (Agresti \& Finlay, 2009: p. 401), the p-value was set at the 0.01 level and the Shapiro-Wilk tests retain the null hypothesis of normality for both low-poverty municipalities $(\mathrm{p}>.01)$ and high-poverty municipalities $(\mathrm{p}>.01)$. 
Table 6 Tests of ANOVA assumptions

\begin{tabular}{llc}
\hline Assumptions & Test & Sig. \\
\hline Equal variances & Levene's test & .261 \\
\hline \multirow{2}{*}{ Normality } & Shapiro-Wilk test for group 1 & .012 \\
\cline { 2 - 3 } & Shapiro-Wilk test for group 2 & .036 \\
\hline
\end{tabular}

Note: Group 1: low-poverty municipalities; Group 2: high-poverty municipalities

\subsection{Results of the ANOVA model}

Table 7 shows that the means of the dependent variable in the two groups are significantly different from each other $(\mathrm{F}=4.473, \mathrm{p}<.05)$. Although the model showed a group difference, it did not show that the non-poor pay extra taxes for public welfare and health. Instead, as the descriptive statistics showed, the means of the dependent variable in both groups are negative, which means not only that the expenditure on public welfare and health mainly came from the federal government and state governments but also that high-poverty municipalities received significantly more intergovernmental funds for public welfare and health than low-poverty municipalities did.

Table 7 Result of the ANOVA model

\begin{tabular}{llllll}
\hline & Sum of squares & df & Mean square & F & Sig. \\
\hline Between Groups & 212965.123 & 1 & 212965.123 & 4.473 & .046 \\
\hline Within Groups & 1047403.285 & 22 & 47609.240 & & \\
\hline Total & 1260368.408 & 23 & & & \\
\hline
\end{tabular}

\section{Results of the MANCOVA Model for Hypothesis II}

This section examines the results of the four MANCOVA models, each of which used a different threshold to form the two groups (the independent variable): low-poverty 
municipalities with no/few low-income affordable housing program participants (G1) and low-poverty municipalities with many low-income affordable housing program participants (G2). Five parts are included in this section: descriptive statistics, correlation, sample size, tests of MANCOVA assumptions, and findings of the MANCOVA model which meets all MANCOVA assumptions.

\subsection{Descriptive statistics for the four models}

Table 8 shows the descriptive statistics of the four models. Considering that covariates were selected only after their correlations with the dependent variables and with the independent variable were examined, this section mainly describes the descriptive statistics of the dependent variables.

The first model used threshold 1 (T1) to form the two groups. Group 1 includes 23 low-poverty municipalities while group 2 includes 92 low-poverty municipalities (see figure 8). The mean of the first dependent variable (DV1) shows that the average growth of non-poor population in group 1 from 2000 to 2012 was about $53.9 \%$ while that in group 2 was about only $12.2 \%$. The mean of the second dependent variable (DV2) shows that the average growth of total population in group 1 from 2000 to 2012 was about $60 \%$ while that in group 2 was about only $18.9 \%$.

The second model used threshold 2 (T2) to form the two groups. Group 1 includes 23 low-poverty municipalities while group 2 includes 142 low-poverty municipalities (see figure 8). The mean of the first dependent variable (DV1) shows that the average growth of non-poor population in group 1 from 2000 to 2012 was also about 53.9\% while that in group 2 was about $12.9 \%$. The mean of the second dependent variable (DV2) 
shows that the average growth of total population in group 1 from 2000 to 2012 was about $60 \%$ while that in group 2 was about only $19.4 \%$.

The third model used threshold 3 (T3) to form the two groups. Both groups include 95 low-poverty municipalities (see figure 8 ). The mean of the first dependent variable (DV1) shows that the average growth of non-poor population in group 1 from 2000 to 2012 was about $33 \%$ while that in group 2 was about only $12.2 \%$. The mean of the second dependent variable (DV2) shows that the average growth of total population in group 1 from 2000 to 2012 was about $38.6 \%$ while that in group 2 was about only $18.9 \%$.

The fourth model used threshold 4 (T4) to form the two groups. Both groups include 71 low-poverty municipalities (see figure 8). The mean of the first dependent variable (DV1) shows that the average growth of non-poor population in group 1 from 2000 to 2012 was about $39.4 \%$ while that in group 2 was about only $9.7 \%$. The mean of the second dependent variable (DV2) shows that the average growth of total population in group 1 from 2000 to 2012 was about $44.6 \%$ while that in group 2 was about only $16.1 \%$.

Overall, the descriptive statistics of these four models show that both the group mean of non-poor population growth rate (DV1) and the group mean of total population growth rate (DV2) in low-poverty municipalities with no/few affordable housing program participants (G1) were higher than those in low-poverty municipalities with more low-income affordable housing program participants (G2). These preliminary results were consistent with the expectation. However, the results of the MANCOVA model still need to be examined to conclude if the group means of each dependent variable and joint dependent variables in group 1 were significantly larger than those in group 2. 
Table 8 Descriptive statistics of the four MANCOVA models

\begin{tabular}{|c|c|c|c|c|c|c|c|c|c|c|c|c|c|}
\hline & & & DV1 & DV2 & $\mathrm{C} 1$ & $\mathrm{C} 2$ & C3-A & C3-B & $\mathrm{C} 4$ & C5_M & C5_W & C5_S & C5_N \\
\hline \multirow{6}{*}{$\mathrm{T} 1$} & \multirow{3}{*}{ G1 } & $\mathrm{N}$ & 23 & 23 & 1 & 23 & 23 & 23 & 17 & 23 & 23 & 23 & 23 \\
\hline & & Mean & 53.892 & 60.012 & 6.031 & 0.216 & 0.184 & 0.058 & -956.468 & 0.087 & 0.348 & 0.565 & 0.000 \\
\hline & & S.D. & 64.724 & 65.993 & - & 0.256 & 0.279 & 0.115 & 977.244 & 0.288 & 0.487 & 0.507 & 0.000 \\
\hline & \multirow{3}{*}{$\mathrm{G} 2$} & $\mathrm{~N}$ & 92 & 92 & 36 & 92 & 92 & 92 & 72 & 92 & 92 & 92 & 92 \\
\hline & & Mean & 12.235 & 18.943 & 20.562 & 0.083 & 0.111 & 0.038 & -938.769 & 0.326 & 0.348 & 0.174 & 0.152 \\
\hline & & S.D. & 23.584 & 24.464 & 11.873 & 0.075 & 0.269 & 0.083 & 976.174 & 0.471 & 0.479 & 0.381 & 0.361 \\
\hline \multirow{6}{*}{$\mathrm{T} 2$} & \multirow{3}{*}{ G1 } & $\mathrm{N}$ & 23 & 23 & 1 & 23 & 23 & 23 & 17 & 23 & 23 & 23 & 23 \\
\hline & & Mean & 53.892 & 60.012 & 6.031 & 0.216 & 0.184 & 0.058 & -956.468 & 0.087 & 0.348 & 0.565 & 0.000 \\
\hline & & S.D. & 64.724 & 65.993 & _ & 0.256 & 0.279 & 0.115 & 977.244 & 0.288 & 0.487 & 0.507 & 0.000 \\
\hline & \multirow{3}{*}{ G2 } & $\mathrm{N}$ & 142 & 142 & 55 & 142 & 142 & 142 & 113 & 142 & 142 & 142 & 142 \\
\hline & & Mean & 12.941 & 19.413 & 19.632 & 0.087 & 0.094 & 0.034 & -948.354 & 0.331 & 0.366 & 0.190 & 0.113 \\
\hline & & S.D. & 23.335 & 24.068 & 11.4198 & 0.077 & 0.252 & 0.107 & 1082.742 & 0.472 & 0.484 & 0.394 & 0.317 \\
\hline \multirow{6}{*}{$\mathrm{T} 3$} & \multirow{3}{*}{ G1 } & $\mathrm{N}$ & 95 & 95 & 22 & 95 & 93 & 93 & 82 & 95 & 95 & 95 & 95 \\
\hline & & Mean & 32.985 & 38.621 & 20.235 & 0.141 & 0.113 & 0.031 & -758.659 & 0.053 & 0.611 & 0.337 & 0.000 \\
\hline & & S.D. & 57.600 & 58.061 & 9.994 & 0.209 & 0.289 & 0.096 & 944.531 & 0.225 & 0.490 & 0.475 & 0.000 \\
\hline & \multirow{3}{*}{$\mathrm{G} 2$} & $\mathrm{~N}$ & 95 & 95 & 37 & 95 & 95 & 95 & 75 & 95 & 95 & 95 & 95 \\
\hline & & Mean & 12.202 & 18.917 & 20.265 & 0.083 & 0.109 & 0.038 & -939.004 & 0.347 & 0.337 & 0.168 & 0.147 \\
\hline & & S.D. & 23.333 & 24.150 & 11.846 & 0.074 & 0.265 & 0.082 & 971.206 & 0.479 & 0.475 & 0.376 & 0.356 \\
\hline \multirow[t]{2}{*}{$\mathrm{T} 4$} & G1 & $\mathrm{N}$ & 71 & 71 & 13 & 71 & 69 & 69 & 58 & 71 & 71 & 71 & 71 \\
\hline & & Mean & 39.361 & 44.580 & 23.235 & 0.164 & 0.132 & 0.042 & -789.117 & 0.070 & 0.535 & 0.394 & 0.000 \\
\hline
\end{tabular}




\begin{tabular}{cl|cccccccccccccc}
\hline & S.D. & 64.695 & 65.333 & 11.476 & 0.235 & 0.259 & 0.081 & 906.442 & 0.258 & 0.502 & 0.492 & 0.000 \\
\hline \multirow{2}{*}{ G2 } & N & 71 & 71 & 29 & 71 & 71 & 71 & 56 & 71 & 71 & 71 & 71 \\
& Mean & 9.675 & 16.1345 & 20.9275 & 0.074 & 0.102 & 0.035 & -893.844 & 0.366 & 0.310 & 0.141 & 0.183 \\
& S.D. & 21.017 & 22.032 & 12.531 & 0.065 & 0.279 & 0.085 & 1009.816 & 0.485 & 0.466 & 0.350 & 0.390 \\
\hline
\end{tabular}

Note:

T1: Threshold which used 0 and the mean of $P / 1000 R$ to form the two groups (see figure 8 )

T2: Threshold which used 0 and the median of $P / 1000 R$ to form the two groups (see figure 8 )

T3: Threshold which used top one-third and bottom one-third of municipalities to form the two groups (see figure 8)

T4: Threshold which used top one-fourth and bottom one-fourth of municipalities to form the two groups (see figure 8)

G1: Low-poverty municipalities with no/few low-income affordable housing program participants

G2: Low-poverty municipalities with many low-income affordable housing program participants

DV1: The percentage of the non-poor population change between 2000 and 2012

DV2: The percentage of the total population change between 2000 and 2012

$\mathrm{C} 1$ : The percentage of population with long travel time (longer than 30 minutes) in 2005

C2: The construction of new housing units from 2000 to 2012/ population in 2000

C3-A: The change of non-white/white composition between 2000 and 2012

C3-B: The change of black/white composition between 2000 and 2012

C4: The change of crime rate between 2000 and 2012

C5: Region_C C5_M means Midwest; C5_W means West; C5_S means South; C5_N means Northeast. 


\subsection{Correlations}

Table 9 shows Pearson correlation coefficients between covariates, dependent variables, and groups (the independent variable). This section first examines the direction of each variable and then mainly discusses the correlation between each covariate and the dependent variables and between each covariate and groups in order to select appropriate covariates for MANCOVA models.

The directions of the association between all variables and the dependent variables were consistent with expectations but not all covariates ${ }^{45}$ had significant correlations with the dependent variables. Only groups (the independent variable), housing supply (C2), the change of crime rate (C4), and region (C5) were highly correlated with both dependent variables. The significant negative correlation between groups and the dependent variables accorded with the expectation that affordable housing program participants had negative impacts on the non-poor population change and total population change. The significant positive correlation between housing supply (C2) and both dependent variables showed that the more new housing units provided during 2000 and 2012, the higher the population growth. The increase of crime rate from 2000 to 2012 (C4) negatively correlated with both dependent variables, indicating that the increase of crime rate had negative impacts on population growth. Region (C5) also significantly correlated with both dependent variables and the direction of its dummy variables (C5_M, C5_W, C5_S, C5_N) were consistent with the previous finding based on the five-decade data

\footnotetext{
${ }^{45}$ The percentage of population with long travel time (C1) and the racial/ethnic composition (C3-A and $\mathrm{C} 3-\mathrm{B})$ were not significantly correlated with the dependent variables. The negative correlation between the percentage of population with long travel time $(\mathrm{C} 1)$ and both dependent variables indicated that the higher percentage of population with long travel time, the less likelihood of population growth. The change of non-white/white composition between 2000 and 2012 (C3-A) was negatively correlated with both dependent variables. The change of black/white composition between 2000 and 2012 (C3-B) was negatively correlated with non-poor population growth (DV1) but positively correlated with total population growth (DV2). All these correlations were not statistically significant.
} 
from 1950s to 1990s (Johnson, et al., 2005).

These three covariates $(\mathrm{C} 2, \mathrm{C} 4$, and $\mathrm{C} 5)$, which were significantly correlated to the dependent variables, were considered to be included in the MANCOVA models after the correlations between these covariates and groups (the independent variable) were examined. A MANCOVA model with covariates that significantly correlated with groups cannot fully show the group differences on the dependent variables because parts of the impact of groups on the dependent variables would be diminished when the model removes the impact of covariates on the dependent variables. Table 9 shows that, among the three covariates $(\mathrm{C} 2, \mathrm{C} 4$, and $\mathrm{C} 5)$, only the change of crime rate $(\mathrm{C} 4)$ was not significantly correlated with groups $(\mathrm{p}>.05)$. However, if housing supply $(\mathrm{C} 2)$ and region (C5) were not included in the models, the research cannot confidently conclude that affordable housing programs had significant impacts on population change even if the models show significant group differences because the significance comes from not only groups but also housing supply (C2) and region (C5). Therefore, all three covariates were included, mindful that the real impact of the groups on the dependent variables is stronger than the models show. (Note: Only three dummy variables for region (C5) ${ }^{46}$ were included in the MANCOVA models.)

${ }^{46}$ Since there are four regions, only three dummy variables need to be included in the MANCOVA models. Table 9 shows only Midwest, South, and North were significantly correlated with the dependent variables. Thus, the three dummy variables would be these three regions. 
Table 9 Correlation matrix (two-sided P-value)

\begin{tabular}{|c|c|c|c|c|c|c|}
\hline & DV1 & DV2 & $\mathrm{G}_{-} \mathrm{T} 1$ & $\mathrm{G} \_\mathrm{T} 2$ & G_T3 & G_T4 \\
\hline DV1: The percentage of the non-poor population change & 1 & $.991 * *$ & $-.428 * *$ & $-.405 * *$ & $-.231 * *$ & $-.297 * *$ \\
\hline DV2: The percentage of the total population change & $.991 * *$ & 1 & $-.414 * *$ & $-.394 * *$ & $-.217 * *$ & $-.282 * *$ \\
\hline G_T1: Groups (formed by using threshold 1) & $-.428 * *$ & $-.414 * *$ & 1 & $1.000 * *$ & $1.000^{* *}$ & $1.000 * *$ \\
\hline G_T2: Groups (formed by using threshold 2) & $-.405 * *$ & $-.394 * *$ & $1.000 * *$ & 1 & $1.000 * *$ & $1.000 * *$ \\
\hline G_T3: Groups (formed by using threshold 3) & $-.231 * *$ & $-.217 * *$ & $1.000 * *$ & $1.000 * *$ & 1 & $1.000^{* *}$ \\
\hline G_T4: Groups (formed by using threshold 4) & $-.297 * *$ & $-.282 * *$ & $1.000 * *$ & $1.000 * *$ & $1.000 * *$ & 1 \\
\hline $\mathrm{C} 1$ : The percentage of population with long travel time & -.129 & -.183 & .200 & .159 & .001 & -.089 \\
\hline C2: Housing supply during 2000 and $2012 /$ population in 2000 & $.958 * *$ & $.968 * *$ & $-.379 * *$ & $-.358 * *$ & $-.182 *$ & $-.255^{* *}$ \\
\hline C3-A: The change of non-white/white composition & -.026 & -.025 & -.107 & -.121 & -.006 & -.054 \\
\hline C3-B: The change of black/white composition & -.001 & .021 & -.086 & -.061 & .039 & -.040 \\
\hline C4: The change of crime rate & $-.134 *$ & $-.152 *$ & .007 & .003 & -.094 & -.055 \\
\hline C5_M: Region_Midwest & $-.177 * *$ & $-.165 * *$ & $.213^{*}$ & $.185 *$ & $.368 * *$ & $.358 * *$ \\
\hline C5_W: Region_West & .072 & .067 & .000 & .013 & $-.274 * *$ & $-.228 * *$ \\
\hline C5_S: Region_South & $.163^{* *}$ & $.164 * *$ & $-.360 * *$ & $-.303 * *$ & $-.194 * *$ & $-.286 * *$ \\
\hline C5_N: Region_Northeast & $-.137 *$ & $-.149 *$ & $.186 *$ & .132 & $.282 * *$ & $.317 * *$ \\
\hline
\end{tabular}

Note: *. Significant at the .05 level

**. Significant at the .01 level 


\subsection{Reexamine sample size}

After including the three covariates, the sample size of each group changed because not every municipality has valid values on the three covariates $(\mathrm{C} 2, \mathrm{C} 4$, and $\mathrm{C} 5)$. Only municipalities with valid values on the dependent variables (DV1 and DV2), groups, housing supply $(\mathrm{C} 2)$, the change of crime rate $(\mathrm{C} 4)$, and region (C5) were included in the models. Each of the four MANCOVA models includes the same dependent variables and the three covariates, but the two groups in each model were formed by using a different threshold. Table 10 shows the group sample size of the four models.

Table 10 Group sample size before and after including covariates

\begin{tabular}{llcc}
\hline & & Original N & Valid N \\
\hline \multirow{2}{*}{ MANCOVA_T1 } & Group 1 & 23 & 17 \\
\cline { 2 - 4 } & Group 2 & 92 & 72 \\
\hline \multirow{2}{*}{ MANCOVA_T2 } & Group 1 & 23 & 17 \\
\cline { 2 - 4 } & Group 2 & 142 & 113 \\
\hline \multirow{2}{*}{ MANCOVA_T3 } & Group 1 & 95 & 82 \\
\cline { 2 - 4 } & Group 2 & 95 & 75 \\
\hline \multirow{2}{*}{ MANCOVA_T4 } & Group 1 & 71 & 58 \\
\cline { 2 - 4 } & Group 2 & 71 & 56 \\
\hline
\end{tabular}

The more variables are in a model, the larger overall sample size is required to run the model. Equation 23 shows the rule of thumb of the maximum number of covariates (Hair et al., 2010: 457). Based on this equation, a MANCOVA model with two groups and three covariates requires 40 overall sample size ${ }^{47}$. Overall sample size includes the

\footnotetext{
${ }^{47}$ Number of covariates $\leqq(.10 \times$ Overall sample size)- (Number of groups -1$)$

$=\mathbf{3} \leqq(.10 \times$ Overall sample size $)-(2-1)$
} 
sample in both groups. All four models have enough observations for analysis.

Number of covariates $\leqq(.10 \times$ Overall sample size $)$ - (Number of groups -1$)$

\subsection{Tests of MANCOVA assumptions}

Table 11 shows the test results of MANCOVA assumptions of the four models. The first model (MANCOVA_T1) violates the assumption of normality and the assumption of homogeneous regression hyperplanes. Although both Levene's tests reject the null hypothesis of equal variance on each dependent variable across groups $(\mathrm{p}<.05)$, Box's $\mathrm{M}$ test retains the null hypothesis of equal covariance on joint dependent variables across groups $(\mathrm{p}>.05)$. All Shapiro-Wilk's $\mathrm{W}$ tests reject the null hypothesis that each dependent variable was normally distributed within each group $(p<.05)$. Since the sample size in group 1 is small, violation of the normality assumption may make the results of MANCOVA analysis unreliable. This model also violates the assumption of homogeneous regression hyperplanes $(\mathrm{p}<.05)$. Thus, the first model may not be appropriate for analysis.

The second model (MANCOVA_T2) violates all three assumptions. Not only that both Levene's tests reject the null hypothesis of equal variance on each dependent variable across groups $(\mathrm{p}<.05)$, but also that Box's M test rejects the null hypothesis of equal covariance on joint dependent variables across groups $(p<.05)$. The research further examined the generalized variances for the two groups to evaluate the effect of this inequality of covariance on the model. Since the larger generalized variance is

\footnotetext{
$=>3 \leqq(.10 \times$ Overall sample size $)-1$

$=>4 \leqq(.10 \times$ Overall sample size $)$

$=>40 \leqq$ Overall sample size
} 
associated with the group with a smaller sample size $e^{48}$, the result of the model tends to be liberal, which means the model tends to overestimate the difference across groups. Thus, even if significant group differences were found, it is uncertain whether the dependent variables were actually significantly different across groups because the significance may come from the overestimation. All Shapiro-Wilk's W tests reject the null hypothesis of normality $(\mathrm{p}<.05)$. With a small sample size in group 1 , this violation makes the results even more unreliable. The assumption of homogeneous regression hyperplanes is also violated $(\mathrm{p}<.05)$. Thus, the results of the second model are not reliable.

The third model (MANCOVA_T3) seems to be a reliable model. Both Levene's tests retain the null hypothesis of equal variance on each dependent variable across groups ( $p$ $>$.05). Moreover, although Box's M test rejects the null hypothesis of equal covariance on joint dependent variables across groups $(\mathrm{p}<.05)$, the generalized variances for the two groups ${ }^{49}$ show that the violation of equal covariance makes the model tend to underestimate the difference across groups. Thus, if significant group differences were found, this result is reliable because, although the group differences are underestimated, the group differences are still significant enough to show on the result. As to the assumption of normality, although all Shapiro-Wilk's W tests show the violation of normality $(\mathrm{p}<.05)$, with large sample sizes ${ }^{50}$ in both groups, the research can further examine kurtosis to evaluate if the impact of nonnormality on the model is troublesome. All 95\% confidence intervals of kurtosis are positive, which means the distributions of each dependent variable in each group are leptokurtosis rather than platykurtosis. Thus,

\footnotetext{
${ }^{48}$ The generalized variance for group 1 is larger than that for group $2(224683>11357)$ and group 1 is the group with a smaller sample size than group $2(17<113)$.

${ }^{49}$ Since the group with the larger generalized variance (102441> 10893), namely group 1, is the group with a larger sample size $(82>75)$, the statistic power of the model would be underestimated.

50 Based on Central Limit Theorem, large sample size is defined as a sample size larger than 30.
} 
nonnormality has little effect on this model. This model retains the assumption of homogeneous regression hyperplanes $(\mathrm{p}>.05)$. Overall, the result of this model, although underestimated, is reliable.

The fourth model (MANCOVA_T4) violates the assumption of homogeneous regression hyperplanes. Like the third model, both Levene's tests retain the null hypothesis of equal variance on each dependent variable across groups $(p>.05)$. Although Box's $\mathrm{M}$ test shows the violation of equal covariance on joint dependent variables across groups $(p<.05)$, the generalized variances for the two groups ${ }^{51}$ show that this violation makes the model tend to be conservative. Thus, if the model shows significant group differences, the result is reliable. As to the assumption of normality, although all Shapiro-Wilk's W tests show the violation of normality $(\mathrm{p}<.05)$, this nonnormality has little effect on this model because of its large sample sizes in both groups and because all 95\% confidence intervals of kurtosis indicate that the distributions of each dependent variable in each group are leptokurtosis rather than platykurtosis. Even though the violations of equal covariance and normality have little effect on this model, the model violates the assumption of homogeneous regression hyperplanes $(\mathrm{p}<.05)$, which may bias the result. Thus, this model is also inappropriate for analysis.

\footnotetext{
${ }^{51}$ Since the larger generalized variance is associated with the group with a larger sample size, the statistic power of the model will be underestimated. (The generalized variance for group 1 is larger than that for the other group and group 1 is the group with a larger sample size.)
} 
Table 11 Tests of MANCOVA assumptions

\begin{tabular}{|c|c|c|c|c|c|}
\hline \multicolumn{2}{|c|}{ 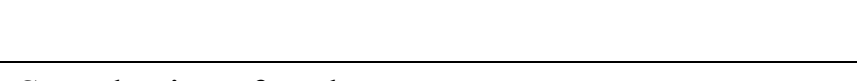 } & MANCOVA_T1 & MANCOVA_T2 & MANCOVA_T3 & MANCOVA_T4 \\
\hline \multirow{2}{*}{\multicolumn{2}{|c|}{ Sample size of each group }} & G1: 17 & G1: 17 & G1: 82 & G1: 58 \\
\hline & & G2: 72 & G2: 113 & $\mathrm{G} 2: 75$ & $\mathrm{G} 2: 56$ \\
\hline \multirow{6}{*}{$\begin{array}{l}\text { Equal variance/ } \\
\text { covariance } \\
\text { matrices }\end{array}$} & Levene_DV1 & $\mathrm{p}=.000 * *$ & $\mathrm{p}=.000 * *$ & $\mathrm{p}=.086$ & $\mathrm{p}=.092$ \\
\hline & Levene_DV2 & $\mathrm{p}=.008^{* *}$ & $\mathrm{p}=.002 * *$ & $\mathrm{p}=.087$ & $\mathrm{p}=.134$ \\
\hline & Box_Joint DVs & $\mathrm{p}=.083$ & $\mathrm{p}=.040^{*}$ & $\mathrm{p}=.000 * *$ & $\mathrm{p}=.000 * *$ \\
\hline & Generalized variance for & - & G1: 224683.2 & G1: 102441.1 & G1: 112676.8 \\
\hline & groups & & G2: 11357.7 & G2: 10893.4 & G2: 9611.9 \\
\hline & & & overestimate & underestimate & underestimate \\
\hline \multirow[t]{9}{*}{ Normality } & Shapiro-Wilk_DV1_G1 & $\mathrm{p}=.000 * *$ & $\mathrm{p}=.000 * *$ & $\mathrm{p}=.000 * *$ & $\mathrm{p}=.000 * *$ \\
\hline & Shapiro-Wilk_DV1_G2 & $\mathrm{p}=.000^{* *}$ & $\mathrm{p}=.000^{* *}$ & $\mathrm{p}=.000^{* *}$ & $\mathrm{p}=.000 * *$ \\
\hline & Shapiro-Wilk_DV2_G1 & $\mathrm{p}=.000^{* *}$ & $\mathrm{p}=.000^{* *}$ & $\mathrm{p}=.000^{* *}$ & $\mathrm{p}=.000 * *$ \\
\hline & Shapiro-Wilk_DV2_G2 & $\mathrm{p}=.000^{* *}$ & $\mathrm{p}=.000 * *$ & $\mathrm{p}=.000 * *$ & $\mathrm{p}=.000 * *$ \\
\hline & 95\% C.I. of Kurtosis_DV1_G1 & $(6.070,9.735)$ & $(6.070,9.735)$ & $(9.151,11.072)$ & $(5.997,8.204)$ \\
\hline & $95 \%$ C.I. of Kurtosis_DV1_G2 & $(7.034,8.987)$ & $(4.838,6.421)$ & $(7.166,9.087)$ & $(12.484,14.691)$ \\
\hline & 95\% C.I. of Kurtosis_DV2_G1 & $(5.101,8.766)$ & $(5.101,8.766)$ & $(8.746,10.667)$ & $(5.677,7.884)$ \\
\hline & 95\% C.I. of Kurtosis_DV2_G2 & $(7.498,9.451)$ & $(5.508,7.091)$ & $(7.733,9.654)$ & $(13.083,15.290)$ \\
\hline & Distribution & leptokurtosis & leptokurtosis & leptokurtosis & leptokurtosis \\
\hline \multicolumn{2}{|c|}{ Homogeneous regression hyperplanes } & $\mathrm{p}=.021 *$ & $\mathrm{p}=.023^{*}$ & $\mathrm{p}=.131$ & $\mathrm{p}=.005 * *$ \\
\hline
\end{tabular}

Note: *. Significant at the .05 level

**. Significant at the .01 level 


\subsection{Results of the MANCOVA model}

Considering that researchers must limit their conclusions to only the model that conforms to the assumptions of the statistical models they choose, this section only reports the results from the third model (MANCOVA_T3) - the model with the two dependent variable, three covariates ( $22, \mathrm{C} 4$, and $\mathrm{C} 5)$, and groups formed by using the third threshold (T3). Results of multivariate and univariate tests are reported respectively.

\subsubsection{Multivariate test: Group differences in joint dependent variables}

Table 12 indicates that, after controlling for housing supply (C2), the change of crime rate (C4), and region (C5), the model shows that the percentage of population changes between 2000 and 2012 (joint dependent variables) was significantly different (p $<.05)$ between low-poverty municipalities with no/fewer affordable housing program participants (G1) and low-poverty municipalities with more affordable housing program participants $(\mathrm{G} 2)$. The effect size $\eta^{2}$ shows that the proportion of variance explained in the joint dependent variables by groups is $5.5 \%$. Cohen (1977) has referred to effects of this magnitude as small to medium in $\operatorname{size}^{52}$. However, as explained in the previous sections, the effect size of groups was underestimated because the model included the covariates with high correlations with the groups-housing supply (C2) and region (C5), and because the violation of equal covariance in this model tends to underestimate group differences. Fortunately, although underestimated, the result still shows a significant group difference. And the observed power indicates $74.8 \%$ chance of correctly rejecting the false null hypothesis.

${ }^{52}$ Cohen (1977) characterized $\eta 2=0.01$ as small, $\eta 2=0.06$ as medium, $\eta 2=0.14$ as a large effect size. 
Table 12 Multivariate results on the percentage of population change (2000-2012)

\begin{tabular}{cccccccc}
\hline & Value & $\mathrm{F}$ & Hypothesis df & Error df & Sig. & $\eta^{2}$ & Observed power* \\
\hline Wilks' $\Lambda$ & .945 & 4.367 & 2 & 149 & .014 & .055 & .748 \\
\hline
\end{tabular}

Note: ${ }^{*}$ Computed using alpha $=.05$

\subsubsection{Univariate test: Group differences in each dependent variable}

When running MANCOVA, SPSS also produces univariate results (ANCOVA), which test group differences on each dependent variable. The following presents the adjusted group means of each dependent variable and the univariate ANCOVA results.

Table 13 shows the group means of each dependent variable before and after the group means were adjusted for the three selected covariates ( $\mathrm{C} 2, \mathrm{C} 4$, or $\mathrm{C} 5)$. The adjusted means show that the non-poor population change from 2000 to 2012 (DV1) in group 1 increased about $23.4 \%$ while that in group 2 increased about only $17.9 \%$. Also, the total population change from 2000 to 2012 (DV2) in group 1 increased about $28.6 \%$ while that in group 2 increased about only $24.7 \%$. The group means of both dependent variables show a similar pattern that population growth in low-poverty municipalities with no/few affordable housing program participants (G1) increased more than that in low-poverty municipalities with many affordable housing program participants (G2).

Table 13 Unadjusted and adjusted group means of the percentage of population change

\begin{tabular}{lcccc}
\hline \multicolumn{3}{c}{ DV1: Non-poor population change (\%) } & DV2: Total population change (\%) \\
\hline & Unadjusted mean ${ }^{53}$ & Adjusted mean & Unadjusted mean & Adjusted mean \\
\hline G1 & 29.01477 & 23.44383 & 34.26794 & 28.56370 \\
\hline G2 & 12.27981 & 17.85075 & 18.98517 & 24.68941 \\
\hline \multicolumn{5}{l}{$\begin{array}{l}\text { 53 } \\
\text { The unadjusted means in this table are different from the means shown in table } 8 \text { because municipalities }\end{array}$} \\
without valid values on the selected covariates (C2, C4, or C5) had been excluded. Thus, although both \\
tables show unadjusted group means, the numbers may not be the same.
\end{tabular}


Table 14 shows the results of univariate tests on the two dependent variables. Both tests are significant $(\mathrm{p}<.05)$, indicating that the pattern of group differences shown in table 13 is significant. The effect size $\eta^{2}$ shows that group differences can explain a greater proportion of variance on non-poor population change $(5.1 \%)$ than on total population change $(3 \%)$. The magnitude of both effect sizes is small to medium (Cohen, 1977) but the actual magnitude is larger than the model shows. (The underestimated effect sizes are due to the covariates with high correlations with the groups and due to the violation of equal covariance.) The observed power indicates $80.6 \%$ chance of correctly rejecting a false null hypothesis of no group difference on non-poor population change and $57.2 \%$ chance of correctly rejecting a false null hypothesis of no group difference on total population change.

Table 14 Univariate results on each dependent variable

\begin{tabular}{lccccccc}
\hline & Sum of Squares & df & Mean Square & F & Sig. & $\eta^{2}$ & Observed Power $^{*}$ \\
\hline DV1 & 881.452 & 1 & 881.452 & 8.079 & .005 & .051 & .806 \\
\hline DV2 & 422.940 & 1 & 422.940 & 4.639 & .033 & .030 & .572 \\
\hline Note: ${ }^{*}$ Computed using & &
\end{tabular}

Note: ${ }^{*}$ Computed using alpha $=.05$

DV1: The percentage of the non-poor population change between 2000 and 2012

DV2: The percentage of the total population change between 2000 and 2012

In sum, the model (MANCOVA_T3), which shows that groups had significant impacts on joint dependent variables and each individual dependent variable, supports the main finding from the dynamic economic model. The dynamic economic model indicated that housing mobility programs, which relocated low-income families to wealthier localities, may increase the non-poor's motivation to move out of the receiving 
municipalities because of the effect of property taxation under a decentralized fiscal system. The economic model shows the non-poor's motivation while the MANCOVA model tests the non-poor's actions. Data showed that affordable housing programs, or, to be more specific, the in-migration of low-income affordable housing program participants, significantly affected the percentage of population change between 2000 and 2012 in low-poverty municipalities. Low-poverty municipalities with more low-income program participants had a significantly lower percentage of population growth, especially the non-poor population growth, than the low-poverty municipalities with no/fewer low-income program participants did. 


\section{CHAPTER VI \\ DISCUSSION AND CONCLUSION}

Concentrated poverty is among the most serious urban problems in America. Poverty is more difficult to address when it is spatially concentrated because the inadequate resources and limited opportunities in poverty-concentrated places decrease the capacity of low-income families to improve their economic status. Aiming to solve the problem, housing mobility programs were created to help disperse eligible families from high-poverty neighborhoods to low-poverty neighborhoods with greater resources and opportunities so that poverty concentration could be solved and families could attain economic self-sufficiency in new neighborhoods.

Empirical evidence showed that the duration of time spent living in low-poverty neighborhoods is one of the key factors that affects the effectiveness of housing mobility programs. Numerous studies on housing mobility programs found no improvement on participants' economic self-sufficiency. Considering that many participants did not actually move to low-poverty neighborhoods or did not stay in low-poverty neighborhoods after their one-year leases expired, these studies were interpreted to reveal the disappointing outcomes of certain housing mobility programs rather than question the approach of relocating the poor to better neighborhoods. When using duration of time lived in low-poverty neighborhoods as an independent variable, Clampet-Lundquist and Massey (2008) found positive effects on the odds of being employed. This positive 
finding reflected the fact that housing mobility programs' mechanisms to improve economic self-sufficiency required time to take effect.

Considering that the duration effect for housing mobility program participants depended on both the residential mobility of the poor to move to wealthier neighborhoods and the willingness of the non-poor to stay in the receiving neighborhoods, the analysis on housing mobility programs' impacts on further migration of different economic classes is essential to reveal whether or not housing mobility programs are effective. If migration of the non-poor changed the mixed-income environment in the long term, the positive impacts of mixed-income neighborhoods on individual outcomes of program participants might not be realized in the long run.

This research argues that fiscal decentralization, which motivates people to vote with their feet according to Tiebout's theory, limits the impact of housing mobility programs. Chapter II described how fiscal decentralization may lead to poverty concentration. Local governments adopted exclusionary zoning to avoid negative impacts of the poor's in-migration on local public finance. Although housing mobility programs aimed to solve poverty concentration by breaking the barrier of exclusionary zoning, housing mobility programs did not change fiscal decentralization by compensating receiving localities to maintain the same level of local financial resources. Therefore, the influx of low-income families inevitably affected local taxes and public goods in receiving localities, which may have stimulated further vote-with-feet behavior. If the wealthier residents out-migrate, the same problem of poverty concentration may be created in receiving localities and the problem of poverty and poverty concentration may remain unsolved because low-income families still live in places with limited resources 
and opportunities. Thus, housing mobility programs may have altered the spatial pattern of poverty, but the policy may not have relieved poverty.

This research created a dynamic economic model of urban migration as a theoretical model to analyze the impacts of housing mobility programs on the change of local tax and public goods in both sending and receiving municipalities and the impacts of this change on further migration of different economic classes. This dynamic model improved the Tiebout model by adopting property taxation for analysis and allowing people to relocate in order to reflect externalities. According to this model, housing mobility programs may decrease the economic surplus of the poor who stay in sending municipalities, thus enhancing their motivation to move out. With the assistance of housing mobility programs, more poor people move to receiving municipalities. At the early stage of the dynamic, both the poor and the non-poor in receiving municipalities have more economic surplus. However, as more poor people move in to receiving municipalities in a short term, the change of the non-poor's economic surplus started to turn from positive to negative, enhancing the possibility of the non-poor's out-migration. The model also predicts that the exodus of wealthier residents may cause three negative long-term consequences: aggravating the problem of urban sprawl, creating more municipalities suffering from poverty concentration, and decreasing the economic surplus of the poor in both sending municipalities and receiving municipalities.

While the economic model serves as a theoretical model, statistical models test the main finding from the economic model — the impacts of housing mobility programs on out-migration of wealthier residents. The ANOVA model, using the financial data from 1991, indicated that the non-poor in high-poverty municipalities did not pay more taxes 
for public welfare and health than the non-poor in low-poverty municipalities did. This finding increases the credibility of the dynamic economic model, which assumes that all public goods are used and shared by all residents living in the same municipality so the model only uses nonexclusive public goods for analysis without including exclusive public goods such as health and welfare. The MANCOVA model is the main model to test the migration of wealthier residents. Due to the lack of data on out-migration, this research used the percentage of population change between 2000 and 2012 as measurement. The MANCOVA results supported the economic model, indicating that the set of population changes between 2000 and 2012 in low-poverty municipalities with no/fewer affordable housing program participants increased significantly more than that in low-poverty municipalities with more affordable housing program participants after controlling for covariates like housing supply, crime rate, and region. The MANCOVA model also showed that housing mobility programs had more impact on the variation of non-poor population change than on that of total population change. Based on the results of both statistical models, the research suggests that even if the federal government was willing to provide public welfare and health for low-income persons in receiving municipalities, the subsidies on nonexclusive public goods through property taxation from the non-poor to the poor were still powerful enough to affect migration.

The findings may serve as a start for scholars to reexamine the effectiveness of housing mobility programs in the framework of political fragmentation/ fiscal decentralization. This research implies that the federal government must consider the reactions of the non-poor when adopting mobility-based polices. Housing mobility programs' dependence on the presence of wealthier residents can be seen from MTO's 
geographical restriction that housing vouchers could only be used in neighborhoods with low poverty rates. However, the stability of mixed-income neighborhoods may require the federal government to change the nature of fiscal decentralization; otherwise, the individual behavior (the out-migration of the non-poor) under a decentralized fiscal system may limit the effectiveness of housing mobility programs.

Although this research did not test the impacts of housing mobility programs on local taxes and public good level in receiving municipalities, the economic model provides a possible explanation for the outmigration of wealthier residents and previous research findings about the deterioration of receiving localities and the decreasing number of neighborhoods with better public goods and job opportunities. This research shows our limited understanding about the impacts of housing mobility programs. Most current research about housing mobility programs focused on the impacts on either participants' individual outcomes or the conditions of receiving neighborhoods after participants moved in. However, when analyzing the impacts of housing mobility programs under a decentralized fiscal system, the economic model surprisingly finds that housing mobility programs may have wider impacts such as urban sprawl.

Considering that many low-income families have moved to other neighborhoods through the assistance of housing mobility programs, supporting measures are provided to prevent or alleviate further problems. Unlike traditional economic models, which are based on utility maximization and thus make out-migration a sure result and leave no room for policy suggestions, the dynamic model in this research uses the concept of "dissatisfaction" for analysis and shows the possibility of adopting supporting measures to maintain mixed-income environment (see the early stage of the dynamic). Two policy 
suggestions are provided based on the economic model. The first suggestion is to change the nature of fiscal decentralization by compensating receiving municipalities to maintain the non-poor's economic surplus. At the early stage of the dynamic, the non poor stay in the receiving municipality is because their economic surplus has not decreased. The MANCOVA results imply that the subsidies through property taxation alone could affect migration. Thus, the research suggests that the federal government not only pay for the health and welfare for low-income families but also compensate receiving municipalities to maintain the same level of tax and public goods.

The second suggestion on the prevention of out-migration is to weaken the effect of property taxation under a decentralized fiscal system. The federal government can exacerbate or ease the negative consequences of political fragmentation by widening the income gap or adopting policies to enhance the poor's economic status and thus weakening the effect of property taxation and externalities (see Chapter II). For example, the federal government may improve the accessibility of public transit from receiving neighborhoods and job markets. (see Chapter II: A positive relationship between MTO movers with the access of transportation and employment outcomes was found in previous research.) The smaller the income gap between the non-poor and the poor, the fewer subsidies would be transferred from the non-poor to the poor through property taxation, the less likelihood of out-migration of wealthier residents.

This research supports scholarship that questions housing mobility programs' effectiveness at improving individual outcomes for two reasons. First, the research challenges the approach that residential mobility leads to economic mobility. This approach depends on better neighborhoods with wealthier residents who serve as role 
models, pay taxes for better public goods, and help create jobs to increase the economic mobility of the poor (see Chapter II). Although this research did not test the effect of mixed-income neighborhoods on employment outcomes, this research points out that even if neighborhoods with more wealthier residents do positively affect individual outcomes, the created mixed-income neighborhoods may not exist in the long run, let alone have positive impacts on the economic mobility of the poor.

Second, the research reminds urban scholars to rethink the traditional idea that better neighborhoods lead to better individual outcomes. Is it better neighborhoods that generates better individual outcomes or is it better individuals, such as high-income persons who contribute more to local tax revenue ${ }^{54}$, that provides local governments financial capacity to create better neighborhoods? If neighborhoods are the causes, not the outcomes, then why were geographical restrictions on housing vouchers related to poverty rates of neighborhoods rather than the availability of resources and opportunities in neighborhoods? A possible explanation may be the assumption that low-poverty neighborhoods tend to have better resources and that relocating the poor to these neighborhoods costs less ${ }^{55}$ than directly providing resources to the poor in where they live. If this assumption is the reason why low-poverty neighborhoods were considered as ideal receiving neighborhoods, then perhaps policy makers need to rethink the direction of causation between higher income residents (low-poverty neighborhoods) and better neighborhood resources. In a decentralized fiscal system, higher income residents do play a role in the provision of resources. Thus, the current housing mobility programs may

\footnotetext{
${ }^{54}$ Even though tax rates are low, as long as tax base, like income, is large, local governments can still receive enough tax to provide better public goods.

${ }^{55}$ Chapter II explained why the interlocal competition in a politically fragmented setting tends to lead to the overprovision of public goods for wealthier people. Thus, the excess capacity of public good in low-poverty localities may save federal funds for providing resources to the poor.
} 
rely more on wealthier-individual effects rather than neighborhood effects. If individuals are the cause of neighborhoods, current housing mobility programs may fail to adopt supporting measures to either keep wealthier residents or improve the employment outcomes of the poor. If individuals are the main cause, then perhaps policy makers should focus on thinking how to actually help low-income persons to escape from poverty rather than relying on poorly understood mobility-based solutions.

The most important implication of this research is that anti-poverty programs should be funded at the federal level rather than at a local level for practical and equity reasons. For the practical reason, funding anti-poverty programs at the local level rather than the national level may stimulate the out-migration of wealthier residents. Once wealthier residents out-migrate to avoid being taxed for anti-poverty programs, there may not be enough tax revenues to implement those programs. Solutions to poverty may be local ${ }^{56}$ but the resources for the solutions should be federal. Although housing mobility programs are federal policies, the policies depend on local resources to solve poverty. Thus, wealthier residents may exit the newly mixed-income municipalities, poverty may re-concentrate, and housing mobility programs may not achieve the policy goals.

The equity reason is that it may be unfair to ask the people who happen to be neighbors with the poor to pay for anti-poverty solutions rather than all citizens in the nation. Some scholars may argue against the practical reason based on the fact that not all non-poor persons are mobile so the out-migration may be much less than the model predicts. While that may be true, would it be fair to collect resources for solving poverty from the non-poor who lack economic mobility to out-migrate to avoid paying subsidies

\footnotetext{
${ }^{56}$ Although poverty may be a common problem for many municipalities in America, there may be some differences in different local contexts. Therefore, it is reasonable that solutions come from local governments.
} 
to the poor through property taxation? Funding anti-poverty programs at a local level may create an inequality between the non-poor with low economic mobility and the non-poor with high economic mobility. This research suggested that compensation for receiving localities is needed to maintain mixed-income environment and the compensation should come from the federal government. This policy suggestion is also based on the equity reason that the resources for solving poverty should not come from local residents, especially the non-poor with low economic mobility.

This research limits the analysis to an economic perspective. The dynamic economic model assumes that only economic incentive influences relocation behavior. However, there are many non-economic reasons for relocation. The MANCOVA model in this research intended to control these non-economic factors by including covariates, but it only included the factors that can be quantified. This limitation means that other equally important non-economic motives would be ignored in this research. This research acknowledges non-economic motives for relocation but limits the analysis to economic factors only. The policy suggestions were also based on an economic perspective. It is possible that even if the federal government compensates receiving municipalities, wealthier residents still out-migrate due to other non-economic reasons.

There are some suggestions for future studies to improve this research. First, future research can gather data on out-migration instead of using population changes to test housing mobility programs' impact on migration. Second, based on this research's finding, future research can test the relationships between housing mobility programs and the three negative consequences predicted by the dynamic economic model. Third, the economic model in this research shows the dynamic process of migration, but it cannot 
predict when the out-migration will occur. Future research may explore factors affecting the length of the dynamic such as the access capacity of public goods in receiving municipalities, how poor the program participants are, the non-poor population in receiving municipalities, and other possible factors. The information may be useful to provide more concrete policy suggestions on how to maintain the early stage of the dynamic at which mixed-income status is stable. Fourth, future research may compare the individual outcomes of housing mobility programs in America with that in another country which adopted similar policies under a centralized fiscal system. 


\section{REFERENCES}

Agresti, A., \& Finlay, B. (2009). Statistical Methods for the Social Sciences (4 ed.). Upper Saddle River, NJ: Pearson Prentice Hall.

Aronson, J. R., \& Schwartz, E. (1973). Financing public goods and the distribution of population in a system of local governments. National Tax Journal, 26, 137-159.

Baicker, K., Clemens, J., \& Singhal, M. (2012). The rise of the states: U.S. fiscal decentralization in the postwar period. Journal of Public Economics, 96(11-12), 1079-1091.

Bauder, H., \& Perle, E. (1999). Spatial and skills mismatch for labor-market segments. Environment and Planning A, 31(6), 959-977.

Bayindir-Upmann, T. (1998). Two games of interjurisdictional competition when local governments provide industrial public goods. International Tax and Public Finance, 5(4), 471-487.

Blumenberg, E., \& Pierce, G. (2014). A driving factor in mobility? Transportation's role in connecting subsidized housing and employment outcomes in the Moving to Opportunity (MTO) program. Journal of the American Planning Association, 80(1), 52-66.

Booza, J., Cutsinger, J., \& Galster, G. (2006). Where did they go? The decline of middle-income neighborhoods in metropolitan America. from http://www.brookings.edu/research/reports/2006/06/poverty-booza

Briggs, X. d. S. (1997). Moving up versus moving out: Neighborhood effects in housing mobility programs. Housing Policy Debate, 8(1), 195-234.

Brueckner, J. K. (2000). Welfare reform and the race to the bottom: Theory and evidence. Southern Economic Journal, 505-525.

Brueckner, J. K. (2011). Lectures on Urban Economics. Cambridge, MA: The MIT Press.

Cebula, R. J., \& Nair-Reichert, U. (2012). Migration and public policies: A further empirical analysis. Journal of Economics and Finance, 36(1), 238-248.

Chaskin, R. J., \& Joseph, M. L. (2013). 'Positive' gentrification, social control and the 'right to the city' in mixed-income communities: Uses and expectations of 
space and place. International Journal of Urban and Regional Research,37(2), 480-502. doi: 10.1111/j.1468-2427.2012.01158.x

City government finances: 1990-91. (1993). Washington: The Bureau.

Clampet-Lundquist, S., \& Massey, D. S. (2008). Neighborhood effects on economic self-sufficiency: A reconsideration of the Moving to Opportunity experiment. American Journal of Sociology, 114(1), 107-143.

Cohen, J. (1977). Statistical Power Analysis for the Behavioral Sciences (Rev ed.): Lawrence Erlbaum Associates, Inc.

Crowder, K., \& South, S. J. (2008). Spatial dynamics of white flight: The effects of local and extralocal racial conditions on neighborhood out-migration. American Sociological Review,73(5), 792-812. doi: 10.1177/000312240807300505

Crowder, K. (2000). The racial context of white mobility: An individual-level assessment of the white flight hypothesis. Social Science Research,29(2), 223-257. doi: 10.1006/ssre.1999.0668

Crump, J. R. (2003). The end of public housing as we know it: Public housing policy, labor regulation and the US city. International Journal of Urban and Regional Research, 27(1), 179-187.

Curley, A. M. (2010). Relocating the poor: Social capital and neighborhood resources. Journal of Urban Affairs, 32(1), 79-103.

Cullen, J. B., \& Levitt, S. D. (1999). Crime, urban flight, and the consequences for cities. Review of Economics and Statistics,81(2), 159-169. doi: $10.1162 / 003465399558030$

DeFilippis, J., \& Fraser, J. (2010). Why do we want mixed-income housing and neighborhoods? In J. S. Davies \& D. L. Imbroscio (Eds.), Critical Urban Studies: New Directions (pp. 135-147). Albany: State University of New York Press.

Deluca, S., Garboden, P. M., \& Rosenblatt, P. (2013). Segregating shelter: How housing policies shape the residential locations of low-income minority families. The ANNALS of the American Academy of Political and Social Science,647(1), 268-299. doi: 10.1177/0002716213479310

Dixit, A. K., \& Nalebuff, B. J. (2008 [2009]). The Art of Strategy: A Game Theorist's Guide to Success in Business and Life (C. C. Tung, E. S. Wang \& W. H. Li, Trans.). Peking: China Machine Press.

Dreier, P., Mollenkopf, J. H., \& Swanstrom, T. (2004). Place Matters: Metropolitics for the $21^{\text {st }}$ Century (2 ed.). Lawrence, Kansas: University Press of Kansas. 
Edin, K., DeLuca, S., \& Owens, A. (2012). Constrained compliance: Solving the puzzle of MTO's lease-up rates and why mobility matters. Cityscape, 181-194.

Ellen, I. G. (2000). Sharing America's Neighborhoods: The Prospects for Stable Racial Integration. Cambridge, MA: Harvard University Press.

Ellen, I. G., \& Turner, M. A. (2003). Do neighborhoods matter and why? In J. M. Goering \& J. D. Feins (Eds.), Choosing a Better Life? Evaluating the Moving to Opportunity Social Experiment (pp. 313-338). Washington, D.C.: The Urban Institute Press.

Ellson, R. (1980). Fiscal impacts on intrametropolitan residential location-further insights on the Tiebout hypothesis. Public Finance Quarterly, 8, 189-212.

Ferreira, S. G., Varsano, R., \& Afonso, J. R. (2005). Inter-jurisdictional fiscal competition: A review of the literature and policy recommendations. Brazilian Journal of Political Economy, 25(3), 295-313.

Finkel, M., \& Buron, L. (2001). Study on Section 8 Voucher Success Rates. Volume I. Quantitative Study of Success Rates in Metropolitan Areas. Washington, DC: US Department of Housing and Urban Development.

Frug, G. E. (1999). City Making: Building Communities without Building Walls. Princeton, N.J.: Princeton University Press.

Galster, G. C., Tatian, P. A., Santiago, A. M., Pettit, K. L., \& Smith, R. E. (2003). Why Not In My Backyard? Neighborhood Impacts of Deconcentrating Assisted Housing. New Brunswick, NJ: Center for Urban Policy Research.

Galster, G. C. (2005a). Consequences from the redistribution of urban poverty during the 1990s: A cautionary tale. Economic Development Quarterly, 19(2), 119-125.

Galster, G. C. (2005b). Rejoinder. Economic Development Quarterly, 19(2), 136-137.

Glaeser, E. L., Kahn, M. E., \& Rappaport, J. (2008). Why do the poor live in cities? The role of public transportation. Journal of urban Economics, 63(1), 1-24.

Glaeser, E. L., \& Shleifer, A. (2005). The Curley effect: The economics of shaping the electorate. Journal of Law, Economics, and Organization, 21(1), 1-19.

Goering, J. M., Feins, J. D., \& Richardson, T. M. (2003). What have we learned about housing mobility and poverty deconcentration? In J. M. Goering \& J. D. Feins (Eds.), Choosing a Better Life? Evaluating the Moving to Opportunity Social Experiment (pp. 3-36). Washington, D.C.: Urban Institute Press.

Goetz, E. G. (2004). Desegregation lawsuits and public housing dispersal: The case of Hollman v. Cisneros in Minneapolis. Journal of the American Planning Association, 70(3), 282-299. doi: 10.1080/01944360408976379 
Goetz, E. G., \& Chapple, K. (2010). Dispersal as anti-poverty policy. In J. S. Davies \& D. L. Imbroscio (Eds.), Critical Urban Studies: New Directions (pp. 149-164). Albany: State University of New York Press.

Grassmueck, G. (2011). What drives intra-county migration: The impact of local fiscal factors on Tiebout sorting. Review of Regional Studies, 41(2-3), 119-138.

Hair, J. F., Black, W. C., Babin, B. J., \& Anderson, R. E. (2010). Multivariate Data Analysis: A Global Perspective (7 ed.). Upper Saddle River, NJ: Pearson Education.

Hamilton, B. W. (1975). Zoning and property taxation in a system of local governments. Urban Studies, 12(2), 205-211. doi: 10.1080/00420987520080301

Hanratty, M., McLanahan, S., \& Pettit, B. (2003). Los Angeles site findings. In J. M. Goering \& J. D. Feins (Eds.), Choosing a Better Life? Evaluating the Moving to Opportunity Social Experiment (pp. 245-274). Washington, D.C.: The Urban Institute Press.

Holzer, H. J. (1991). The spatial mismatch hypothesis: What has the evidence shown? Urban Studies, 28(1), 105-122.

Imbroscio, D. L. (2004a). Can we grant a right to place? Politics \& Society, 32(4), 575-609.

Imbroscio, D. L. (2004b). Fighting poverty with mobility: A normative policy analysis. Review of Policy Research, 21(3), 447-461. doi: 10.1111/j.1541-1338.2004.00086.x

Imbroscio, D. L. (2006). Shaming the inside game: A critique of the liberal expansionist approach to addressing urban problems. Urban Affairs Review, 42(2), 224-248. doi: $10.1177 / 1078087406291444$

Imbroscio, D. L. (2008). "[U]nited and actuated by some common impulse of passion": Challenging the dispersal consensus in American housing policy research. Journal of Urban Affairs, 30(2), 111-130. doi: 10.1111/j.1467-9906.2008.00381.x

Imbroscio, D. (2012). Beyond mobility: The limits of liberal urban policy. Journal of Urban Affairs, 34(1), 1-20.

Jargowsky, P. A. (2003). Stunning Progress, Hidden Problems: The Dramatic Decline of Concentrated Poverty in the 1990s. Retrieved from Brookings website: http://www.brookings.edu/research/reports/2003/05/demographics-jargowsky

Johnson, K. M., Voss, P. R., Hammer, R. B., Fuguitt, G. V., \& McNiven, S. (2005). Temporal and spatial variation in age-specific net migration in the United States. Demography, 42(4), 791-812. doi: 10.1353/dem.2005.0033 
Kantor, P. (1995). The Dependent City Revisited: The Political Economy of Urban Development and Social Policy. Boulder, CO.: Westview Press.

Kasintiz, P., \& Rosenberg, J. (1996). Missing the connection: Social isolation and employment on the Brooklyn waterfront. Soc. Probs., 43, 180.

Katz, L. F., Kling, J., \& Liebman, J. B. (2003). Boston site findings. In J. M. Goering \& J. D. Feins (Eds.), Choosing a Better Life? Evaluating the Moving to Opportunity Social Experiment (pp. 177-212). Washington, D.C.: The Urban Institute Press.

Katz, L. F., Kling, J. R., \& Liebman, J. B. (2000). Moving to opportunity in Boston: Early results of a randomized mobility experiment. National Bureau of Economic Research.

Kirby, A. (2004). Metropolitics or retropolitics? Antipode, 36(4), 753-759.

Kleit, R. G. (2002). Job search networks and strategies in scattered-site public housing. Housing Studies, 17(1), 83-100.

Konishi, H. (2008). Tiebout's tale in spatial economies: Entrepreneurship, self-selection, and efficiency. Regional Science and Urban Economics, 38, 461-477.

Ladd, H. F., \& Ludwig, J. (2003). The effects of MTO on educational opportunities in Baltimore. In J. M. Goering \& J. D. Feins (Eds.), Choosing a Better Life? Evaluating the Moving to Opportunity Social Experiment (pp. 117-151). Washington, D.C.: The Urban Institute Press.

Leventhal, T., \& Brooks-Gunn, J. (2003). New York City site findings. In J. M. Goering \& J. D. Feins (Eds.), Choosing a Better Life? Evaluating the Moving to Opportunity Social Experiment (pp. 213-244). Washington, D.C.: The Urban Institute Press.

Logan, J. R., \& Molotch, H. L. (1987 [2002]). Urban fortunes: The political economy of place. In G. Bridge \& S. Watson (Eds.), The Blackwell City Reader (pp. 464-476). Malden, MA: Wiley, John and Sons.

Ludwig, J., Duncan, G. J., \& Hirschfield, P. (2001). Urban poverty and juvenile crime: Evidence from a randomized housing-mobility experiment. The Quarterly Journal of Economics, 116(2), 655-679. doi: 10.1162/00335530151144122

Ludwig, J., Duncan, G. J., \& Pinkston, J. C. (2000). Neighborhood effects on economic self-sufficiency: Evidence from a randomized housing-mobility experiment. unpublished paper, Georgetown University.

Ludwig, J., Duncan, G. J., \& Ladd, H. F. (2003). The effects of MTO on children and parents in Baltimore. In J. M. Goering \& J. D. Feins (Eds.), Choosing a Better Life? Evaluating the Moving to Opportunity Social Experiment (pp. 153-176). Washington, D.C.: The Urban Institute Press. 
Newman, S., \& Harkness, J. (2003). Neighborhood poverty, housing assistance, and children's educational attainment. In J. M. Goering \& J. D. Feins (Eds.), Choosing a Better Life? Evaluating the Moving to Opportunity Social Experiment (pp. 339-364). Washington, D.C.: The Urban Institute Press.

Orr, L., Feins, J., Jacob, R., Beecroft, E., Sanbonmatsu, L., Katz, L. F., . . Kling, J. R. (2003). Moving to Opportunity: Interim Impacts Evaluation.

Ostrom, E. (1990 [2012]). Governing the Commons: The Evolution of Institutions for Collective Action (X.-D. Yu \& X.-D. Chen, Trans.). Shanghai: Shanghai Translation Publishing House.

Pattillo, M. (2008). Investing in poor black neighborhoods "As is". In M. A. Turner, S. J. Popkin \& L. Rawlings (Eds.), Public Housing and the Legacy of Segregation (pp. 31-42). Washington DC: Urban Institute Press.

Peterson, P. E. (1981). City Limits. Chicago: University of Chicago Press.

Pituch, K. A., Whittaker, T. A., \& Stevens, J. P. (2007). Intermediate Statistics: A Modern Approach. New York, NY: Taylor \& Francis.

Quigley, J. M., \& Raphael, S. (2008). Neighborhoods, economic self-sufficiency, and the MTO program. Brookings-Wharton Papers on Urban Affairs(9), 1-29.

Retsinas, N. P., \& Belsky, E. S. (2008). Revisiting Rental Housing: Policies, Programs, and Priorities. Washington, D.C.: Brookings Institution Press.

Rhode, P. W., \& Strumpf, K. S. (2003). Assessing the importance of Tiebout sorting: Local heterogeneity from 1850 to 1990. American Economic Review, 93(5), 1648-1677.

Rosenbaum, E., \& Harris, L. E. (2001). Residential mobility and opportunities: Early impacts of the Moving to Opportunity demonstration program in Chicago. Housing Policy Debate, 12(2), 321-346. doi: 10.1080/10511482.2001.9521408

Rothwell, J. T., \& Massey, D. S. (2010). Density zoning and class segregation in U.S. metropolitan areas. Social Science Quarterly, 91(5), 1123-1143.

Rubin, I. S., \& Rubin, H. J. (1987). Economic development incentives: The poor (cities) pay more. Urban Affairs Review, 23(1), 37-62.

Sanbonmatsu, L., Kling, J. R., Duncan, G. J., \& Brooks-Gunn, J. (2006). Neighborhoods and academic achievement: Results from the Moving to Opportunity experiment. Journal of Human Resources, 41(4), 649-691.

Sanbonmatsu, L., Ludwig, J., Katz, L. F., Gennetian, L. A., Duncan, G. J., Kessler, R. C., . . . Lindau, S. T. (2011). Moving to Opportunity for Fair Housing Demonstration Program - Final Impacts Evaluation. 
Sanbonmatsu, L., Potter, N. A., Adam, E., Duncan, G. J., Katz, L. F., Kessler, R. C., . . . Congdon, W. J. (2012). The long-term effects of Moving to Opportunity on adult health and economic self-sufficiency. Cityscape, 109-136.

Sard, B. (2008). How to Promote Housing Integration and Choice Through the Section 8 Voucher Program. testimony before the National Commission on Fair Housing and Equal Opportunity, September, 22.

Savitch, H. V., Vogel, R. K., \& Ye, L. (2010). Beyond the rhetoric: Lessons from Louisville's consolidation. The American Review of Public Administration, 40(1), 3-28.

Schelling, T. C. (1971). Dynamic models of segregation. The Journal of Mathematical Sociology,1(2), 143-186. doi: 10.1080/0022250X.1971.9989794

Schutt, R. K. (2012). Investigating the Social World: The Process and Practice of Research (7 ed.). Thousand Oaks, CA: Sage Publications.

Shroder, M. (2002). Does housing assistance perversely affect self-sufficiency? A review essay. Journal of Housing Economics, 11(4), 381-417.

Shroder, M. (2003). Locational constraint, housing counseling, and successful lease-up. In J. M. Goering \& J. D. Feins (Eds.), Choosing a Better Life? Evaluating the Moving to Opportunity Social Experiment (pp. 59-80). Washington, D.C.: The Urban Institute Press.

Shroder, M. D., \& Orr, L. L. (2012). Moving to Opportunity: Why, how, and what next? Cityscape, 31-56.

Siegel, F. (1999). Is regional government the answer? Public Interest(137), 85-98.

Slater, C., \& Hall, G. E. (1993). 1993 County and City Extra: Annual Metro, City and County Data Book. Lanham, MD: Bernan Press.

Stone, C. N. (1989 [2013]). Urban regimes. In P. Kantor \& D. R. Judd (Eds.), American Urban Politics in a Global Age (7 ed., pp. 20-34). Upper Saddle River, N.J.: Pearson Education.

Stone, D. (2002 [2007]). Policy Paradox: The Art of Political Decision Making (T. K. Chu, Trans.). Taipei: Socio Publishing Co.

Tiebout, C. M. (1956). Pure theory of local expenditures. The Journal of Political Economy, 64(5), 416-424.

Turner, M. A., Popkin, S. J., \& Cunningham, M. K. (2000). Section 8 Mobility and Neighborhood Health. Washington, DC: The Urban Institute. 
U.S. HUD (Department of Housing and Urban Development). (2002). American housing survey for the United States 2001. Washington, DC: U.S. Government Printing Office.

U.S. HUD (Department of Housing and Urban Development). (2004). American housing survey for the United States 2003. Washington, DC: U.S. Government Printing Office.

U.S. HUD (Department of Housing and Urban Development). (2006). American housing survey for the United States 2005. Washington, DC: U.S. Government Printing Office.

U.S. HUD (Department of Housing and Urban Development). (2008). American housing survey for the United States 2007. Washington, DC: U.S. Government Printing Office.

U.S. HUD (Department of Housing and Urban Development). (2010). American housing survey for the United States 2009. Washington, DC: U.S. Government Printing Office.

U.S. HUD (Department of Housing and Urban Development). (2012). American housing survey for the United States 2011. Washington, DC: U.S. Government Printing Office.

Varady, D. P., \& Walker, C. C. (2003). Housing vouchers and residential mobility. Journal of Planning Literature, 18(1), 17-30.

Wasserman, M. (2001). The geography of life's chances. Regional Review(Q 4), 25-31.

Wildasin, D. E., \& Wilson, J. D. (1991). Theoretical issues in local public economics: An overview. Regional Science and Urban Economics, 21(3), 317-331.

Williamson, T., Imbroscio, D., \& Alperovitz, G. (2002). Making a Place for Community: Local Democracy in a Global Era. New York: Routledge.

Wilson, J. D. (1986). A theory of interregional tax competition. Journal of Urban Economics, 19(3), 296-315.

Wilson, W. J. (1987). The Truly Disadvantaged: The Inner City, the Underclass, and Public Policy. Chicago: University of Chicago Press.

Wilson, W. J. (1997). When Work Disappears: The World of the New Urban Poor. New York: Knopf Doubleday Publishing Group.

Wilson, W. J. (2009). More Than Just Race. New York: Norton and Company.

Wyly, E. K., Glickman, N. J., \& Lahr, M. L. (1998). A top 10 list of things to know about American cities. Cityscape, 3(3), 7-32. 
Zodrow, G. R., \& Mieszkowski, P. (1986). Pigou, Tiebout, property taxation, and the underprovision of local public goods. Journal of Urban Economics, 19 (3), 356-370. 


\section{APPENDIX 1: ALGEBRAS USED IN THE DYNAMIC ECONOMIC MODEL}

\section{Demand Curve}

- $D_{p}$ : The demand curve of the poor

- $D_{r}$ : The demand curve of the non-poor

\section{$\underline{\text { Population }}$}

- $N_{p 0}$ : The number of the poor in the sending municipality before housing mobility programs were adopted

- $N_{p 1}$ : The number of the poor who move from the sending municipality to the receiving municipality through housing mobility programs

- $N_{p 2}$ : The tipping point of the poor program participants which starts to cause the out-migration of the non-poor in the receiving municipality

- $N_{r 0}$ : The number of the non-poor in the receiving municipality before housing mobility programs were adopted

\section{Shared Cost (SC)}

- $\quad C_{p 0}$ : The shared cost of the poor in the sending municipality before housing mobility programs were adopted

- $C_{p 1}$ : The shared cost of the poor in the sending municipality after some other poor persons move out to the receiving municipality through housing mobility programs

- $C_{p 2}$ : The shared cost of the poor after they move to the receiving municipality 
through housing mobility programs

- $C_{p 3}$ : The shared cost of the poor in the sending municipality after further out-migration of the poor in the sending municipality

- $C_{p 4}$ : The shared cost of the poor in the receiving municipality after the out-migration of the non-poor in the receiving municipality

- $C_{r 0}$ : The shared cost of the non-poor in the receiving municipality before housing mobility programs were adopted

- $C_{r 1}$ : The shared cost of the non-poor in the receiving municipality after some poor persons move in to the receiving municipality through housing mobility programs

\section{Quantity of public goods}

- $Z_{p 0}$ : The poor's optimal quantity of public goods in the sending municipality before housing mobility programs were adopted

- $Z_{p 1}$ : The poor's optimal quantity of public goods in the sending municipality after housing mobility programs were adopted

- $Z_{r 0}$. The non-poor's optimal quantity of public goods in the receiving municipality before housing mobility programs were adopted

- $Z_{r 1}$. The non-poor's optimal quantity of public goods in the receiving municipality after housing mobility programs were adopted

\section{$\underline{\text { Others }}$}

- P: The price of a unit of public good 


\section{APPENDIX 2: POVERTY THRESHOLDS FOR 1990, 2000, 2012}

The Census Bureau uses a set of income thresholds that vary by family size, age of householder, and number of related children under 18 present to determine who is in poverty. This appendix shows the poverty thresholds for 1990, 2000, and 2012 respectively. 
Table 15 Poverty thresholds for 1990

\begin{tabular}{|c|c|c|c|c|c|c|c|c|c|c|}
\hline \multirow[b]{2}{*}{ Size of family unit } & \multirow[b]{2}{*}{$\begin{array}{r}\text { Weighted } \\
\text { average } \\
\text { thresholds }\end{array}$} & \multicolumn{9}{|c|}{ Related children under 18 years } \\
\hline & & None & One & Two & Three & Four & Five & Six & Seven & $\begin{array}{l}\text { Eight } \\
\text { or } \\
\text { more }\end{array}$ \\
\hline One person (unrelated individual) & $\$ 6,652$ & & & & & & & & & \\
\hline Under 65 years & 6,800 & 6,800 & & & & & & & & \\
\hline 65 years and over & 6,268 & 6,268 & & & & & & & & \\
\hline Householder under 65 years & 8,794 & 8,752 & 9,009 & & & & & & & \\
\hline Householder 65 years and over & 7,905 & 7,900 & 8,975 & & & & & & & \\
\hline Three people & 10,419 & 10,223 & 10,520 & 10,530 & & & & & & \\
\hline Four people & 13,359 & 13,481 & 13,701 & 13,254 & 13,301 & & & & & \\
\hline Five people & 15,792 & 16,257 & 16,494 & 15,989 & 15,598 & 15,359 & & & & \\
\hline Nine people or more & 26,848 & 28,946 & 29,087 & 28,700 & 28,375 & 27,842 & 27,108 & 26,445 & 26,280 & 25,268 \\
\hline
\end{tabular}

Source: The Census Bureau: https://www.census.gov/hhes/www/poverty/data/threshld/ 
Table 16 Poverty thresholds for 2000

\begin{tabular}{|c|c|c|c|c|c|c|c|c|c|c|}
\hline \multirow[b]{2}{*}{ Size of family unit } & \multirow[b]{2}{*}{$\begin{array}{l}\text { Weighted } \\
\text { average } \\
\text { thresholds }\end{array}$} & \multicolumn{9}{|c|}{ Related children under 18 years } \\
\hline & & None & One & Two & Three & Four & Five & Six & Seven & $\begin{array}{l}\text { Eight } \\
\text { or } \\
\text { more }\end{array}$ \\
\hline One person (unrelated individual) & $\$ 8,794$ & & & & & & & & & \\
\hline Under 65 years & 8,959 & 8,959 & & & & & & & & \\
\hline 65 years and over & 8,259 & 8,259 & & & & & & & & \\
\hline Householder under 65 years & 11,590 & 11,531 & 11,869 & & & & & & & \\
\hline Householder 65 years and over & 10,419 & 10,409 & 11,824 & & & & & & & \\
\hline Three people & 13,738 & 13,470 & 13,861 & 13,874 & & & & & & \\
\hline Four people & 17,603 & 17,761 & 18,052 & 17,463 & 17,524 & & & & & \\
\hline Five people & 20,819 & 21,419 & 21,731 & 21,065 & 20,550 & 20,236 & & & & \\
\hline
\end{tabular}

Source: The Census Bureau: https://www.census.gov/hhes/www/poverty/data/threshld/ 
Table 17 Poverty thresholds for 2012

\begin{tabular}{|c|c|c|c|c|c|c|c|c|c|c|}
\hline \multirow[b]{2}{*}{ Size of family unit } & \multirow[b]{2}{*}{$\begin{array}{r}\text { Weighted } \\
\text { average } \\
\text { thresholds }\end{array}$} & \multicolumn{9}{|c|}{ Related children under 18 years } \\
\hline & & None & One & Two & Three & Four & Five & Six & Seven & $\begin{array}{l}\text { Eight } \\
\text { or } \\
\text { more }\end{array}$ \\
\hline One person (unrelated individual) & $\$ 11,720$ & & & & & & & & & \\
\hline Under 65 years & 11,945 & 11,945 & & & & & & & & \\
\hline 65 years and over & 11,011 & 11,011 & & & & & & & & \\
\hline Householder under 65 years & 15,450 & 15,374 & 15,825 & & & & & & & \\
\hline Householder 65 years and over & 13,892 & 13,878 & 15,765 & & & & & & & \\
\hline Three people & 18,284 & 17,959 & 18,480 & 18,498 & & & & & & \\
\hline Four people & 23,492 & 23,681 & 24,069 & 23,283 & 23,364 & & & & & \\
\hline Five people & 27,827 & 28,558 & 28,974 & 28,087 & 27,400 & 26,981 & & & & \\
\hline Nine people or more & 47,297 & 50,849 & 51,095 & 50,416 & 49,845 & 48,908 & 47,620 & 46,454 & 46,165 & 44,387 \\
\hline
\end{tabular}

Source: The Census Bureau: https://www.census.gov/hhes/www/poverty/data/threshld/ 


\section{APPENDIX 3: GEOGRAPHIC DISTRIBUTION OF MUNICIPALITIES}

This appendix includes the geographic distribution of each group of municipalities used for analysis. Figure 9 includes 15 low-poverty municipalities (below 15 percent) and 9 high-poverty municipalities (above 25 percent), which had the financial data needed to calculate the dependent variable of the ANOVA model.

MANCOVA models used four different thresholds of $P / 1000 R$ (the number of poor program participants every 1000 non-poor persons have to take care of) (see figure 8) to select two groups of municipalities from the 284 low-poverty municipalities (below 15 percent), which had a 2000 population of 65,000 or more and experienced no boundary changes or HOPE VI programs during the time from 2000 to 2012. Figure 10 shows the geographic distribution of the two groups of municipalities formed by threshold 1 , including 23 low-poverty municipalities in group 1 and 92 low-poverty municipalities in group 2. Figure 11 shows the geographic distribution of the two groups of municipalities formed by threshold 2, including 23 low-poverty municipalities in group 1 and 142 low-poverty municipalities in group 2 . Figure 12 shows the geographic distribution of the two groups of municipalities formed by threshold 3, including 95 low-poverty municipalities in each of the two groups. Figure 13 shows the geographic distribution of the two groups of municipalities formed by threshold 4, including 71 low-poverty municipalities in each of the two groups. 


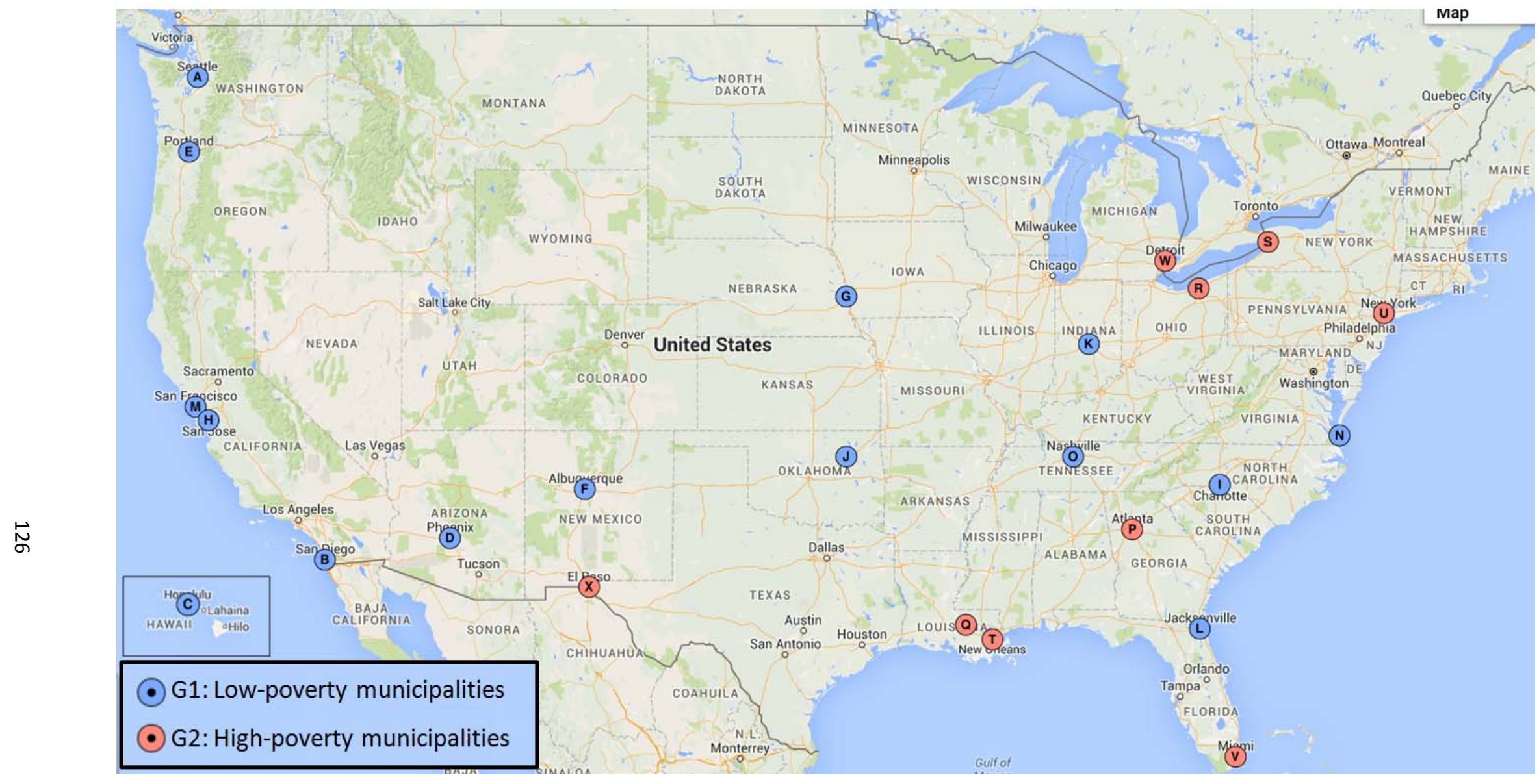

Figure 9 Geographic distribution of the two groups of municipalities used for the ANOVA analysis 


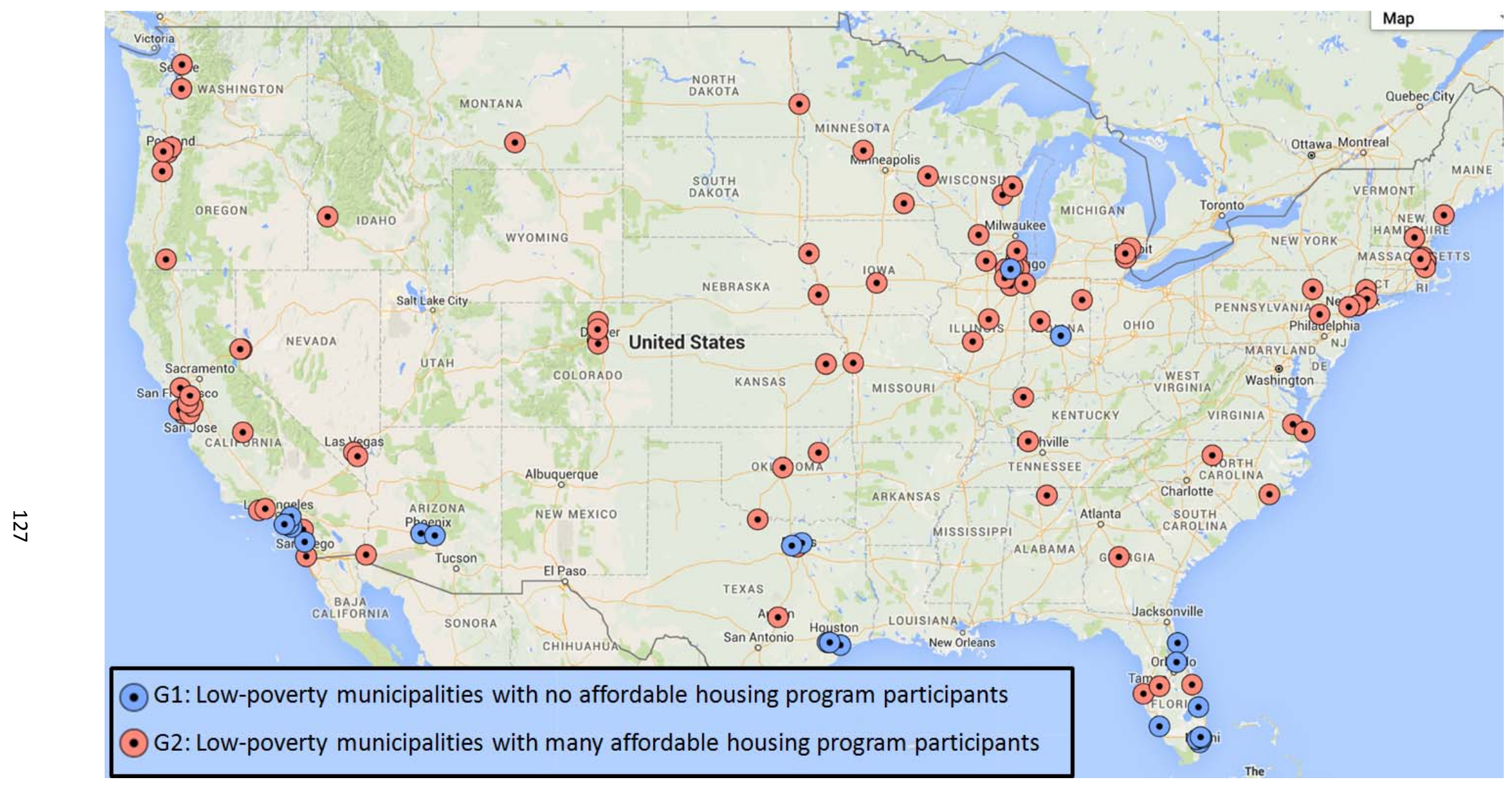

Figure 10 Geographic distribution of the two groups of municipalities formed by threshold 1 


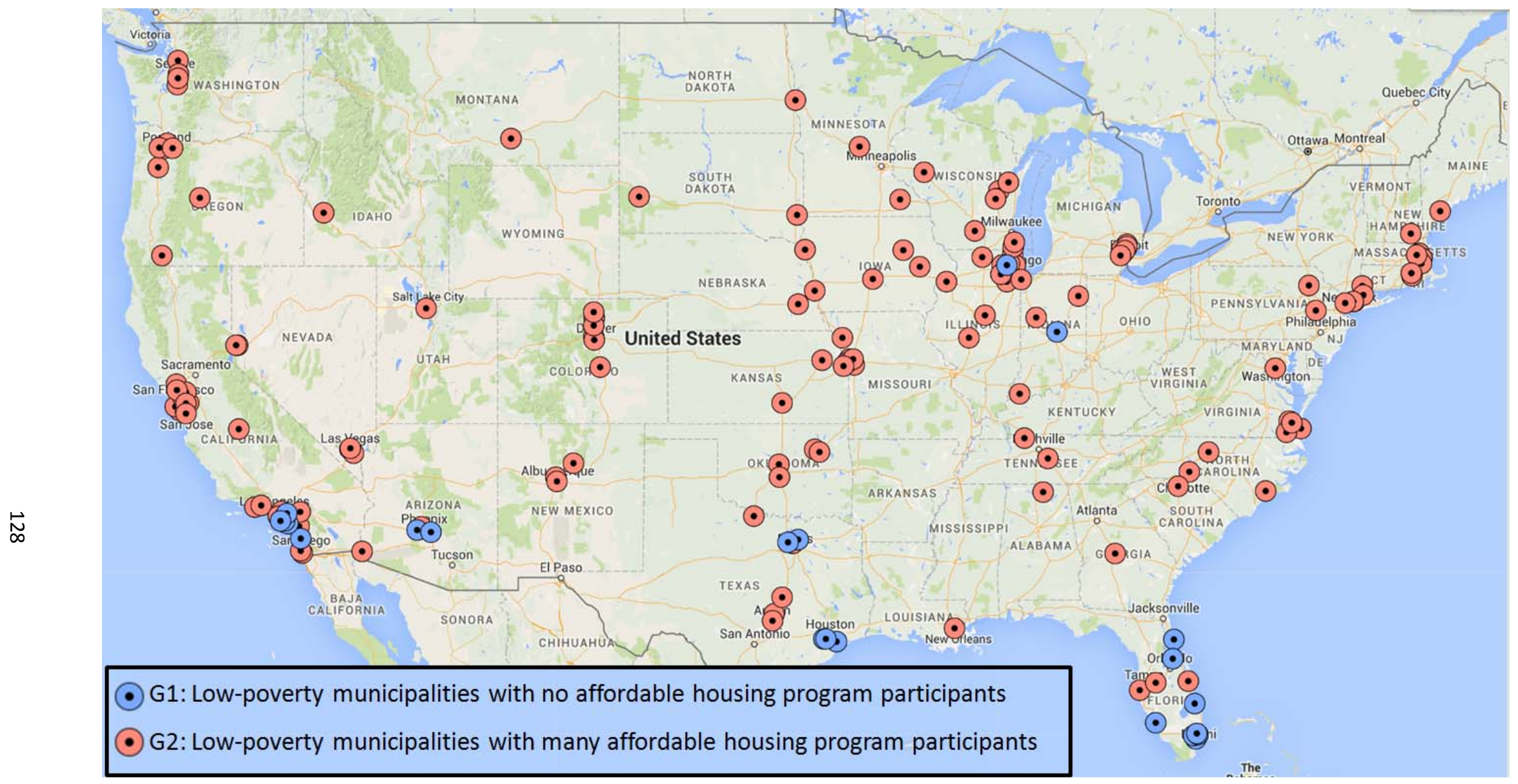

Figure 11 Geographic distribution of the two groups of municipalities formed by threshold 2 


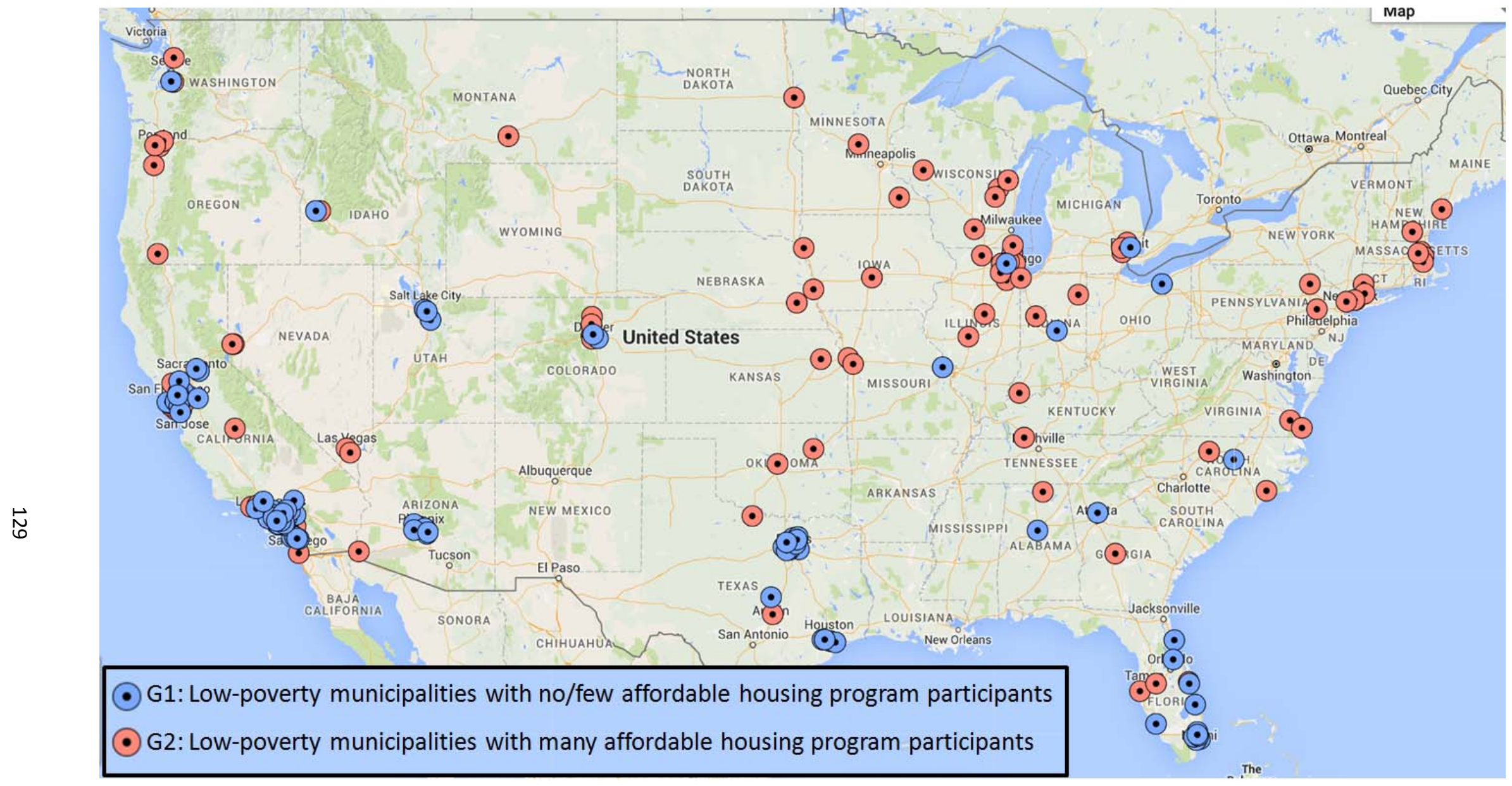

Figure 12 Geographic distribution of the two groups of municipalities formed by threshold 3 


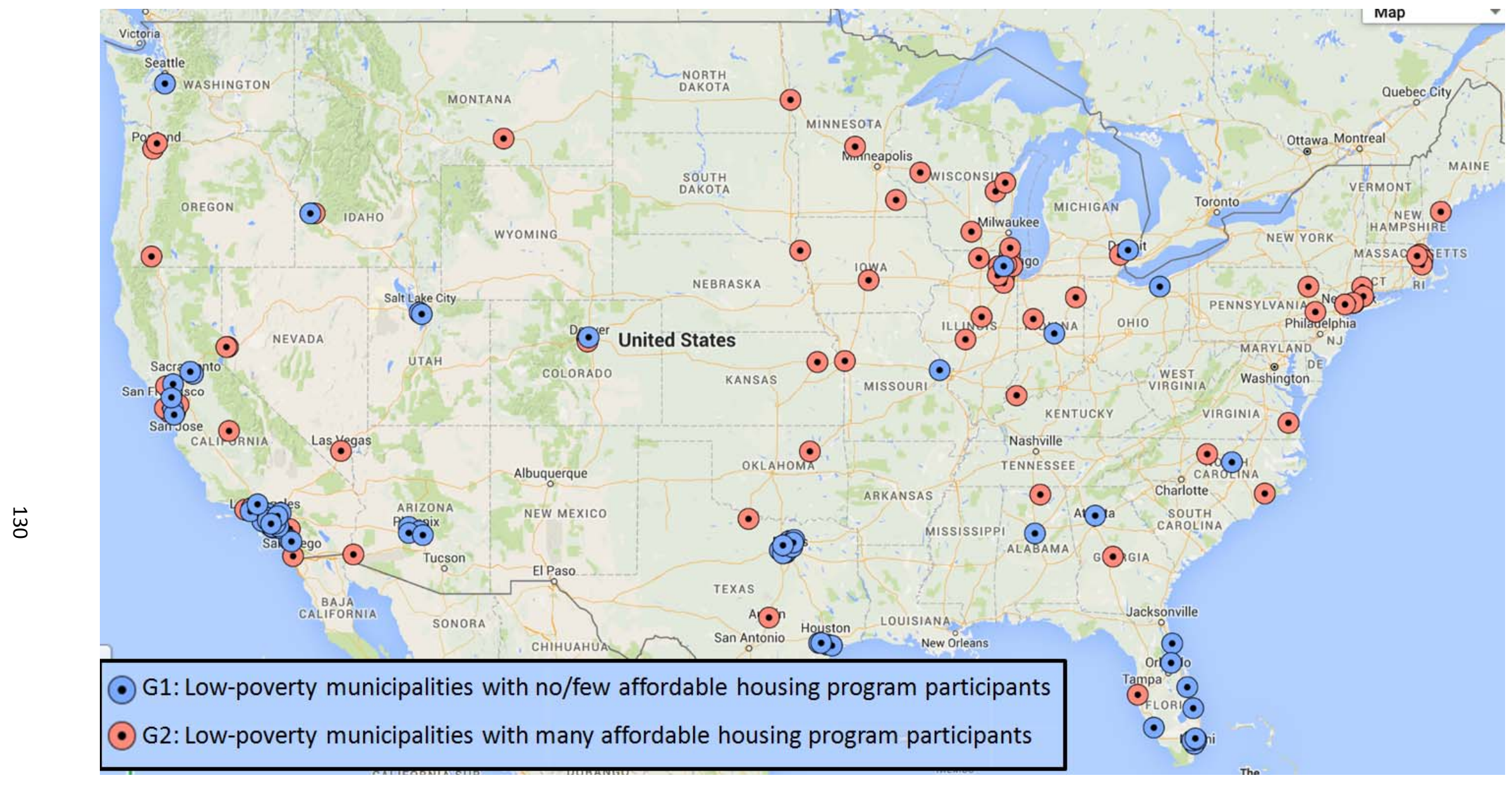

Figure 13 Geographic distribution of the two groups of municipalities formed by threshold 4 


\title{
CURRICULUM VITA
}

\author{
Yu-Chih Lin \\ Department of Urban and Public Affairs \\ 426 W. Bloom Street, University of Louisville \\ Louisville, KY 40208 \\ Email: bravo0112@gmail.com
}

\section{EDUCATION}

2015 Ph.D., Urban and Public Affairs, University of Louisville, USA

Major: Urban Policy and Administration

Dissertation Title: Trapped in the Tiebout Model-The Impact of Federal Affordable Housing Programs on Migration of Wealthier Residents

2010 M.S., Building and Planning, National Taiwan University, Taiwan Major: Urban Planning

Thesis Title: An Influence Analysis on Urban Renewal Application Process by the Characteristics of Landlords in Taipei City Using Game Theory

2007 B.A., Land Economics, National Chengchi University, Taiwan

Major: Land Resource Planning

\section{RESEARCH INTERESTS}

Urban Economics

Urban Development

Urban Policy and Governance

Policy Analysis

Game Theory

\section{PUBLICATIONS IN PEER-REVIEWED JOURNALS}

\section{Papers Published}

2014 Lin, Y.-C., \& Lin, F.-T. A strategic analysis of urban renewal in Taipei City using game theory. Environment and Planning B: Planning and Design, 41(3), 472-492. doi: 10.1068/b37164

Working Papers/Manuscripts in Preparation for Submission

Lin Y.-C, "The counterpart of the Tiebout model- The market-analog mechanism for the poor." 
Lin Y.-C, "Game models for promoting local government collaboration in public service delivery in America."

Lin Y.-C, "The impacts of housing mobility programs on wealth disparity and the number of poor population."

Lin Y.-C, "Does housing mobility programs increase the rate of urban sprawl in America?"

\section{AWARDS / HONORS}

2013 Scholarship, International Center, University of Louisville

2012 Scholarship, International Center, University of Louisville

2011 The Best Thesis Award, The Chinese Institute of Land Economics

2004 Scholarship, National Chengchi University, Taiwan.

2003 Scholarship, National Chengchi University, Taiwan.

\section{INVITED PRESENTATION}

2011 Lin Y-C, "An Influence Analysis on Urban Renewal Application Process by the Characteristics of Landowners in Taipei City Using Game Theory" The Chinese Institute of Land Economics Annual Conference. Taipei, Taiwan (April).

\section{CONFERENCE PRESENTATIONS}

2009 "Challenges of Transnational Collaborative Planning in Slum Communities in Pasay City, Philippines" (with Chia-Hsuan Lee, Liang-Chun Chen, Feng-Tyan Lin, Ching-Yi Wu, Yi-Han Lin, Yen-Hao Liao, and Wan-Yu Tseng). Presented at $14^{\text {th }}$ International Meeting of Inter-University Seminar on Asian Mega-cities, Taipei, Taiwan (March). (digital proceedings)

\section{CERTIFICATES}

2015 Grant Writing Academy, University of Louisville

2015 Diversity and Graduate Teaching Assistant Program, University of Louisville

PROFESSIONAL EXPERIENCE (full-time position)

Oct. 2010- Research assistant, Department of Land Economics, National Chengchi Jun. 2011 University

Established principles for dividing the national territory into four 
districts $^{57}$ and the guidelines of managing these functional districts. The technical report was sent to a regulatory agency (Urban and Rural Development Branch, Construction and Planning Agency, Ministry of the Interior, Taiwan.).

\section{PLANNING EXPERIENCE (team member)}

\section{Jul. 2008- Collaborative Planning in Slum Communities in Pasay City, Mar. 2009 Philippines}

- Assessed the living condition in slum areas by exploring the area, interviewing, and holding several workshops with the residents and local NGOs (TAO, SHEC, and SHACC).

- Provided a practical project to tackle energy shortage and improve sanitary environment in light of resource restrictions.

- Presented the results of the interdisciplinary and inter-organizational project at the 14th Inter-University Seminar, including universities from Japan, China, Korea, and other countries.

Jul. 2008- Sunty Architectural Contest (holding by a construction company)

Aug. 2008 Project included market analysis, product positioning, product design, financial assessment, and marketing plan.

Sep. 2007- Temple Street Project in Hsin-Chuang City, Taiwan

Jun. 2008 - Combined the plan with the project of Blue Route (ship route) in Taipei city, mobilized local residents, and persuaded the city councilor to move on the plan.

- The construction of a water gate was completed and officially opened on March, 2010. (Before this project, the plan of opening a water gate had been discussed for over 20 years but never been realized.)

Aug. 2007- Design in Yangminshan-International Workshop

Sep. 2007 - Local NGO (OURs) and students from Taiwan and University of Washington, USA produced plans for the preservation and reuse of historical buildings - American Army dormitory.

- The team developed the concept of permaculture, introduced waste water system to the area, and combined needs for different people to create a short distance community.

Sep. 2004- Residential and Commercial Design Project in Hsin-Tien City, Jun. 2005 Taiwan

Prepared a plan for the residential and commercial area in the city to avoid the disordered development due to the increasing housing price.

\footnotetext{
57 The four districts include National Territorial Preservation District, Ocean Resource District,
} Agricultural Development District, and City-Country Development District. 
Sep. 2003- Taipei City Wen-Shan District Integral Review and Planning Project

Jun. 2004 - Analyzed land use, transportation, infrastructure, and other environmental conditions in the district to set the goal for the future in 25 years.

- Provided and evaluated several alternative schemes to produce an eclectic one. 